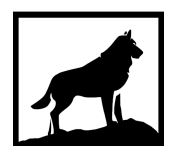

Michigan Technological

1 8 8 5 University
Michigan Technological University Digital Commons @ Michigan Tech

2017

THE EMISSION AND PARTICULATE MATTER OXIDATION PERFORMANCE OF A SCR CATALYST ON A DIESEL PARTICULATE FILTER WITH A DOWNSTREAM SCR

Sagar Sharma

Michigan Technological University, sagsharm@mtu.edu

Copyright 2017 Sagar Sharma

Recommended Citation

Sharma, Sagar, "THE EMISSION AND PARTICULATE MATTER OXIDATION PERFORMANCE OF A SCR CATALYST ON A DIESEL PARTICULATE FILTER WITH A DOWNSTREAM SCR", Open Access Master's Report, Michigan Technological University, 2017.

https://doi.org/10.37099/mtu.dc.etdr/464

Follow this and additional works at: https://digitalcommons.mtu.edu/etdr

Part of the Heat Transfer, Combustion Commons, and the Other Mechanical Engineering Commons 


\title{
THE EMISSION AND PARTICULATE MATTER OXIDATION PERFORMANCE OF A SCR CATALYST ON A DIESEL PARTICULATE FILTER WITH A DOWNSTREAM SCR
}

By

Sagar Sharma

\begin{abstract}
A REPORT
Submitted in partial fulfillment of the requirements for the degree of MASTER OF SCIENCE

In Mechanical Engineering
\end{abstract}

MICHIGAN TECHNOLOGICAL UNIVERSITY

2017

(C) 2017 Sagar Sharma 
This report has been approved in partial fulfillment of the requirements for the Degree of MASTER OF SCIENCE in Mechanical Engineering.

Department of Mechanical Engineering - Engineering Mechanics

Report Co-Advisor: Dr. Jeffrey D. Naber

Report Co-Advisor: Dr. John H. Johnson

Committee Member: Dr. Scott A. Miers

Department Chair: Dr. William Predebon 


\section{Table of Contents}

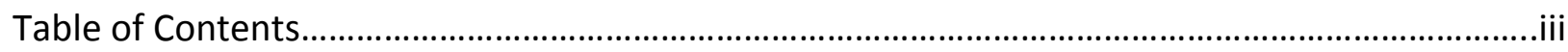

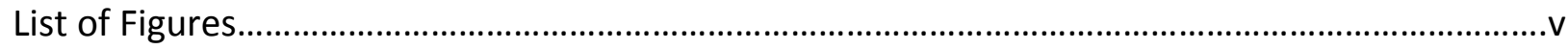

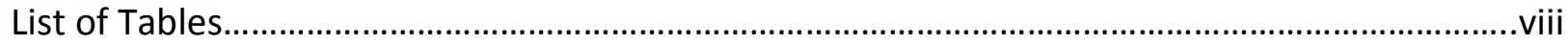

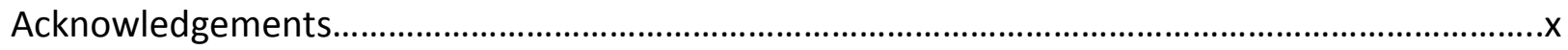

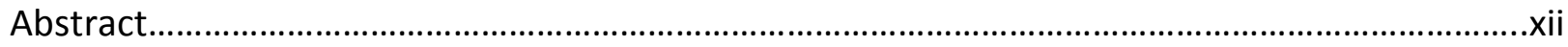

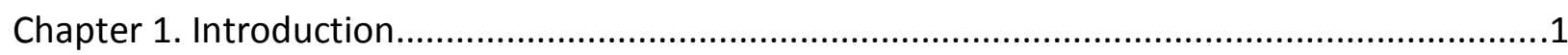

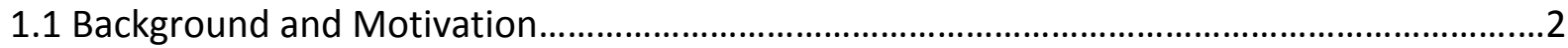

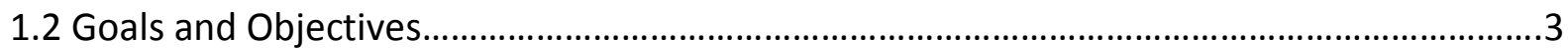

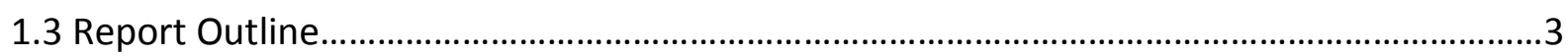

Chapter 2. Background and Literature Review......................................................................

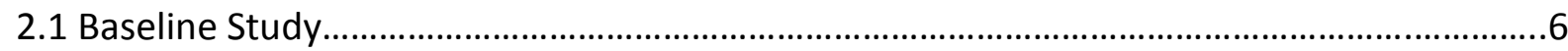

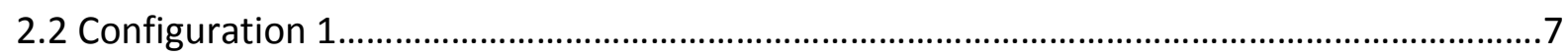

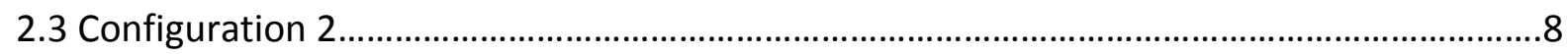

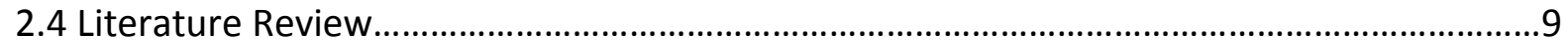

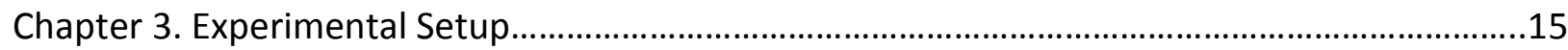

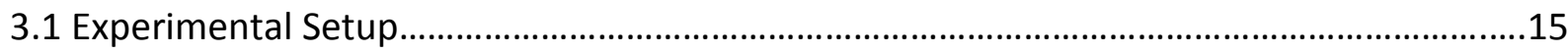

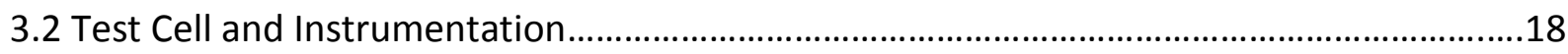

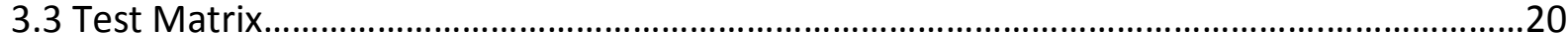

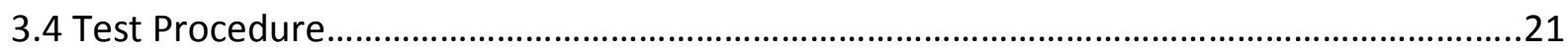

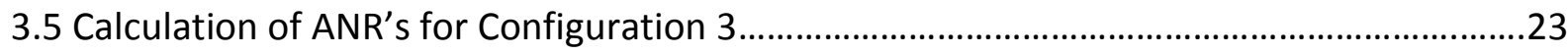

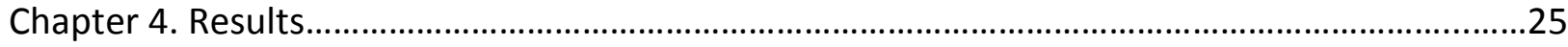

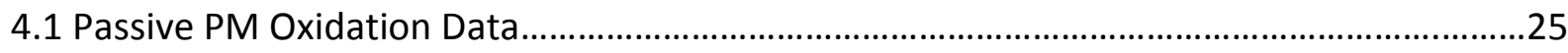

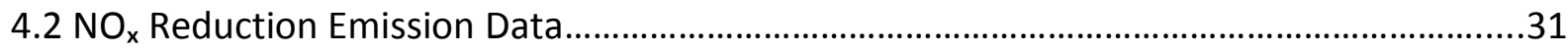

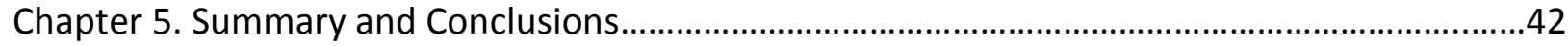

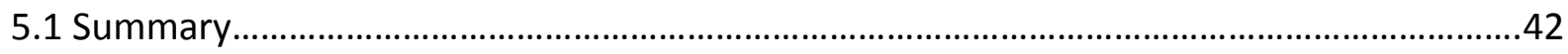

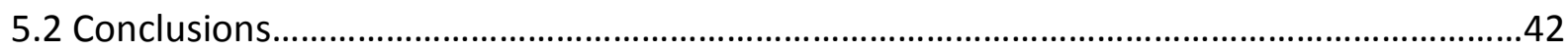

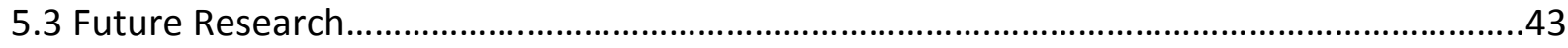


References..

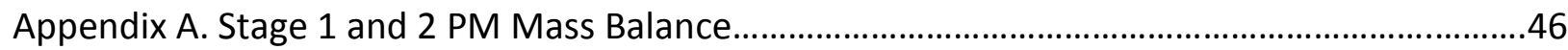

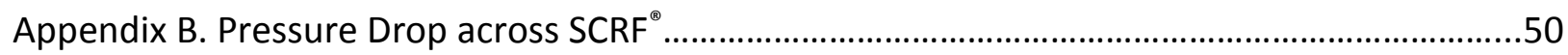

Appendix C. Gas Temperature Distribution in the SCRF ${ }^{\circledR}$ During PO.............................................55

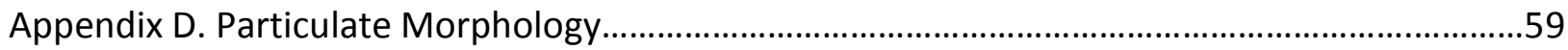

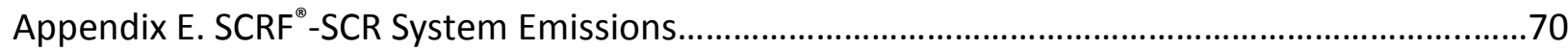

Appendix F. Comaprison of Passive Oxidation with Urea Injection and $\mathrm{NO}_{x}$ Conversion Efficiencies in Configurations 1 and 2 to Configuration 3.......................................76

Appendix G. Corrected Procedure to Calculate ANR's for Configuration 3................................85

Appendix H. Permissions to Use Copyrighted Material................................................................90 


\section{List of Figures}

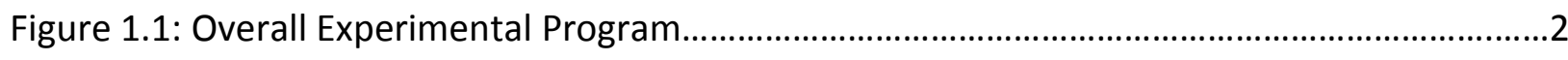

Figure 2.1: $\mathrm{NO}_{x}$ Conversion and average $\mathrm{NH}_{3}$ Slip over NRTC at ANR 1.2 for Different

Systems [5]. 10

Figure 2.2: $\mathrm{NO}_{x}$ Conversion over Hot WHTC and NRTC Tests for Different Configurations [5].....11

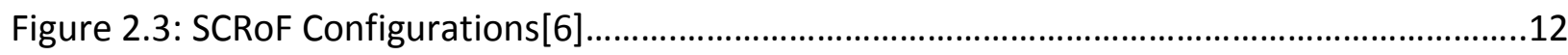

Figure 2.4: Outlet $\mathrm{NO}_{\mathrm{x}}$ at Different Configurations vs Transient Cycles[6]..................................12

Figure 3.1: Aftertreatment System Used for the Experimental Study at MTU ............................15

Figure 3.2: Test Cell Layout and Instrumentation for Configuration 3.......................................16

Figure 3.3: Sampling Probe Between the $\mathrm{SCRF}^{\circledR}$ and SCR-A in Configuration 3..........................17

Figure 3.4: Stages of a Passive Oxidation Test with Urea Dosing with Configuration 1[2]...........21

Figure 3.5: Delta Pressure Across $\mathrm{SCRF}^{\circledR}$ vs Time for a Typical Passive Oxidation Test[2]............22

Figure 4.1: Line of Best Fit for $\ln [\mathrm{K}]$ vs 1000/Temperature for Passive Oxidation Experiments

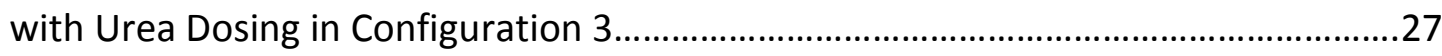

Figure 4.2: Line of Best Fit for $\ln [\mathrm{K}]$ vs 1000/Temperature for Passive Oxidation Experiments

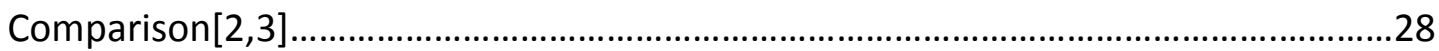

Figure 4.3: Stage-wise Pressure Drop - Test Point A..................................................................30

Figure 4.4: Emission Concentrations at Inlet and Outlet of the SCRF ${ }^{\circledR}$ and SCR-A during Passive Oxidation Stage for Test Point A................................................................................. 32

Figure 4.5: Emission Concentrations at Inlet and Outlet of the SCRF ${ }^{\circledR}$ and SCR-A during Passive

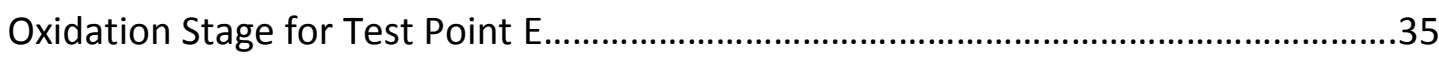

Figure A.1. PM Mass Retained vs Pressure Drop for Loading Stage S1 and S2 ...........................49

Figure A.2. PM Mass into the $\mathrm{SCRF}^{\circledR}$ vs PM Mass Retained for Loading Stage S1 and S2 .............49

Figure B.1: Pressure Drop across SCRF ${ }^{\oplus}$ for Test Point A............................................................51

Figure B.2: Pressure Drop across SCRF ${ }^{\oplus}$ for Test Point B.............................................................52

Figure B.3: Pressure Drop across SCRF ${ }^{\circledR}$ for Test Point C.............................................................52

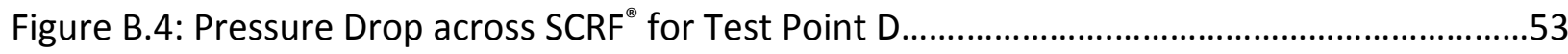


Figure B.5: Pressure Drop across SCRF ${ }^{\oplus}$ for Test Point E.............................................................53

Figure B.6: Pressure Drop across SCRF ${ }^{\circledR}$ for Test Point 1..........................................................54

Figure B.7: Combined Pressure Drops across SCRF ${ }^{\oplus}$ for Loading - Stage 1 and Stage 2................54

Figure C.1: Temperature Distribution Test Point A......................................................................56

Figure C.2: Temperature Distribution Test Point B...................................................................56

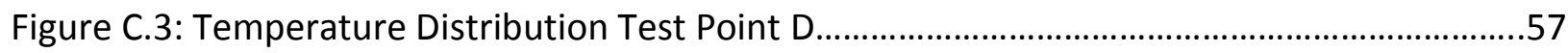

FigureC.4: Temperature Distribution Test Point E........................................................................57

Figure C.5: Temperature Distribution Test Point 1...................................................................58

Figure C.6: Temperature Distribution Test Point C [2] ................................................................58

Figure D.1: Number of Primary Particles vs Fuel Injection Pressure for Diesel and B 20

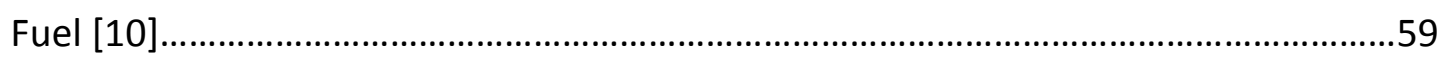

Figure D.2: Primary Particle Size Distribution at Different EGR Rates [12]..................................60

Figure D.3: SEM Image of Primary Particle Agglomerate at 750 Bar Fuel Rail Injection

Pressure

Figure D.4: SEM Image of Primary Particle Agglomerate at 1050 Bar Fuel Rail Injection Pressure.

Figure D.5: SEM Image of Primary Particle Agglomerate at 1500 Bar Ruel Rail Injection Pressure .62

Figure D.6: Primary Particle Diameter at Different Fuel Rail Injection Pressures. .64

Figure D.7: Primary Particle Diameter for Diesel and B20 Soot from TEM Image at Different Fuel Injection Pressures[10]......................................................................................64

Figure D.8: EC/OC Analysis of PM at Different Fuel Rail Injection Pressure (Cummins Inc.)........69

Figure F.1: Pressure Drop Comparison Between Configuration 1 and Configuration 3 Test Point A. .76

Figure F.2: Pressure Drop Comparison Between Configuration 1 and Configuration 3 Test Point C.

Figure F.3: Pressure Drop Comparison Between Configuration 1 and Configuration 3 Test Point D.

Figure F.4: Pressure Drop Comparison Between Configuration 1 and Configuration 3 Test Point E. 
Figure F.5: Comparison of $\mathrm{NO}_{x}$ Conversion Efficiency, $\mathrm{NH}_{3}$ and $\mathrm{NO}$ vs ANR for Test Point 1 (ANR $0.8,1.0,1.2$ in Configurations 2 and ANR 1.06 in Configuration 3.............................83

Figure F.6: Comparison for ANR's in Configuration 1 and Configuration 3..................................84

Figure F.7: Comparison of $\mathrm{NO}_{x}$ Conversion Efficiencies in Configuration 1 and

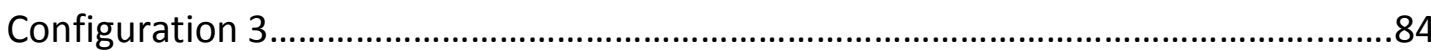




\section{List of Tables}

Table 3.1: Test Matrix for Engine and Exhaust Conditions for Configuration 3 (with Urea

Dosing). .21

Table 3.2: Engine Operating Conditions for PM Collection at Different Fuel Rail Pressures.........23

Table 3.3: Performance of the $\mathrm{SCRF}^{\circledR}$ during the Passive Oxidation Tests with Urea Injection in Configuration $1[2,3]$

Table 3.4: Comparison of Target, Corrected Target and Actual Dosed ANR. .24

Table 4.1: Engine and Exhaust Conditions for Passive Oxidation with Urea Dosing in Configuration 3. .25

Table 4.2: Variables Important in Calculating Kinetics of $\mathrm{NO}_{2}$ Assisted Passive Oxidation Experiments with Urea Dosing for Configuration 3. .26

Table 4.3: Overall Kinetics for Passive Oxidation Experiments with Urea Dosing in Configuration 3. 27

Table 4.4: Emissions Concentration - Test Point A .32

Table 4.5: SCRF ${ }^{\circledR}$-SCR System Emissions - Test Point A. .33

Table 4.6: Emissions Concentration - Test Point E .35

Table 4.7: SCRF ${ }^{\circledR}$-SCR System Emissions - Test Point E. .36

Table 4.8 Engine and Exhaust Conditions, Emission Concentrations and $\mathrm{NO}_{\mathbf{x}}$ Conversion Efficiency of the $\mathrm{SCRF}^{\circledR}$ - Configuration 3 .38

Table 4.9: Emission Concentrations at the Inlet and Outlet of the SCR and $\mathrm{NO}_{\mathrm{x}}$ Conversion Efficiency of the $\mathrm{SCRF}^{\circledR}$ and SCR Together - Configuration 3.

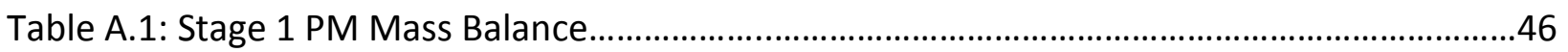

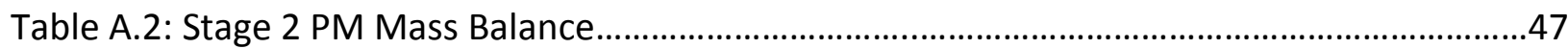

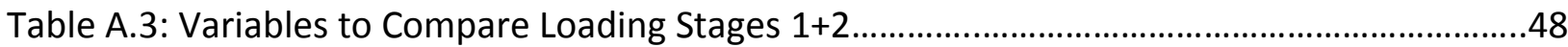

Table D.1: Primary Particle Diameter at Different Fuel Rail Injection Pressures..........................63

Table D.2: Primary Particle Diameter of 20 Randomly Chosen Particles at Different Fuel Rail Injection Pressures..... .66

Table D.3: EC/OC Analysis at Different Fuel Rail Injection Pressures using NIOSH Method 5040 (Cummins Inc.) 
Table E.1: SCRF ${ }^{\oplus}$-SCR System Emissions - Test Point A.................................................................70

Table E.2: SCRF ${ }^{\oplus}$-SCR System Emissions - Test Point B.................................................................71

Table E.3: SCRF ${ }^{\oplus}$-SCR System Emissions - Test Point C ...............................................................72

Table E.4: SCRF ${ }^{\oplus}$-SCR System Emissions - Test Point D.............................................................73

Table E.5: SCRF ${ }^{\oplus}$-SCR System Emissions - Test Point E.................................................................74

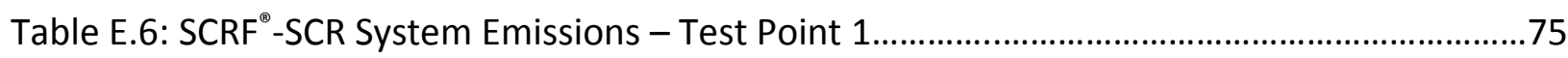

Table F.1: Comparison of Results in Configuration 1 vs Configuration 3 for Passive Oxidation

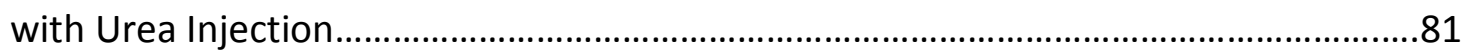

Table F.2: Comparison of $\mathrm{NO}_{\mathrm{x}}$ Conversion Efficiency across SCRF ${ }^{\circledR}$ in Configurations 1,2 and 3.

Table F.3: Comparison of $\mathrm{NO}$ and $\mathrm{NO}_{2}$ In and Out of DOC in Configurations 1, 2 and 3............82

Table F.4: Comaprison of NO Conversion Efficiency across DOC in Configurations 1, 2 and 3.....83

Table G.1: Corrected Target ANR's for Configuration 3.................................................................89 


\section{Acknowledgements}

I would like to thank several people who provided me with an opportunity and support to pursue and complete this research study at Michigan Technological University. To begin with, I would like to thank my advisors Dr. Jeffrey D. Naber and Dr. John H. Johnson for their constant support, motivation and guidance in this research. Without their constant support and guidance this research effort would not have been possible. They not only provided technical support in terms of data analysis and the understanding of the data collected but also helped in troubleshooting problems in the lab which saved a lot of time. They have been a constant source of inspiration for me and also have guided me when I needed help understanding concepts and writing my report. I am also thankful to Dr. Scott A. Miers for spending his valuable time being a committee member on my defense and critically reviewing my research effort.

I would also like to show my sincere gratitude to my parents who have always been there for me. They have motivated me during the rough patches of my research. I want to thank Chris Pinnow and Steve Lehmann for their help fixing the controllers and other electrical and electronics related problems that constantly occur in the lab. They have always found time to visit the lab on short notices. Their help is much appreciated. Paul Dice has always been there to guide in solving hardware related problems in the lab and providing with tools and materials. He has also helped us in making changes to the hardware set up in the lab. I thank him for his support. I would also like to thank Bob Page for permitting the use of Welding Lab to bake filter papers. Mr. Owen Mills has been of great help in collecting SEM Images at his Lab. His guidance regarding SEM image processing was very helpful. I thank him for his guidance.

Vaibhav Kadam, Erik Gustafson and Saksham Gupta were the researchers working on the same project and they have participated in gathering data in this report. They taught me how to conduct the experiments, maintain the lab and analyze the data so obtained. They have helped me whenever I faced difficulties during my research. I thank them for their constant support. Abhishek Jadav has been instrumental in my research effort. I thank him for his assistance during experimentation. I would like to thank our Consortium (Cummins, John Deere, ISUZU, Daimler, Johnson Matthey, Tenneco and Corning) for your supporting this project and my graduate 
research support and providing key inputs whenever needed. Lastly, my sincere thanks to Walter Woodland at V\&F and Andreas Fredrich at AVL for their help in solving analyzer related problems. 


\section{Abstract}

Selective catalytic reduction (SCR) systems along with a $\mathrm{NH}_{3}$ slip control catalyst (ASC) offers $\mathrm{NO}_{x}$ conversion efficiency $>90 \%$ with $\mathrm{NH}_{3}$ slip $<20$ ppm. However, future heavy duty diesel (HDD) engines are designed for higher engine-out $\mathrm{NO}_{\mathrm{x}}$ to improve fuel consumption. Consequently, there is a strong desire to further improve the $\mathrm{NO}_{x}$ reduction performance of SCR systems, to meet the 2015 California Optional Low $\mathrm{NO}_{x}$ Standard. SCR catalysts on a diesel particulate filter provide an effective solution to reduce $\mathrm{NO}_{\mathrm{x}}$ and $\mathrm{PM}$ using a single aftertreatment device. It also provides an opportunity to increase the SCR volume to achieve $\mathrm{NO}_{x}$ conversion efficiency $>95 \%$. A downstream SCR catalyst substrate can be used to get additional $\mathrm{NO}_{x}$ conversion by using the $\mathrm{SCRF}^{\oplus}$ outlet $\mathrm{NH}_{3}$ to increase the cumulative $\mathrm{NO}_{x}$ conversion of the system.

In this study, $\mathrm{NO}_{x}$ reduction, $\mathrm{NH}_{3}$ slip and $\mathrm{PM}$ oxidation performance of a $\mathrm{Cu}$-zeolite $\mathrm{SCRF}^{\bullet}$ with a downstream Cu-zeolite SCR were investigated based on engine experimental data at steady state conditions. The experimental data were collected at varying $\mathrm{SCRF}^{\circ}$ inlet temperatures, space velocities, inlet $\mathrm{NO}_{x}$ concentrations, $\mathrm{NO}_{2} / \mathrm{NO}_{x}$ ratios at ammonia to $\mathrm{NO}_{x}$ ratios (ANR) between 1.02 to 1.10 . The results demonstrated that the $\mathrm{SCRF}^{\circ}$ with downstream SCR together can achieve $\mathrm{NO}_{x}$ conversion efficiency $>98 \%$ at ANRs between $1.02-1.10$ (which may have been due to measurement inaccuracies in downstream $\mathrm{SCRF}^{\circ}$ /SCR data), for the inlet temperature range of $200-370^{\circ} \mathrm{C}$, space velocity in the range of 10 to $34 \mathrm{k} / \mathrm{hr}$ and inlet $\mathrm{NO}_{2} / \mathrm{NO}_{\mathrm{x}}$ in the range of $0.3-$ 0.5. However, $\mathrm{NH}_{3}$ slip from the $\mathrm{SCRF}^{\circ}$ decreases and $\mathrm{NO}_{x}$ concentration downstream of the $\mathrm{SCRF}^{\oplus}$ increases with the oxidation of $\mathrm{PM}$ in the $\mathrm{SCRF}^{\circ}$. The PM oxidation kinetics are affected by the deNO ${ }_{x}$ reactions, hence, the $\mathrm{SCRF}^{\circledR}$ with urea dosing showed $\sim 80 \%$ lower reaction rates during passive oxidation when compared to the production CPF. The effect of varying fuel rail injection pressure on the primary particle diameter and on the Elemental Carbon (EC) and Organic Carbon (OC) fraction of the total carbon was also studied. The primary particle diameter was found to be in the range of $28-30 \mathrm{~nm}$ with no effect of the variation in fuel rail injection pressure on it. The OC part of the Total Carbon (TC) did not vary significantly with fuel rail injection pressure. The EC content increased with decrease in fuel rail injection pressure. 


\section{Chapter 1. Introduction}

Today, diesel engines are used in various different applications ranging from use as a power plant in passenger vehicles, small generators to large scale uses such as in ships, trains and heavy duty trucks. The emissions from these engines are a global concern due to their effect on human health and thus efforts are being made to reduce these to as low as possible. In North America, the U.S. EPA has set standards for engine emissions and these standards are continuously evaluated and have been tightened every few years so that manufacturers develop new solutions to achieve those goals. The major emissions of concern from the diesel engines are oxides of nitrogen $\left(\mathrm{NO}_{2}, \mathrm{NO}\right.$ and $\left.\mathrm{N}_{2} \mathrm{O}\right)$, collectively termed $\mathrm{NO}_{x}$ and particulate matter (PM). The other gases emitted from these engines are carbon monoxide ( $\mathrm{CO})$, carbon dioxide $\left(\mathrm{CO}_{2}\right)$ and oxides of sulphur. The proportion of $\mathrm{CO}$ and $\mathrm{HC}$ produced by the diesel combustion engine is low in comparison to gasoline internal combustion engines.

Various methods have been deployed to control and minimize these emissions that are produced from diesel engines. These include diesel particulate filters (DPF), lean $\mathrm{NO}_{\mathrm{x}}$ traps, selective catalytic reduction (SCR) systems used in conjunction with a reductant in the exhaust stream (usually a urea and water solution called DEF, which is $32.5 \%$ by volume). Modern day aftertreatment systems typically consist of the combination of a diesel oxidation catalyst (DOC), catalyzed particulate filter (CPF), and a SCR system with a downstream ammonia oxidation catalyst (AMOX).

One of the present research areas is to improve the existing aftertreatment system by reducing the weight of the current DOC-CPF-SCR-AMOX system. This is achieved by combining the SCR catalyst layer onto the inlet channels of a DPF or within the walls of the substrate, resulting in a wall flow device termed the $\mathrm{SCRF}^{\circledR}$ (Johnson Matthey). The $\mathrm{SCRF}^{\circledast}$ is smaller in size and in volume than the DPF and SCR combination and thus, has the potential to improve the aftertreatment installation.

This report focuses on the study of passive oxidation $(\mathrm{PO})$ and $\mathrm{NO}_{\mathrm{x}}$ reduction with urea injection at different ammonia to $\mathrm{NO}_{x}$ ratio (ANR) using the $\mathrm{SCRF}^{\circledR}$ with an additional SCR downstream. A 
total of six passive oxidation experiments were carried out at different engine conditions and ANR values. The experimental data obtained from this study will be used to calibrate the SCR-F model being developed at MTU along with the SCR 1D model [1].

\subsection{Background and Motivation}

Figure 1.1 represents the overall experimental plan that defined the research to be conducted as a part of the Consortium effort. This report focuses on the DOC-SCRF ${ }^{\circledR}$-SCR system in Configuration 3 and describes the research conducted in this phase. Prior to this study, the SCRF ${ }^{\circledR}$ Configuration 1 , the $\mathrm{SCRF}^{\circledR}$ Configuration 2 and the baseline system were studied and results were published, the detailed results of which can be found in references [2], [3] and [4] respectively.

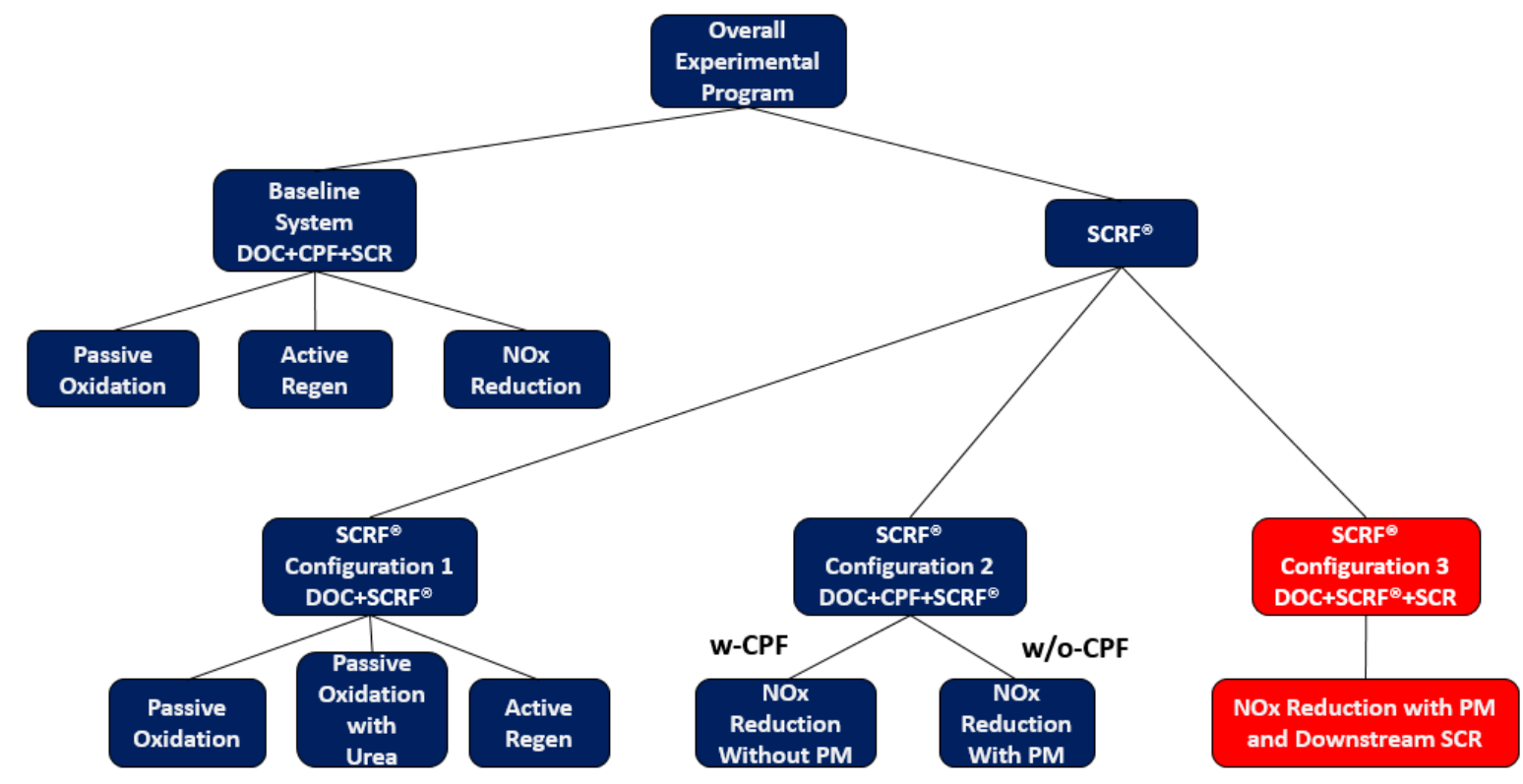

Figure 1.1: Overall Experimental Program

Each of the experimental studies conducted within the overall plan are important to understand the performance characteristics and effect of various parameters in the $\mathrm{SCRF}^{\circledR}$ system. Since the $\mathrm{SCRF}^{\circledR}$ and $\mathrm{SCR}$ are separate substrates developed to perform different functions, it is not possible to compare all aspects of performance together. Thus, in depth experimental studies, well designed experimental test procedures, and modelling support are critical to understanding the complex processes occurring inside the system. With a desire of achieving a $\mathrm{NO}_{\mathrm{x}}$ conversion efficiency of greater than $95 \%$ along with an ammonia slip of no more than $30 \mathrm{ppm}$ to meet the upcoming emission standards, it becomes imperative to conduct multiple experiments in various configurations so as to decouple the performance of each system and develop a stronger 
understanding of the experimental results. The experimental data collected will be used to help develop a working model, thus saving time and cost in the long run.

\subsection{Goals and Objectives}

1) Apply test procedures developed for Configurations 1 and 2 to the $\mathrm{DOC}_{\mathrm{SCRF}}{ }^{\circledR} \mathrm{SCR}$ Configuration 3 system in order to collect experimental data for the study of the effect of one downstream SCR (brick A) on the system performance for a range of temperatures from 200 to $370{ }^{\circ} \mathrm{C}$ and space velocities from 10 to $34 \mathrm{k} / \mathrm{hr}$.

2) Perform analysis of the acquired experimental data to determine the $\mathrm{NO}_{2}$ assisted passive oxidation kinetics, $\mathrm{NO}_{x}$ reduction characteristics and temperature distribution in the $\mathrm{SCRF}^{\circledR}$ at $\mathrm{ANR}>1$. The experimental data collected will be used to calibrate the SCR-F model being developed at MTU and to validate the 1-D SCR model developed in reference [1]

3) Determine the ANR value required to achieve a cumulative $\mathrm{NO}_{x}$ conversion efficiency greater than $95 \%$ and with a minimum $\mathrm{NH}_{3}$ slip at the outlet of the SCR.

4) Determine the $\mathrm{NO}_{x}$ reduction and $\mathrm{NH}_{3}$ slip characteristics of the $\mathrm{SCRF}^{\circledR}$ and a downstream SCR (substrate A) together and study the effect on the $\mathrm{NO}_{x}$ reduction performance of the system and the SCRF ${ }^{\circledR}$ and SCR separately.

\subsection{Report Outline}

The focus of this report is to study the PM oxidation characteristics and NOx reduction performance of the DOC-SCRF ${ }^{\circledR}$-SCR system in Configuration 3. This chapter presented a brief introduction, background and motivation for this research, and the goals and objectives of the research.

Chapter 2 presents the background and the literature review. The work done by previous researchers on the same project is first discussed. This is then followed by the work done by various research groups.

Chapter 3 describes the experimental setup used to test this configuration along with some of the additional instrumentation. The major changes made to the hardware and instrumentation 
are discussed in this section. This is followed by the test matrix and test procedures that were used in Configuration 3.

Chapter 4 discusses the experimental results obtained, along with the analysis of the data for the six experiments conducted in this configuration. The focus of the discussion is the passive oxidation (PO) performance in terms of the kinetics of PM oxidation with urea dosing, and the $\mathrm{NO}$ reduction performance of the $\mathrm{SCRF}^{\circledR}$ and $\mathrm{SCR}$ together and separately. The substrate temperature distributions trends observed during oxidation in the $\mathrm{SCRF}^{\circledR}$ are also discussed in this chapter.

Chapter 5 summarizes the results and presents the key findings of the research and how it relates to the overall experimental plan.

This is followed by Appendices A to $G$ which elaborate on the details of various aspects of this study. 


\section{Chapter 2. Background and Literature Review}

This chapter focuses on the background studies conducted at MTU prior to this research effort. After this, the literature available pertaining to the DOC - SCR in DPF - SCR configuration is discussed.

The aftertreatment production system of the Cummins ISB 2013 engine consists of a Diesel Oxidation Catalyst (DOC), a Catalyzed Particulate Filter (CPF) and a Selective Reduction Catalyst (SCR) along with an Ammonia Oxidation Catalyst (AMOX). There is a need to develop lower volume and weight aftertreatment systems. Other short comings of this production system include low temperature at the SCR inlet during start up periods which makes the SCR reactions not effective.

One of the possible solutions to these problems is the integration of a SCR catalyst on a DPF, termed $\mathrm{SCRF}^{\circledR}$, which was supplied by Johnson Matthey. The $\mathrm{SCRF}^{\circledR}$ is a wall flow device. This means that it has alternately open and closed channels. Every open channel at the input is closed at the output side and vice versa. This results in the exhaust flowing through the wall of the substrate. This DOC - SCRF ${ }^{\circledR}$ system has a lower weight and volume than the combined DOC-CPFSCR system. Since, the $\mathrm{SCRF}^{\circledR}$ can both filter Particulate Matter (PM) and reduce $\mathrm{NO}_{x}$, there is a competition for $\mathrm{NO}_{2}$ which changes the PM loading and oxidation reaction kinetics and $\mathrm{NO}_{\mathrm{x}}$ reduction as compared to that in the CPF - SCR system. The SCRF ${ }^{\circledR}$ and SCR (2013 production) used in this study have copper zeolite based SCR coating.

As a part of the Diesel Aftertreatment Consortium effort to study the PM oxidation kinetics and the $\mathrm{NO}_{\mathrm{x}}$ reduction in $\mathrm{SCRF}^{\circledR}$ systems, various studies were performed by different researchers at MTU. These studies include baseline, Configuration 1 and Configuration 2 and are discussed in the following paragraphs. All these studies were performed at steady state conditions using the Cummins ISB 2013, 6.7 L Engine and ULSD-2 fuel. 


\subsection{Baseline Study}

Reference [4] shows experimental data on the PM oxidation kinetics in the CPF at different exhaust conditions. The aftertreatment system consisted of a DOC followed by a CPF and two SCR bricks. The urea injector was placed between the CPF and the SCR bricks in the decomposition tube. This configuration is similar to the current production system but lacks an ammonia oxidation catalyst (as a part of the second SCR brick) to oxidize $\mathrm{NH}_{3}$ slip out of the SCR. The CPF was loaded at a $30 \%$ reduced rail pressure to achieve a target loading of $3.0 \pm 0.4 \mathrm{~g} / \mathrm{L}$. Both $\mathrm{NO}_{2}$ assisted oxidation (Passive Oxidation) and $\mathrm{O}_{2}$ assisted thermal oxidation (Active Regeneration) studies of the PM were performed to understand the oxidation kinetics in the CPF. In addition, PM loading data were also collected to understand the loading rates, mass retained and corresponding pressure drops across the filter. Being a wall flow device, the pressure drop across the CPF increases with more PM retained. The pressure drops are important because the back pressure on the engine due to the aftertreatment system causes an increase in PM, CO and hydrocarbon emissions as well as an increase in fuel consumption.

The study found that the $\mathrm{NO}_{2}$ assisted oxidation can be fit to a single set of kinetics for the CPF inlet temperature ranging between 299 and $385^{\circ} \mathrm{C}$ and $\mathrm{CPF}$ inlet $\mathrm{NO}_{2}$ concentrations between 330 and 1013 ppm. The activation energy $E_{a}$ and pre exponential factor $A$ in the standard Arrhenius equation were found to be $E_{a}=94 \mathrm{~kJ} / \mathrm{gmol}$ and $\mathrm{A}=25.51 / \mathrm{ppm} / \mathrm{s}$ respectively for $\mathrm{NO}_{2}$ assisted oxidation. Similarly, the $\mathrm{O}_{2}$ assisted oxidation kinetics can also be represented by standard Arrhenius equation. This was studied during active regeneration experiments conducted at CPF inlet temperatures ranging between 498 and $575{ }^{\circ} \mathrm{C}$. An activation energy $E_{\text {th }}=136 \mathrm{KJ} / \mathrm{gmol}$ and a pre exponential factor $A_{\text {th }}=3.561 / \mathrm{ppm} / \mathrm{s}$ was determined for thermal oxidation.

It was also found that the $\mathrm{NO}_{2}$ assisted kinetics for stage 2 loading was higher than that during passive oxidation with an activation energy $\mathrm{Ea}=94 \mathrm{KJ} / \mathrm{gmol}$ and a pre exponential factor $\mathrm{A}=244$ $1 / \mathrm{ppm} / \mathrm{s}$. The average CPF inlet temperature during loading was $285^{\circ} \mathrm{C}$ and average filtration efficiency was $97.8 \%$. The results obtained from the study define the baseline conditions against 
which the performance of the $\mathrm{SCRF}^{\circledR}$ is compared. This helps in evaluating the possibility of using the $\mathrm{SCRF}^{\circledR}$ to meet the EPA emission standards.

\subsection{Configuration 1}

Reference [2] showed experimental data on the PM loading and oxidation characteristics of the $\mathrm{SCRF}^{\circledR}$. For this study, the aftertreatment system comprised a DOC - SCRF ${ }^{\circledR}$ system - Configuration 1. The physical dimensions of the $\mathrm{SCRF}^{\circledR}$ vs the CPF can be found in reference [2]. The $\mathrm{SCRF}^{\circledR}$ was loaded at a $30 \%$ reduced rail pressure to decrease the loading time and attain a target loading of $1.7 \pm 0.4 \mathrm{~g} / \mathrm{L}$. Seven experiments each were performed at different engine conditions to study passive oxidation characteristics of the $\mathrm{PM}$ in the $\mathrm{SCRF}^{\circledR}$ with and without urea dosing respectively $(A N R=1.01)$. Also, four active regeneration tests were performed $w / o$ urea injection to understand the $\mathrm{O}_{2}$ assisted thermal oxidation in the $\mathrm{SCRF}^{\circledR}$. Studies were also conducted to understand the loading kinetics, the PM mass retained, the pressure drops across the $\mathrm{SCRF}^{\circledR}$ and the temperature distribution in the $\mathrm{SCRF}^{\circledR}$. The data obtained were compared to the baseline data obtained in reference [4] and the data are being used to calibrate the 1-D SCR-F model being developed at MTU.

The study determined that for $\mathrm{NO}_{2}$ assisted oxidation without urea in the $\mathrm{SCRF}^{\circledR}$, the data can be fit to a single set of kinetics computed from standard Arrhenius equation with an activation energy $E_{a}=99.2 \mathrm{~kJ} / \mathrm{gmol}$ and a pre exponential factor $A=113.71 / \mathrm{ppm} / \mathrm{s}$ in the average substrate temperature range of 273 to $377^{\circ} \mathrm{C}$ and inlet $\mathrm{NO}_{2}$ concentration ranging between 117 to 792 ppm. This showed that for the $\mathrm{SCRF}^{\circledR}$, the rate constant was $44 \%$ lower and the reaction rates are $56 \%$ lower when compared to that of the CPF. Similarly, for the case of passive oxidation with urea injection, a single set of kinetics gave an activation energy $\mathrm{Ea}=96.2 \mathrm{KJ} / \mathrm{gmol}$ and a pre exponential factor $A=23.11 / p p m / s$ for an average substrate temperature ranging between 274 and $373^{\circ} \mathrm{C}$ and $\mathrm{SCRF}^{\circledR}$ inlet $\mathrm{NO}_{2}$ varied from 171 to $821 \mathrm{ppm}$. The urea was dosed at an $\mathrm{ANR}>=1$ (except for 2 tests). The average $\mathrm{NO}_{x}$ conversion efficiency across the SCRF ${ }^{\circledR}$ was found to be 94 $\%$ with an ammonia slip ranging between 1 to $17 \mathrm{ppm}$. The rate constant $\mathrm{k}$ for PO with urea dosing was found to be $60 \%$ lower when compared to the case where urea wasn't dosed and was $78 \%$ lower when compared to the production CPF (baseline). The reaction rate was found to be 
lower by $51 \%$ as compared to the case where urea wasn't dosed and was $79 \%$ lower when compared to the production CPF (baseline).

The $\mathrm{O}_{2}$ assisted oxidation, studied during AR tests had an activation energy Ea $=211.5 \mathrm{~kJ} / \mathrm{gmol}$ and a pre exponential $A=2.52 * 10^{5} 1 / \mathrm{ppm} / \mathrm{s}$ in the average substrate temperature range of 510 to $577^{\circ} \mathrm{C}$ and $\mathrm{SCRF}^{\circledR}$ inlet $\mathrm{O}_{2}$ ranging between 8.17 to $8.86 \%$. For the stage 2 loading, the average filtration efficiency was found to be $98 \%$ and the average temperature was found to be $276^{\circ} \mathrm{C}$. Although the mass retained in the $\mathrm{SCRF}^{\circledR}$ and $\mathrm{CPF}$ were the same (29.0 vs $29.2 \mathrm{~g}$ ) at the end of stage 2, the pressure drop for the $\mathrm{SCRF}^{\circledR}$ was higher than that for the CPF (7.9 vs 7.4 kPa), even though it was loaded for 300 minutes as compared to 330 minutes for the CPF. The temperature distribution across the $\mathrm{SCRF}^{\circledR}$ was studied and different trends in temperature with and without urea dosing were observed. It was found that injection of urea affects the temperature distribution in the $\mathrm{SCRF}^{\circledR}$. Lower temperature and low space velocity test points saw higher impact on substrate temperature distribution with urea dosing meaning that the variation in maximum and minimum temperatures across the $\mathrm{SCRF}^{\circledR}$ was large.

\subsection{Configuration 2}

The author of Reference [3] performed experiments to study the $\mathrm{NO}_{x}$ reduction and $\mathrm{NH}_{3}$ storage characteristic of the $\mathrm{SCRF}^{\circledR}$ with and without PM loading and compare it to the 2013 production SCR (without PM loading). Both the 2013 production SCR and the SCRF ${ }^{\circledR}$ are Cu-Zeolite substrates. For the experimentation, the aftertreatment system comprised a DOC-CPF- SCRF ${ }^{\circledR}$ Configuration 2. The upstream CPF was replaced with a spacer when the $\mathrm{SCRF}^{\circledR}$ was intended to be loaded with $\mathrm{PM}$. The $\mathrm{NO}_{\mathrm{x}}$ reduction tests were performed with the $\mathrm{SCRF}^{\circledR}$ being loaded at 0,2 and $4 \mathrm{~g} / \mathrm{L}$ of PM. The 0 and $2 \mathrm{~g} / \mathrm{L} \mathrm{PM}$ loading were run at a $30 \%$ reduced rail pressure while the $4 \mathrm{~g} / \mathrm{L} \mathrm{PM}$ loading was run at $50 \%$ reduced rail pressure. Four test points were run with and with PM loading which had the $\mathrm{SCRF}^{\circledR}$ inlet temperatures ranging from 200 to $450^{\circ} \mathrm{C}$ and $\mathrm{NO}_{\mathrm{x}}$ ranging from 280 to 1600 ppm . A comparison of both Configuration 1 and Configuration 2 data for $\mathrm{NO}_{\mathrm{x}}$ reduction and $\mathrm{NH}_{3}$ slip was made with the baseline data for the 2013 production SCR. 
Analyzing the data for the 2013 production SCR from the baseline tests, it was found that $\mathrm{NO}_{\mathrm{x}}$ reduction of $90-95 \%$ with $\mathrm{NH}_{3}$ slip less than 40 ppm at ANR 1.0 is achieved in the temperature range of $300-350^{\circ} \mathrm{C}$. At temperatures less than $200^{\circ} \mathrm{C}$ and greater than $450^{\circ} \mathrm{C}$, the $\mathrm{NO}_{x}$ reduction performance decreases to $80-85 \%$ and while $\mathrm{NH}_{3}$ slip is less than 20 ppm and less than 70 ppm respectively at the two temperature ranges. Maximum $\mathrm{NH}_{3}$ storage of $75 \mathrm{gmol} / \mathrm{m}^{3}$ was observed at $200^{\circ} \mathrm{C}$. Configuration 1 tests showed that $\mathrm{NO}_{x}$ conversion efficiency greater than $90 \%$ with $\mathrm{NH}_{3}$ slip less than $20 \mathrm{ppm}$ at ANR 1.0 was achieved in the temperature range of 260 to $370^{\circ} \mathrm{C}$. However, for ANR values ranging between 1.05 and 1.10, the $\mathrm{NO}_{\mathrm{x}}$ reduction efficiency of greater than $95 \%$ can be attained without considerable $\mathrm{NH}_{3}$ slip.

From Configuration 2 tests, it was observed that the $\mathrm{NO}_{\mathrm{x}}$ conversion efficiency of greater than $90 \%$ with $\mathrm{NH}_{3}$ slip less than 50 ppm at ANR 1.0 is achieved with the $\mathrm{SCRF}^{\circledR}$ in the temperature range of 200 to $450^{\circ} \mathrm{C}$ with and without PM loading. This when compared to the baseline SCR shows a $5-7 \%$ improvement in $\mathrm{NO}_{x}$ reduction at temperatures below 250 and above $400^{\circ} \mathrm{C}$. It was also concluded that the $\mathrm{NO}_{2}$ for the SCR reactions is significantly lower based on the decrease in $\mathrm{NO}_{2} / \mathrm{NO}_{\mathrm{x}}$ values observed at the outlet of the $\mathrm{SCRF}^{\circledR}$ with increase in PM loading from 0 to 2 to 4 $\mathrm{g} / \mathrm{L}$. This is because of competition for $\mathrm{NO}_{2}$ for $\mathrm{NO}_{2}$ assisted PM oxidation reactions and SCR reactions. $\mathrm{NO}_{\mathrm{x}}$ reduction in the $\mathrm{SCRF}^{\circledR}$ was not affected at temperatures below $300^{\circ} \mathrm{C} \mathrm{SCRF}^{\circledR}$ inlet temperatures with an increase in PM loading. A decrease of 3-5\% in $\mathrm{NO}_{x}$ reduction was however observed above $350^{\circ} \mathrm{C}$. A decrease in ammonia storage of $20-30 \%$ in the $\mathrm{SCRF}^{\circledR}$ was observed at a temperature range of 200 to $350^{\circ} \mathrm{C}$ when the PM loading increased from 0 to $2 \mathrm{~g} / \mathrm{L}$. However, any significant change wasn't observed when the PM loading changed from 2 to $4 \mathrm{~g} / \mathrm{L}$ or when the temperature was above $350^{\circ} \mathrm{C}$. Maximum $\mathrm{NH}_{3}$ storage in the $\mathrm{SCRF}^{\circledR}$ was the same as that for the SCR in the production system. The $\mathrm{NH}_{3}$ storage between the $\mathrm{SCRF}^{\circledR}$ and the baseline SCR was found to be within $\pm 5 \mathrm{gmol} / \mathrm{m}^{3}$.

\subsection{Literature Review}

Lopez et al. [5] studied the $\mathrm{NO}_{\mathrm{x}}$ reduction and PM oxidation over a DPF coated with Vanadium based SCR coating (termed V.SCR-DPF). The tests were conducted both for steady state and 
transient cycles - Non Road Transient Cycle (NRTC) and World Harmonized Test Cycle (WHTC), using different configurations. They found that using a downstream V.SCR the $\mathrm{NO}_{\mathrm{x}}$ conversion efficiency increased from 81 to $92 \%$ on a Hot NRTC cycle (V.SCR-DPF inlet temperature $302^{\circ} \mathrm{C}$ ) and the ammonia slip was less than 60 ppm. For the same cycle, an increase from 81 to $95 \%$ in $\mathrm{NO}_{x}$ conversion efficiency was observed when a ASC (Ammonia Slip Catalyst) was also placed downstream the V.SCR and ammonia slip was less than $5 \mathrm{ppm}$. The $\mathrm{NO}_{2} / \mathrm{NO}_{x}$ ratio was 0.46 , ANR 1.2 and these tests were carried out on a US 2007, 8.9 L engine. This data are shown in Figure 2.1.

For a EU VI, 8L engine, 97 and 92\% NO conversion efficiency was obtained for NRTC and WHTC with ANR 1.2 and a downstream V.SCR and ASC as shown in Figure 2.2. Different volumes of aftertreatment components than the previous tests were used for this testing. The $\mathrm{NO}_{2} / \mathrm{NO}_{x}$ ratio was 0.51 and 0.44 and temperatures were 320 and $250^{\circ} \mathrm{C}$ at the V.SCR-DPF inlet for NRTC and WHTC respectively. An ammonia slip of less than 10 ppm was observed for both cycles.

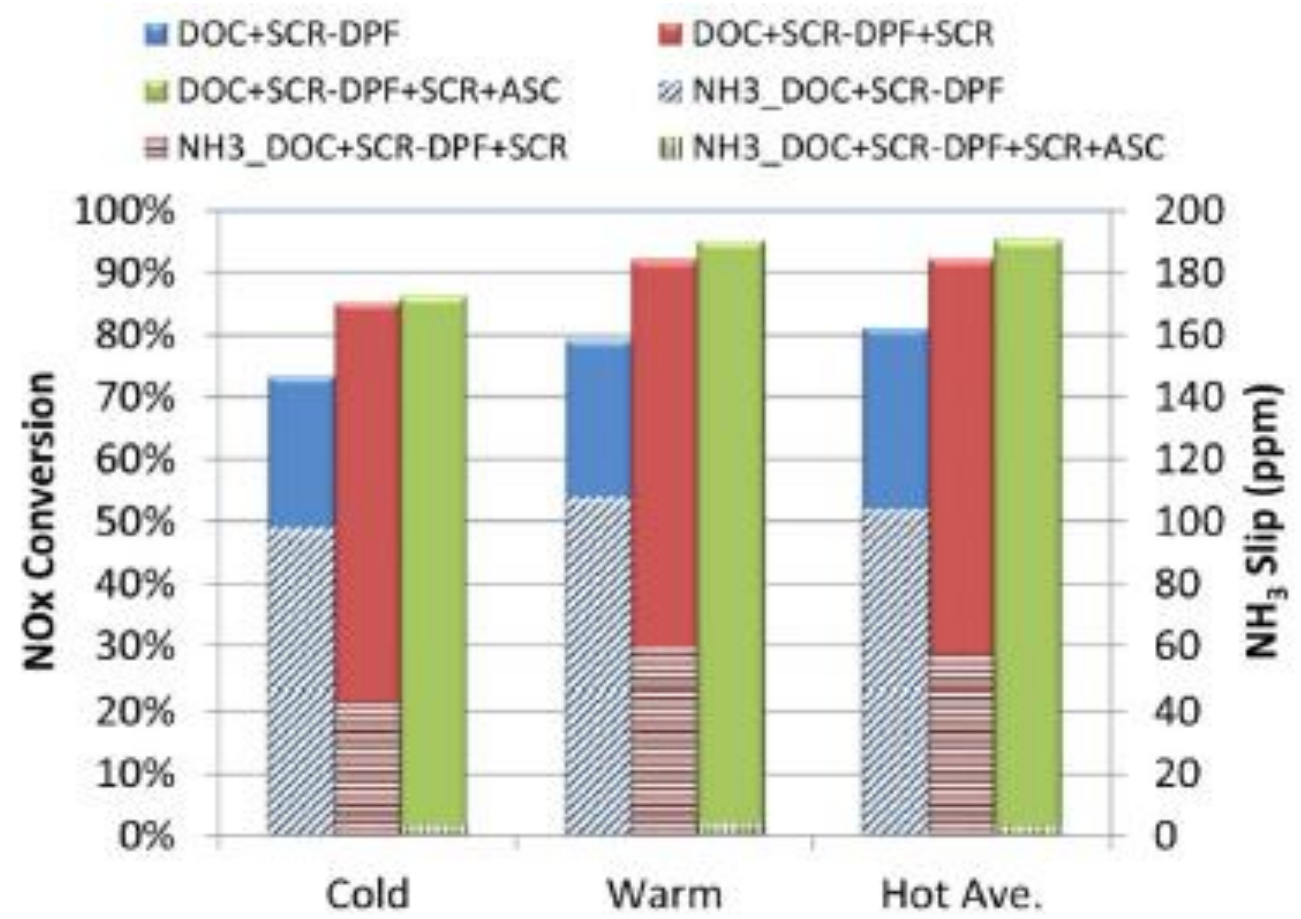

Figure 2.1: $\mathrm{NO}_{x}$ conversion and average $\mathrm{NH}_{3}$ slip over the $\mathrm{NRTC}$ at ANR 1.2 for different systems [5] 


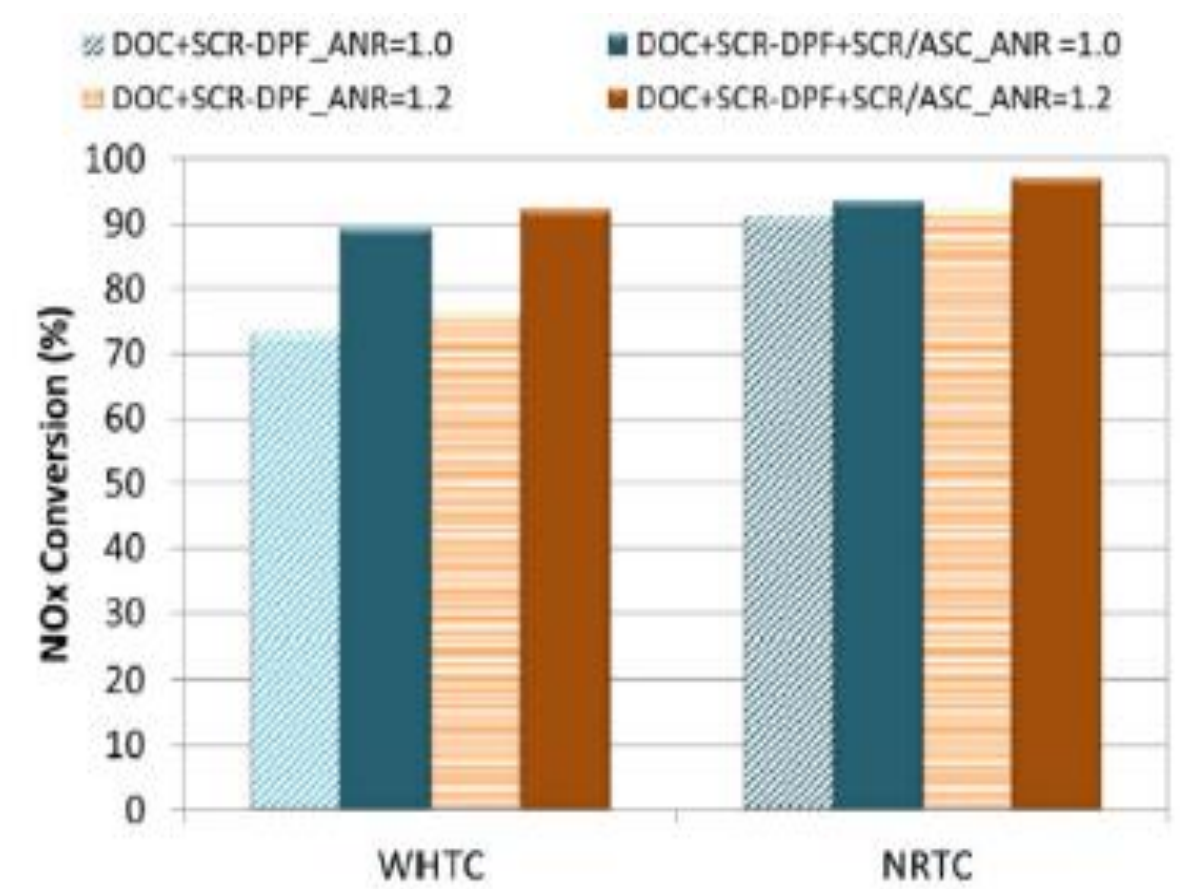

Figure 2.2: NOx conversion over hot WHTC and NRTC tests for different configurations [5]

Balland et al.[6] studied different SCR on Filter (SCRoF) configurations for passenger car applications as shown in Figure 2.3. They found that due to the closer location of the SCRoF to the DOC, faster light off and higher temperatures are attained. This results in a high $\mathrm{NO}_{\mathrm{x}}$ conversion efficiency. But since the volume of SCRoF is less, at high inlet $\mathrm{NO}_{x}$ and space velocities, $\mathrm{NO}_{x}$ conversion drops. The conversion efficiencies can then be improved by using a SCR downstream of the SCRoF. For the same combined volume of SCRoF and SCR as compared to a large underfloor $\mathrm{SCR}$, the former shows much better $\mathrm{NO}_{x}$ conversion results for various transient cycles - New European Driving Cycle (NEDC), World Harmonized Light Duty Vehicle Test Procedure (WLTC) and Real Driving Cycle (RDE). The data for the three configurations are shown in Figure 2.4. They also proposed a control strategy for urea injection which suggested that $\mathrm{NO}_{\mathrm{x}}$ conversion efficiency can be maximized if the SCRoF has high $\mathrm{NH}_{3}$ storage and the SCR also stores $\mathrm{NH}_{3}$ instead of just behaving as a passive aftertreatment device. This means that some ammonia 
must slip out of the SCRoF into the SCR so that SCR also converts $\mathrm{NO}_{x}$ actively and can provide very low $\mathrm{NO}_{\mathrm{x}}$ out even in driving conditions such as sudden accelerations or sudden changes in load.

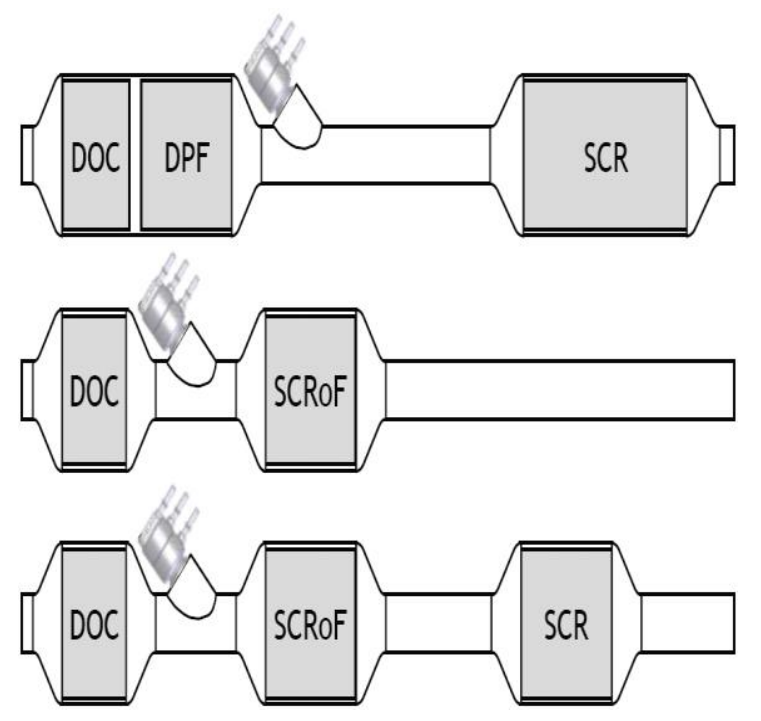

Figure 2.3: SCRoF Configurations[6]

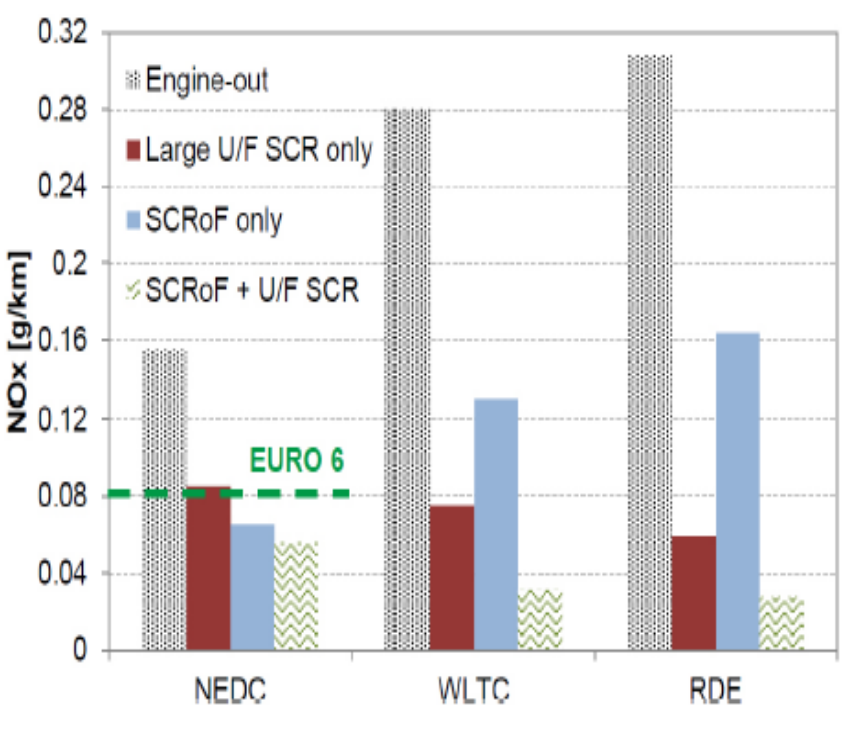

Figure 2.4: Outlet NOx at different configurations vs Transient Cycles [6]

Johansen et al. [7] performed experiments to understand $\mathrm{NO}_{\mathrm{x}}$ conversion and $\mathrm{PM}$ oxidation characteristics of a Vanadium SCR catalyst on a DPF. Their aftertreatment system consisted of DOC+ VSCRonDPF +VSCR+ASC. The engine used for testing was a MAN D26, $13 \mathrm{~L}$. The testing was performed with and without EGR so as to achieve a low engine out PM and high $\mathrm{NO}_{x}$. They obtained a $\mathrm{NO}_{x}$ conversion efficiency of $97 \%$ while running the engine without EGR. It was also discussed that in the temperature range of $180-300^{\circ} \mathrm{C}$, fast SCR reactions are preferred. Since the residence time of $\mathrm{NO}_{2}$ in the VSCRonDPF is low, faster reaction kinetics is required (because the SCR catalyst is deposited in or on the wall of the filter and the gas is forced through the wall). This causes the need of an optimum amount of $\mathrm{NO}_{2}$ in the VSCRonDPF because there is competition for $\mathrm{NO}_{2}$ between the $\mathrm{SCR}$ reactions and the $\mathrm{NO}_{2}$ assisted oxidation reactions of soot. $\mathrm{A} \mathrm{NO} / \mathrm{NO}_{\mathrm{x}}$ ratio of at least 0.5 at VSCRonDPF inlet was recommended. Equations 2.1 to 2.7 show these reactions. 
Passive Oxidation of soot

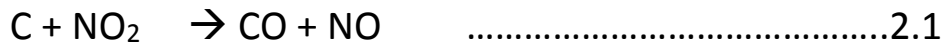

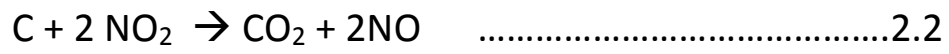

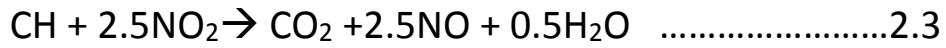

SCR Reactions

\begin{tabular}{|c|c|}
\hline Urea Decomposition & $\left(\mathrm{NH}_{2}\right)_{2} \mathrm{CO}+\mathrm{H}_{2} \mathrm{O} \rightarrow 2 \mathrm{NH}_{3}+\mathrm{CO}$ \\
\hline Standard SCR & $4 \mathrm{NH}_{3}+4 \mathrm{NO}+\mathrm{O}_{2} \rightarrow 4 \mathrm{~N}_{2}+6 \mathrm{H}_{2} \mathrm{O}$ \\
\hline Fast SCR & 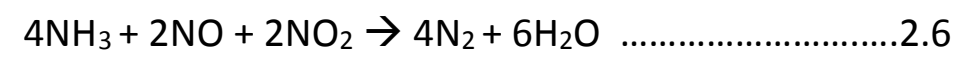 \\
\hline Slow SCR & $4 \mathrm{NH}_{3}+3 \mathrm{NO}_{2} \rightarrow 3.5 \mathrm{~N}_{2}+6 \mathrm{H}_{2} \mathrm{O}$ \\
\hline
\end{tabular}

Johansen et al. [8] studied the effect of Copper-Zeolite ( $\mathrm{Cu}$ ) and Vanadium (V) based SCR coating on a DPF. They found that for colder drive cycle the Cu-based DPF is preferable which can also undergo active regenerations because of the high temperature withstanding ability of CopperZeolite-DPF $\left(800^{\circ} \mathrm{C}\right)$. For warmer drive cycles, the Vanadium based DPF is preferred which can solely rely upon passive oxidations to regenerate the filters as the temperature withstanding is low $\left(600^{\circ} \mathrm{C}\right)$. In $\mathrm{WHTC}$, at low temperatures and low $\mathrm{NO}_{2} / \mathrm{NO}_{\mathrm{x}}$ ratio, Cu-DPF had better $\mathrm{NO}_{\mathrm{x}}$ conversion performance than V-DPF while at higher temperatures V-DPF showed better performance. $\mathrm{Cu}$-DPF showed a higher $\mathrm{NH}_{3}$ storage capacity while passive oxidation response of V-DPF was higher. 
Jan et al. [9] performed experiments to study emissions and regeneration behavior of the SCRF ${ }^{\circledR}$ system compared to a conventional production aftertreatment system. The tests were performed both under steady state conditions and transient conditions using the World Harmonized Transient Cycle (WHTC) using a modified Iveco, 3L 4-cylinder engine. It was found that the increase in filter weight did not correspond to the back pressure. This was explained on the basis of a heterogeneous distribution of the soot load in the volume of the $\mathrm{SCRF}^{\circledR}$ which causes different flow patterns due to different resistance to the flow within the $\mathrm{SCRF}^{\circledR}$. Thus for the same mass of soot deposition different backpressures are observed. It was also found that the $\mathrm{NH}_{3}$ mixing in the exhaust gas is heterogeneous and the concentrations of $\mathrm{NH}_{3}$ and $\mathrm{NO}_{x}$ vary along the exhaust pipe diameter. The $\mathrm{NH}_{3}$ concentration is highest at the middle of the pipe diameter and decreases radially towards the pipe wall. $\mathrm{NO}_{\mathrm{x}}$ concentration follows an opposite trend. They found $\mathrm{NO}_{\mathrm{x}}$ conversion efficiencies to be greater than $90 \%$ with the $\mathrm{SCRF}^{\circledR}$ with urea injection. 


\section{Chapter 3. Experimental Setup}

This chapter describes the engine test cell, instrumentation, and test procedures used for the steady state experiments performed using the $\mathrm{SCRF}^{\circledR}$ and SCR system in Configuration 3. The engine, fuel, and aftertreatment components used in this configuration are the same as that used in Configurations 1 and 2 and have been described by references [2,3]. A description of the experimental setup is presented followed by a discussion of the physical changes made to the hardware for this configuration. After this, the instrumentation and test procedures for this configuration are described.

\subsection{Experimental Setup}

The engine and aftertreatment hardware used for Configuration 3 is the same as the one used for Configurations 1 and 2 except for a few minor changes that were made to the system. Figure 3.1 shows a picture of the aftertreatment system in the test cell that was used to conduct the research during Configuration 3.

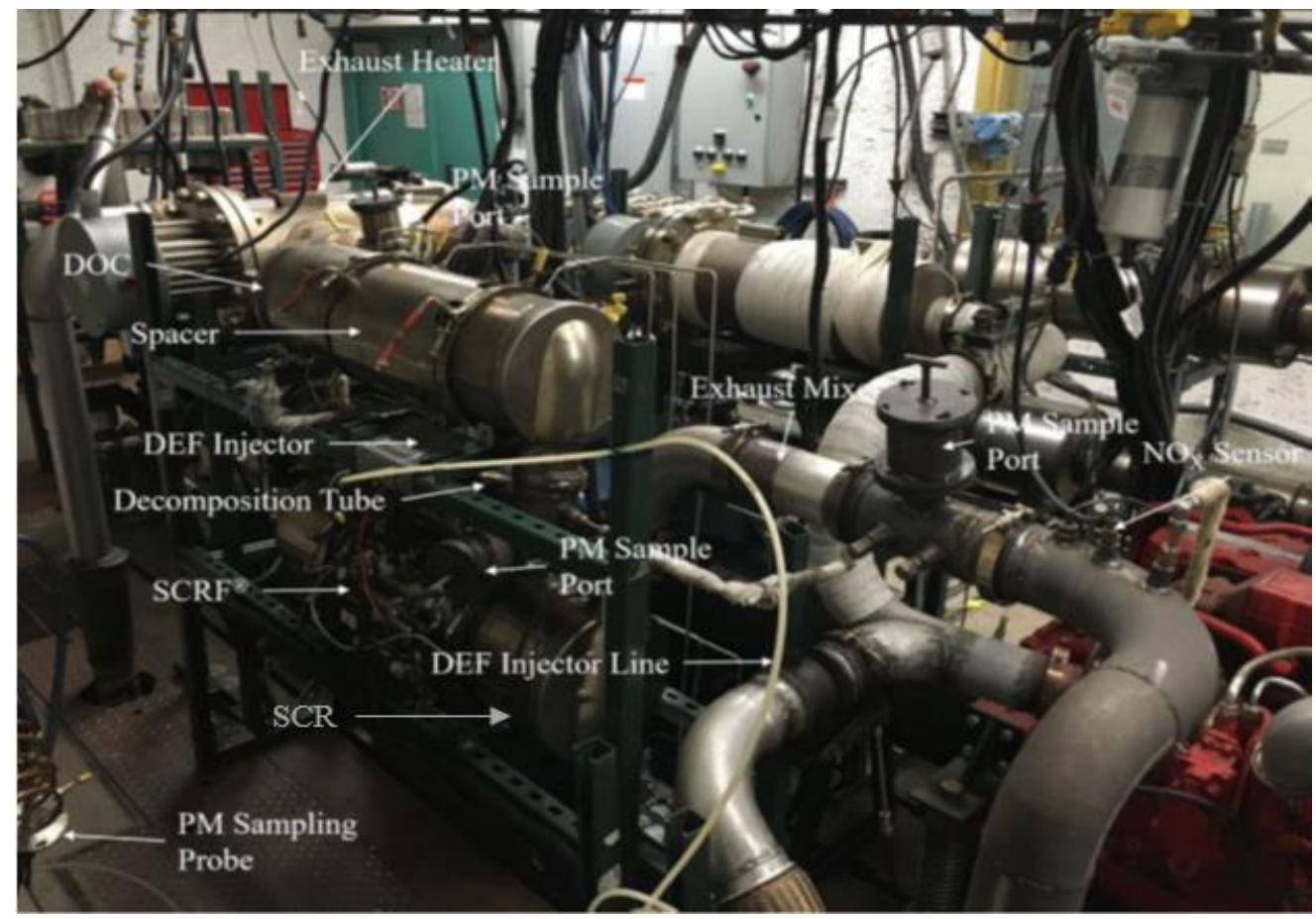

Figure 3.1: Aftertreatment System Used for the Experimental Study at MTU 
The schematic of the engine, the aftertreatment components (DOC, SCRF ${ }^{\circledR}$ and SCR-A), the instrumented sensors, and the sampling locations within the test cell are shown in Figure 3.2. The engine exhaust can either flow through the bypass line or the trap line, which flows into the aftertreatment components. In the trap line, exhaust gas flows through a $25 \mathrm{~kW}$ exhaust heater which can be used to raise the temperature of the exhaust gas entering the aftertreatment system. The exhaust flows through the $\mathrm{DOC}$, where the $\mathrm{HC}, \mathrm{CO}$ and $\mathrm{NO}$ are oxidized to $\mathrm{H}_{2} \mathrm{O}, \mathrm{CO}_{2}$ and $\mathrm{NO}_{2}$. The next component in the experimental setup is an insulated spacer (replacing the CPF for this Configuration). The exhaust then flows through the decomposition tube where Diesel Exhaust Fluid (DEF) can be injected into the exhaust stream. Next is a production mixer which ensures homogenous mixing of the DEF decomposition products/droplets and the exhaust gas. After this, the exhaust flows through the $\mathrm{SCRF}^{\circledR}$, where the concentration of $\mathrm{NO}_{\mathrm{x}}$ is reduced in the filter during urea dosing, and the PM is filtered and oxidized. Next, the exhaust flows through the SCR-A brick, where the remaining $\mathrm{NO}_{x}$ can be reduced as long as $\mathrm{NH}_{3}$ slips out of the filter, which is used for further conversion. The $\mathrm{SCRF}^{\circledR}$ and the SCR-A are separated by a spacer 3 inch long, where mid bed emission samples between the two substrates were measured. Finally, the exhaust gas flows through another downstream exhaust mixer after the SCR-A brick and then to the building exhaust.

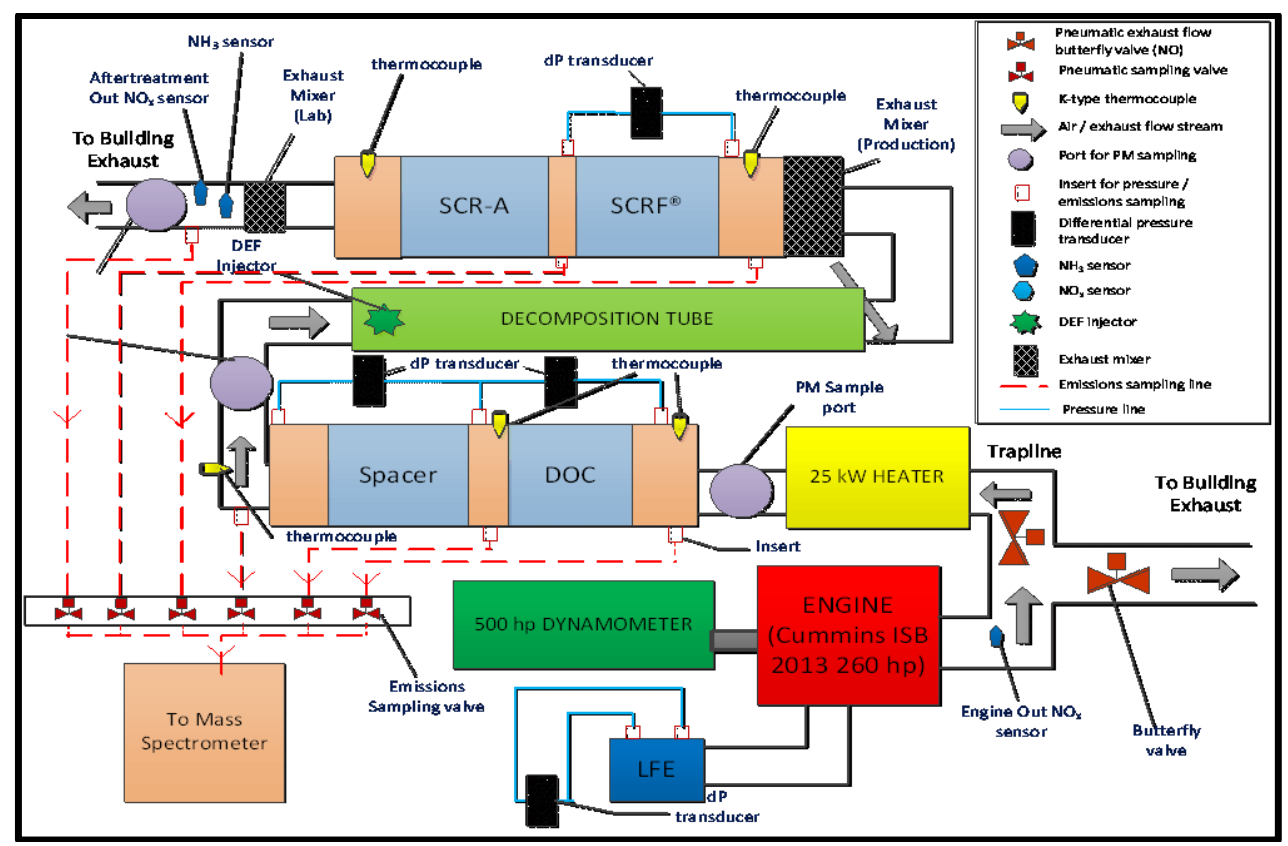

Figure 3.2: Test Cell Layout and Instrumentation for Configuration 3 
Emission sampling probes were installed upstream and downstream of the DOC, upstream of the $\mathrm{SCRF}^{\circledR}$, between the $\mathrm{SCRF}^{\circledR}$ and SCR-A and downstream of the SCR-A brick. A modification of the production mid bed ammonia sampling ring was performed to sample the exhaust gas between the $\mathrm{SCRF}^{\circledR}$ and SCR-A, as shown in Figure 3.3. The ring has holes in the ducts arranged in an " $\mathrm{X}$ " pattern across the diameter to ensure a representative sample is obtained between the SCRF ${ }^{\circledR}$ and the SCR substrate. The emission concentrations were measured using the mass spectrometer and a prototype Delphi $\mathrm{NH}_{3}$ sensor. The differential pressure sensors are installed across the laminar flow element (LFE), the $\mathrm{DOC}$ and the $\mathrm{SCRF}^{\circledR}$ to measure the pressure drop across the various components. The thermocouples were installed at the inlet and outlet of each device to measure the exhaust gas temperature. The $\mathrm{SCRF}^{\circledR}$ was also instrumented with twenty thermocouples (10 in the inlet channels and 10 in the outlet channels) to obtain the gas temperature distribution in the $\mathrm{SCRF}^{\circledR}$. Additional details about the instrumentation are given in references $[2,3]$.

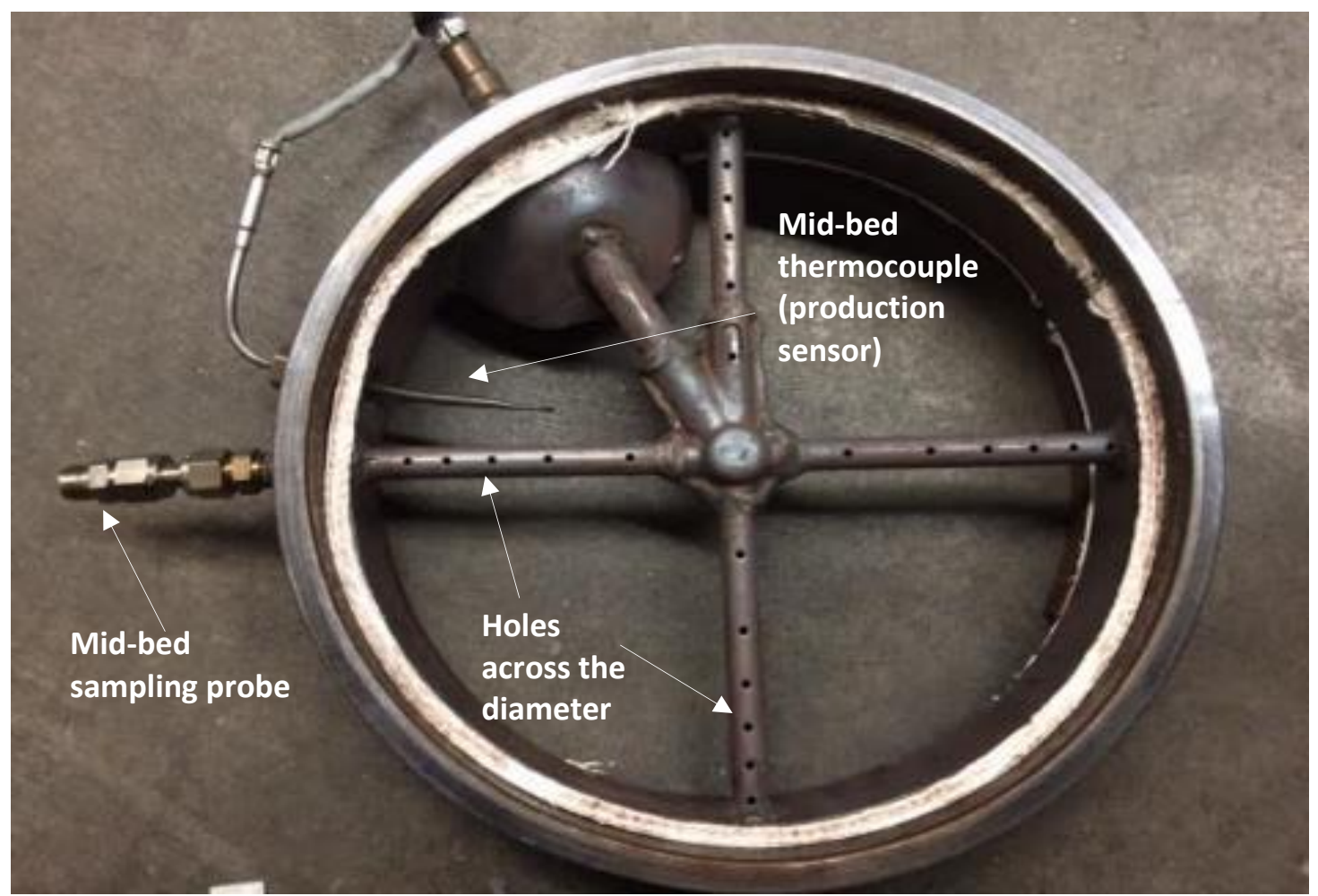

Figure 3.3: Sampling Probe Between the $\mathrm{SCRF}^{\circledR}$ and the SCR-A in Configuration 3 


\subsection{Test Cell and Instrumentation}

\section{Engine and Dynamometer}

A Cummins 2013 ISB 6.7 L, 6 cylinder diesel engine was used for conducting the tests. The engine was coupled to an eddy current dynamometer from Eaton Corp. The specifications for the engine and the dynamometer can be found in reference [4]. A Digalog Model 1022A controller was used to control the speed and torque of the engine.

\section{Fuel Properties}

Ultra-low sulfur diesel number 2 (ULSD \# 2) summer blend fuel was used during the testing. This fuel is same as the one used during baseline testing as well as during Configuration 1 and Configuration 2 testing. The properties of this fuel can be found in reference [4].

\section{Aftertreatment System}

The aftertreatment system for this configuration consists of a diesel oxidation catalyst (DOC), which is a flow through device. It is used for oxidizing CO, NO and HC. Downstream of the DOC there is an insulated spacer followed by decomposition tube where diesel exhaust fluid (DEF) can be injected into the exhaust stream. DEF is a aqueous solution of $32.5 \%$ urea concentration by weight with water [3]. This injected solution eventually decomposes to $\mathrm{NH}_{3}$ which then reduces the $\mathrm{NO}_{\mathrm{x}}$ across the $\mathrm{SCRF}^{\oplus}$ and SCR.

A production exhaust mixer follows the decomposition tube to mix the injected DEF with the exhaust gases to enhance the urea decomposition. After the exhaust mixer and inlet cone there is the SCRF ${ }^{\oplus}$ supplied by Corning and Johnson Matthey. Both PM oxidation and SCR reactions take place within the SCRF ${ }^{\circledast}$.

The $\mathrm{SCRF}^{\oplus}$ is followed by the sampling ring shown in Figure 3.3 and discussed earlier in the chapter. The purpose of installing a sampling probe is to collect the emissions samples in between the $\mathrm{SCRF}^{\oplus}$ and the SCR to determine the $\mathrm{NO}_{\mathrm{x}}$ reduction performance of the $\mathrm{SCRF}^{\circledR}$ alone. The sampling ring is equipped with a Delphi Ammonia sensor that gives $\mathrm{NH}_{3}$ concentrations in ppm. The readings from this $\mathrm{NH}_{3}$ sensor were not used due to its malfunctioning. This is followed by the SCR-A brick. The designation for the different bricks was given by Cummins, and denotes that it only has the $\mathrm{Cu}$-Zeolite catalyst. The reason for using brick type $\mathrm{A}$ is that it does not have an 
ammonia oxidation catalyst (AMOX) [4], which then allows the study of the $\mathrm{NH}_{3}$ slip in the combined system. The SCR brick used downstream of the $\mathrm{SCRF}^{\oplus}$ provides further $\mathrm{NO}_{\mathrm{x}}$ reduction and adsorbs any $\mathrm{NH}_{3}$ slipping out of the SCRF ${ }^{\oplus}$. After the $\mathrm{SCR}$, there is an exhaust mixer to ensure a homogenous mixture of the exhaust gasses before the downstream emission sampling location.

There are three sampling ports for hot sampling of the particulate matter (PM) at the upstream DOC, upstream $\mathrm{SCRF}^{\oplus}$ and downstream SCR. These can be seen in Figures 3.1 and 3.2. The exhaust is sampled using a manual sampling train (MST) made by Andersen Instruments Inc. and a Dry Gas Meter (DGM). The procedure is same as used for the baseline and for Configurations 1 and 2 testing. The filter papers used for collecting PM are A/E type $47 \mathrm{~mm}$ glass fiber filter papers manufactured by Pall Corporation, WA. The filters are baked and conditioned prior to weighing to remove any volatile compounds before their use in sampling for PM. A Mettle Toledo UMT2 scale is used to perform gravimetric weighing of the filters, which has a readability of up to 0.1 $\mu \mathrm{g}$. Further details of the PM collection procedure and filter weighing procedure is described in references $[2,4]$.

Laminar Flow Element: A laminar flow element (LFE) manufactured by Meriam Instruments was used to measure the flow rate of the air going into the engine. This was done by measuring the corresponding pressure drop across the LFE using a delta pressure transducer details of which are given in references [2] and [4].

Ambient Temperature and Humidity: This was measured using an Omega HX94V temperature and relative humidity transmitter installed in the test cell [2] [4].

Data Acquisition System: Two NI CDAQ-9178 chassis were used to acquire the data from various sensors installed in the test cell. A NI LabVIEW program was developed and modified to display and save the data. Also, the same program was used to control the electro-pneumatic valves that allowed the exhaust gas sample to flow into the IMR-MS and Pierburg bench gas analyzers from various sampling locations (sampled one at a time). Fuel flowrate was measured using a Micromotion Coriolis flowmeter and the data were transmitted and communicated using a transmitter and RS-485 driver. Data and measured values from the Delphi $\mathrm{NH}_{3}$ sensor were collected using a NI USB Can-8473 device. Engine data from various production sensors were 
acquired using ECM via CAN communication and displayed and saved using Calterm III, which is Cummins proprietary software $[2,4]$.

Pressure and Temperature: Differential pressure transducers were connected across the LFE, $\mathrm{DOC}$, and $\mathrm{SCRF}^{\circledR}$, to measure the pressure drop across these components. The $\mathrm{SCRF}^{\circledR}$ was instrumented with twenty K-type thermocouples at various axial and radial locations to measure the substrate temperature distribution within the filter [3]. Additional K-type thermocouples were used to measure temperatures at the inlet and outlet of each major component in the aftertreatment system as shown in Figure 3.2. The details and specifications of the location of thermocouples within the $\mathrm{SCRF}^{\circledR}$ as well as specifications for the pressure transducers can be found in references $[2,4]$.

\subsection{Test Matrix}

Six test conditions were selected, including five different Test Points from Configuration 1 [2] and Test Point 1 from Configuration 2 [3]. The test matrix and important exhaust conditions for Configuration 3 are shown in Table 3.1. The six test conditions span the $\mathrm{SCRF}^{\circledR}$ inlet temperatures from $200-370^{\circ} \mathrm{C}$, space velocities ranging from $10.0-34.0 \mathrm{k} / \mathrm{hr}, \mathrm{SCRF}^{\circledR}$ inlet $\mathrm{NO}_{\mathrm{x}}$ concentrations ranging from $420-1600$ ppm, $\mathrm{SCRF}^{\circledR}$ inlet $\mathrm{NO}_{2}$ concentrations ranging from $160-760 \mathrm{ppm}$ and inlet $\mathrm{NO}_{2} / \mathrm{NO}_{x}$ ratio ranging from 0.29 to 0.48 . 
Table 3.1: Test Matrix for Engine and Exhaust Conditions for Configuration 3 (with Urea Dosing)

\begin{tabular}{|c|c|c|c|c|c|c|c|}
\hline $\begin{array}{l}\text { Test } \\
\text { Point }\end{array}$ & Speed & Load & \begin{tabular}{|} 
Exhaust \\
Flow Rate
\end{tabular} & $\begin{array}{c}\text { SCRF }^{\circledR} \\
\text { Inlet } \\
\text { Temp. }\end{array}$ & $\begin{array}{c}\mathrm{SCRF}^{\circledR} \\
\text { Inlet } \mathrm{NO}_{2}\end{array}$ & $\begin{array}{c}\text { SCRF }^{\circledR} \\
\text { Inlet NO }\end{array}$ & $\begin{array}{c}\mathrm{SCRF}^{\circledR} \\
\text { Inlet } \\
\mathrm{NO}_{2} / \mathrm{NO}_{\mathbf{x}}\end{array}$ \\
\hline$[-]$ & [RPM] & [N.m] & {$[\mathrm{kg} / \mathrm{min}]$} & {$\left[{ }^{\circ} \mathrm{C}\right]$} & [ppm] & [ppm] & [-] \\
\hline A & 1301 & 303 & 5.6 & 267 & 215 & 590 & 0.44 \\
\hline C & 1399 & 543 & 6.9 & 339 & 290 & 689 & 0.44 \\
\hline$E$ & 1203 & 648 & 7.1 & 342 & 584 & 1450 & 0.37 \\
\hline B & 902 & 449 & 3.7 & 256 & 758 & 1580 & 0.48 \\
\hline D & 2100 & 598 & 12.5 & 366 & 161 & 450 & 0.38 \\
\hline 1 & 1201 & 203 & 5.2 & 203 & 182 & 625 & 0.29 \\
\hline
\end{tabular}

\subsection{Test Procedure}

The test procedures followed in Configuration 3 were developed and adapted from test procedures developed in references $[2,3]$. The schematic of several stages in the test procedure of a passive oxidation (PO) test with urea dosing is shown in Figure 3.4.

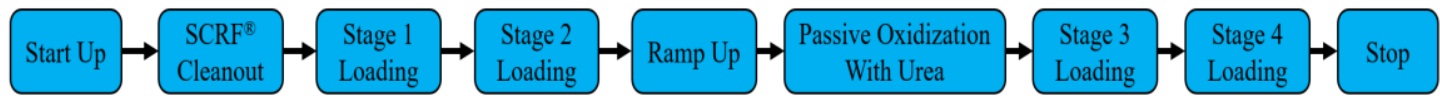

Figure 3.4: Stages of a Passive Oxidation Test with Urea Dosing with Configuration 1 [2]

The primary objective of this configuration was to determine the $\mathrm{NO}_{\mathrm{x}}$ reduction and ammonia slip characteristics of the SCRF ${ }^{\circledR}$ with a downstream SCR together. The $\mathrm{NO}_{2}$ assisted oxidation kinetics of $\mathrm{PM}$ in the $\mathrm{SCRF}^{\circledR}$ during passive oxidation (PO) stage, with urea dosing was also determined from the experimental data.

The first two stages are loading stages where the SCRF ${ }^{\circledR}$ is loaded with PM to a target value of 2 $\pm 0.2 \mathrm{~g} / \mathrm{L}$ at $30 \%$ reduced fuel rail pressure (1050 bar) at $2400 \mathrm{rpm}$ and $200 \mathrm{Nm}$. This is done so that the target loading is achieved in less time. The retained PM in the $\mathrm{SCRF}^{\circledR}$ is oxidized in the PO stage, during which the urea injection is performed. The urea dosing during the PO stage has a target ANR between $1.02-1.13$, which is calculated based on $\mathrm{SCRF}^{\circledR}$ inlet $\mathrm{NO}_{\mathrm{x}}$ concentrations and shown in Appendix G. The PO stage is followed by post loading stages at $30 \%$ reduced fuel rail pressure at $2400 \mathrm{rpm}$ and $200 \mathrm{Nm}$ - stage 3 and stage 4, which provide the post oxidation 
filter loading characteristics. The detailed procedure for passive oxidation test with urea dosing is described in section 3.7 of reference [2].

A plot of pressure drop across the $\mathrm{SCRF}^{\circledR}$ is shown in Figure 3.5 and gives a better graphical representation of the loading profile during a PO test with urea injection. When comparing one PO test to another, the factors designed to change are the engine speed, the engine load, which changes the inlet temperature and $\mathrm{NO}_{2}$ concentrations, and the duration of the the oxidation stage [2]. All of the other stages of the test are run for predetermined lengths of time at specific engine operating conditions.

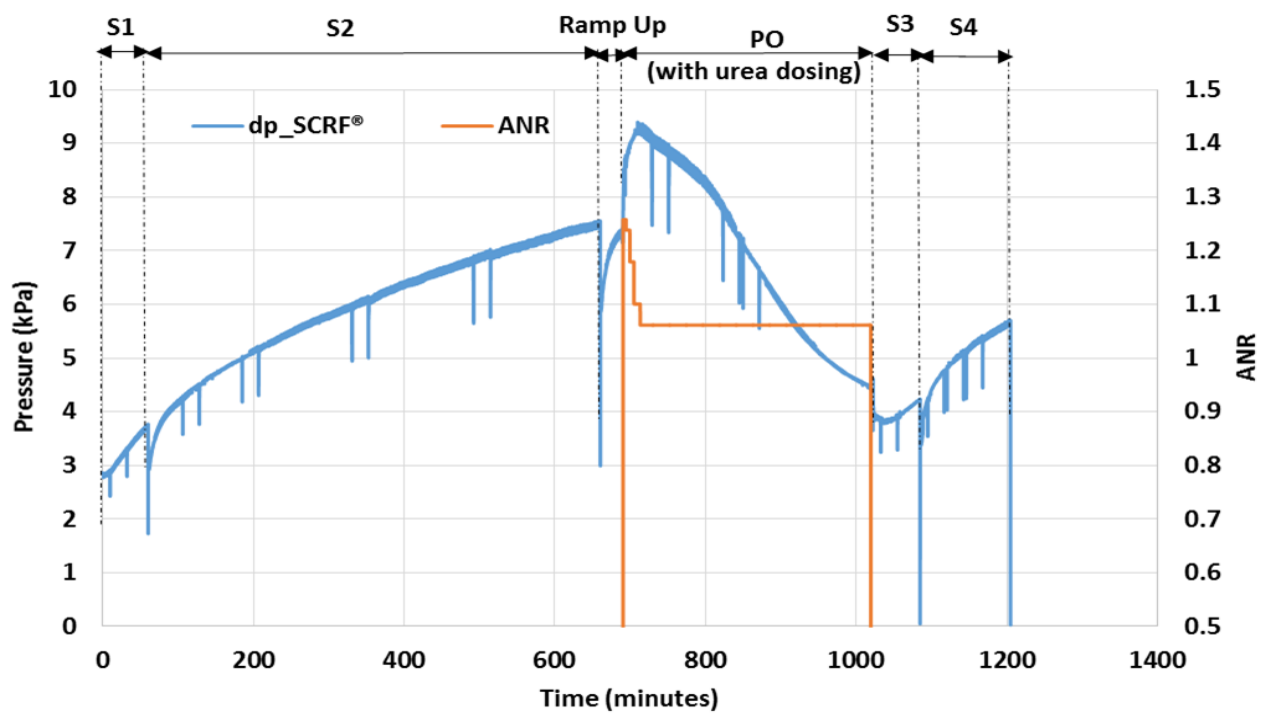

Figure 3.5: Delta Pressure Across SCRF ${ }^{\circledR}$ vs Time for a Typical Passive Oxidation Test [2]

As mentioned previously, all the loading stages were performed at a reduced rail pressure so as to decrease the loading time by increasing the PM concentration. The lower rail pressure could have caused a change in the particulate matter morphology which may led to different oxidation characteristics and rates in the $\mathrm{SCRF}^{\circledR}$. This could be due to change in surface area because of different primary particle diameter and or fractal dimension $[9,10]$. Hence, a study as given in Appendix $D$, was conducted to see the variation in primary particle diameter with change in fuel rail pressure. PM samples were collected at three different fuel rail pressures of 750 (50\% reduced), 1050 (30\% reduced) and 1500 bar (production rail pressure). These pressures were chosen since they were used for the data in references [2] and [3] for the loading stages. This 
study helps to understand the difference in oxidation rates compared to production rail pressure. The engine conditions while collecting these samples are shown in Table 3.2. The set up used to collect the samples was the same as used by reference $[2,3]$ and consisted of a Dry Gas Meter connected to a Manual Sampling Train (MST), which were used to measure volume flow rate, temperature, pressure drop and sampling time. PM was collected on a A/E type $47 \mathrm{~mm}$ diameter glass fiber filter paper. Scanning Electron Microscope (SEM) was used to collect images which is capable of measuring particles on a nanometer scale and an image analysis software "ImageJ" was used to process these images to compute primary particle diameter.

Table 3.2: Engine Operating Conditions for PM Collection at Different Fuel Rail Pressures

\begin{tabular}{|c|c|}
\hline Parameter & Value \\
\hline Fuel Rail Injection Pressure (bar) & $1500 ; 1050 ; 750$ \\
\hline Engine Speed (rpm) & 2400 \\
\hline Engine Load (Nm) & 200 \\
\hline EGR Rate (\%) & 21 \\
\hline
\end{tabular}

A study was also conducted to understand the effect of decreased fuel rail pressure on Elemental Carbon (EC) and Organic Carbon (OC) fractions of the PM formed. EC fraction produces a direct effect on the rate of loading in the filter since EC is basically comprised of the solid particles. OC fraction on the other hand is comprised of the volatile components which are in the gas phase and do not affect the filtration mechanism [14]. National Institute of Occupational Safety and Health (NIOSH) Method 5040, which is a Thermal Optical Method (TOM), was used to determine the EC - OC fractions from PM samples at different rail pressures. Due to the lack of apparatus at MTU for the Thermal Optical analysis, three samples each were collected at different fuel rail pressures and were sent to Cummins for evaluation of EC-OC fractions of the total carbon (TC).

\subsection{Calculation of ANR's for Configuration 3 [3]}

The experimental data obtained in references $[2,3]$ were analyzed and the targeted ANR was calculated in reference [3] for the PO stage of Test Points $A, B, C, D$ and $E$ and $\mathrm{NO}_{x}$ reduction stage of Test Point 1. The data for Test Points $A$ and $E$ obtained from passive oxidation tests with urea injection as a part of Configuration $1[2,3]$ are shown in Table 3.3. The $\mathrm{NO}_{\mathbf{x}}$ and $\mathrm{NH}_{3}$ concentrations at the inlet and outlet of the $\mathrm{SCRF}^{\circledast}, \mathrm{N}_{2}$ balance and ANR dosed in Configuration 
1 were used to calculate the targeted ANR for Configuration 3. The calculation procedure and target ANR are shown in Appendix G.

The procedure used in reference [3] to calculate the target ANR considers only the SCRF ${ }^{\circledR}$. This causes the calculation of ANR in such a way that we get minimum $\mathrm{NO}_{x}$ and minimum $\mathrm{NH}_{3}$ slip out of the $\mathrm{SCRF}^{\circledR}$. Since Configuration 3 has a SCR downstream of the $\mathrm{SCRF}^{\circledR}$, the calculation for the target ANR must consider the effect of the SCR as well. Thus, the initial values computed for Target ANR are in error. Table 3.4 shows a comparison of the Corrected Target ANR to the Target ANR from reference 3 and the actual dosed ANR. Appendix G shows the corrected calculation procedure considering a SCR downstream the $\mathrm{SCRF}^{\circledR}$ and provides a detailed reasoning on the calculation of the target ANR for Configuration 3. Test Point $A$ and $D$ have significant difference between the Target ANR in Reference 3 and corrected value as shown in Table 3.4.

Table 3.3: Performance of the $\mathrm{SCRF}^{\circledR}$ during the Passive Oxidation Tests with Urea Injection in Configuration 1 [2, 3]

\begin{tabular}{|c|c|c|c|c|c|c|c|}
\hline $\begin{array}{c}\text { Test } \\
\text { Points }\end{array}$ & ANR & $\begin{array}{c}\text { SCRF }^{\oplus} \\
\text { Inlet NO }\end{array}$ & $\begin{array}{c}\text { SCRF }_{\mathbf{x}} \text { Inlet } \\
\mathbf{N H}_{\mathbf{3}}\end{array}$ & $\begin{array}{c}\mathbf{S C R} \\
\text { Outlet } \\
\mathbf{N O}_{\mathbf{x}}\end{array}$ & $\mathbf{N H}_{\mathbf{3}}$ Slip & $\begin{array}{c}\mathbf{N O}_{\mathbf{x}} \\
\text { Conv. } \\
\text { Eff. }\end{array}$ & $\begin{array}{c}\text { Nitrogen } \\
\text { Balance }\end{array}$ \\
\hline$[-]$ & {$[-]$} & {$[\mathrm{ppm}]$} & {$[\mathrm{ppm}]$} & {$[\mathbf{p p m}]$} & {$[\mathrm{ppm}]$} & {$[\%]$} & {$[\%]$} \\
\hline $\mathrm{A}$ & 1.03 & 590 & 607 & 43 & 0 & 91 & 90 \\
\hline $\mathrm{E}$ & 1.01 & 1450 & 1465 & 80 & 5 & 94 & 94 \\
\hline
\end{tabular}

Table 3.4: Comparison of Target, Corrected Target and Actual Dosed ANR

\begin{tabular}{|c|c|c|c|}
\hline Test Point & $\begin{array}{c}\text { Target } \\
\text { ANR from Ref. 3 }\end{array}$ & $\begin{array}{c}\text { Corrected Target } \\
\text { ANR }\end{array}$ & $\begin{array}{c}\text { Actual ANR } \\
\text { Dosed } \\
\text { Config. 3 }\end{array}$ \\
\hline A & 1.13 & 1.11 & 1.10 \\
\hline C & 1.02 & 1.02 & 1.02 \\
\hline E & 1.07 & 1.07 & 1.03 \\
\hline B & 1.11 & 1.10 & 1.10 \\
\hline D & 1.04 & 1.01 & 1.06 \\
\hline 1 & 1.09 & 1.08 & 1.06 \\
\hline
\end{tabular}




\section{Chapter 4. Results}

This chapter discusses the results and analysis of the passive oxidation with urea injection and $\mathrm{NO}_{x}$ reduction data obtained from testing in Configuration 3 using the targeted ANR proposed in reference 3 .

\subsection{Passive PM Oxidation Data}

This section of Chapter 4 discusses the results of the passive oxidation performance of the SCRF ${ }^{\circledR}$ in Configuration 3 in terms of the $\mathrm{PM} \mathrm{NO}_{2}$ assisted kinetics, pressure drop across the filter, and the substrate temperature distribution during the passive oxidation stage.

\section{$\mathrm{NO}_{2}$ Assisted Oxidation}

To introduce the results of the passive oxidation tests, the engine and exhaust conditions during the stage are shown in Table 4.1. These experimental values may differ slightly from the data in the test matrix (Table 3.1) but these were the values obtained during each of the six tests performed.

Table 4.1: Engine and Exhaust Conditions for Passive Oxidation tests with Urea Dosing in Configuration 3

\begin{tabular}{|c|c|c|c|c|c|c|}
\hline Expt. & Speed & Load & $\begin{array}{c}\text { Exhaust } \\
\text { Flow Rate }\end{array}$ & $\begin{array}{c}\text { Std. Space } \\
\text { Velocity }\end{array}$ & C $_{\text {in }}$ & PMstart \\
\hline [-] & {$[$ RPM] } & {$[\mathbf{N m}]$} & {$[\mathrm{kg} / \mathrm{min}]$} & {$[\mathrm{k} / \mathrm{hr}]$} & $*[\mathrm{mg} / \mathbf{s c m}]$ & {$[\mathrm{g}]$} \\
\hline A & 1300 & 302 & 5.6 & 15.3 & 2.5 & 29.1 \\
\hline C & 1399 & 543 & 6.9 & 18.8 & 3.0 & 25.7 \\
\hline E & 1203 & 648 & 7.1 & 19.3 & 3.0 & 26.8 \\
\hline B & 902 & 449 & 3.7 & 10.1 & 1.4 & 26.7 \\
\hline D & 2100 & 598 & 12.5 & 33.9 & 2.0 & 25.7 \\
\hline 1 & 1205 & 206 & 5.2 & 14.2 & 3.0 & 26.5 \\
\hline
\end{tabular}

${ }^{*} \mathrm{mg} / \mathrm{scm}$ : milli gram/standard cubic meter of exhaust flow

The PM retained at the beginning of the passive oxidation stage (from stage 1 , stage 2 , and the ramp up) is denoted $\mathrm{PM}_{\text {start. }}$. For the Configuration 3 tests an average of $26.8 \mathrm{~g}$ was loaded at the start of the PO stage. As mentioned earlier, the test conditions were selected initially to span a 
wide range of $\mathrm{NO}_{2}$, inlet temperatures, and standard space velocities. This wide range of inlet conditions were used in the previous testing performed during the baseline tests, Configuration 1 , and Configuration 2.

In order to calculate the kinetics of $\mathrm{NO}_{2}$ assisted $\mathrm{PM}$ oxidation, the average substrate temperature, $\mathrm{NO}_{2}$ concentration, and experimental reaction rates are required. Table 4.2 shows these values along with the duration and percent oxidized.

Table 4.2: Variables Important in Calculating Kinetics of $\mathrm{NO}_{2}$ Assisted Passive Oxidation Experiments with Urea Dosing for Configuration 3

\begin{tabular}{|c|c|c|c|c|c|c|}
\hline Expt. & Duration & $\begin{array}{c}\text { PM \% } \\
\text { Oxidized }\end{array}$ & $\begin{array}{c}\mathrm{NO}_{2} \text { Into } \\
\mathrm{SCRF}^{\circledR}\end{array}$ & $\begin{array}{c}\text { Average } \\
\text { Substrate } \\
\text { Temp }\end{array}$ & Exptl. RRo & $\mathrm{k}=\mathrm{NO}_{2} / \mathrm{RR}_{\mathrm{o}}$ \\
\hline$[-]$ & [min] & [\%] & [ppm] & {$\left[{ }^{\circ} \mathrm{C}\right]$} & {$\left[10^{-4} / \mathrm{s}\right]$} & {$\left[10^{6} / \mathrm{ppm} / \mathrm{s}\right]$} \\
\hline$A$ & 551 & 11 & 215 & 278 & 0.10 & 0.05 \\
\hline $\mathrm{C}$ & 141 & 40 & 290 & 348 & 0.63 & 0.22 \\
\hline$E$ & 67 & 39 & 584 & 362 & 1.25 & 0.21 \\
\hline$B$ & 258 & 15 & 758 & 274 & 0.11 & 0.01 \\
\hline D & 166 & 44 & 161 & 374 & 0.64 & 0.40 \\
\hline 1 & 114 & 41 & 182 & 219 & & \\
\hline
\end{tabular}

Figure 4.1 shows the natural log of the rate constant $k$ versus $1000 / T_{\text {avg. }}$ A line of best fit on this figure is used to determine the kinetics of passive oxidation with urea injection for the $\mathrm{SCRF}^{\circledR}$ in Configuration 3. 


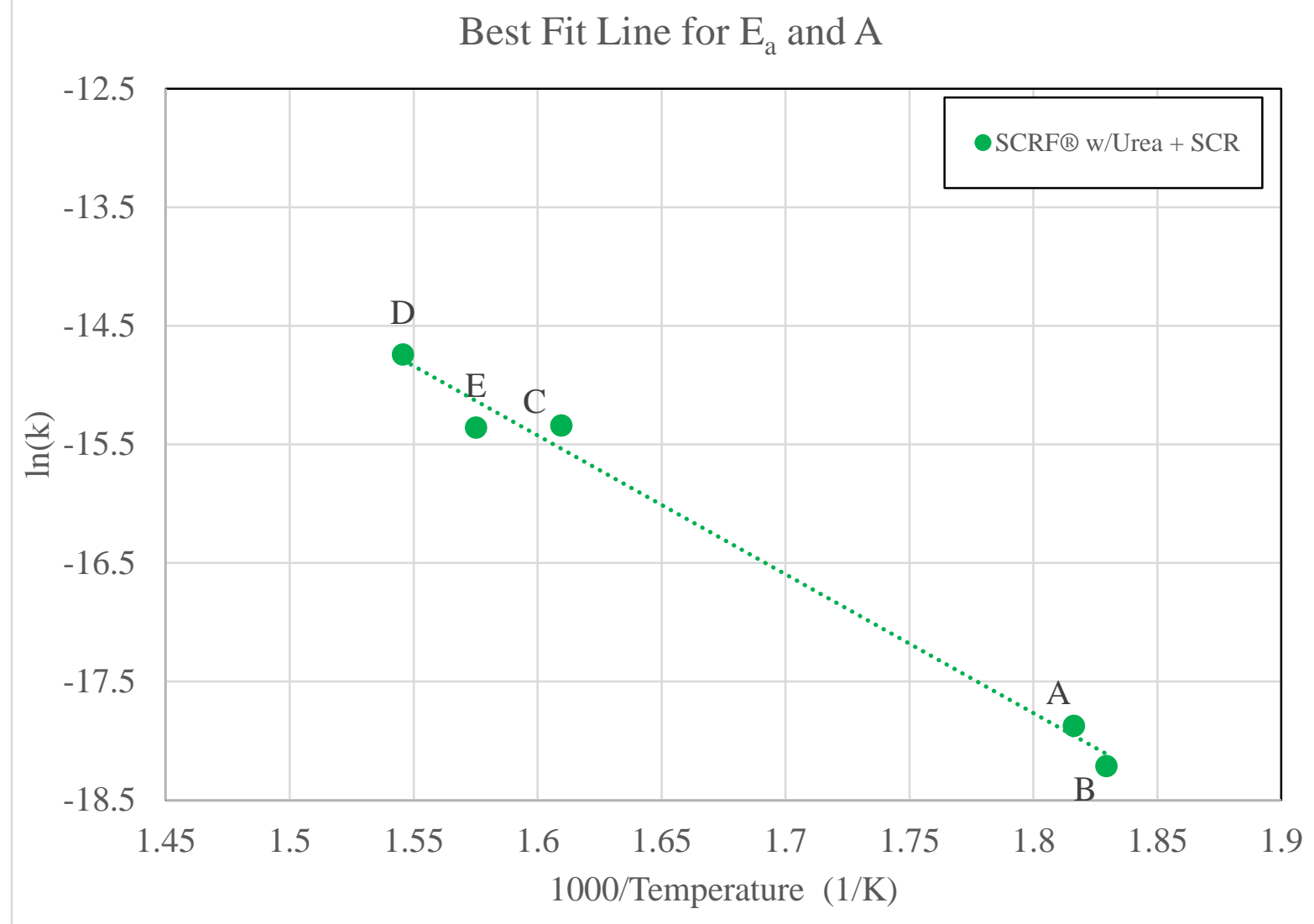

Figure 4.1: Line of Best Fit for In(k) vs 1000/Temperature for Passive Oxidation Experiments with Urea Dosing in Configuration 3

Using the fit line, the activation energy $\left(E_{a}\right)$ and pre exponential factor $(A)$ are determined for passive oxidation with urea injection for Configuration 3. The significance of the activation energy is that it is the minimum amount of energy required for the reaction of $\mathrm{PM}$ and $\mathrm{NO}_{2}$ to take place. Similarly, the pre exponential factor relates to the probability that particles will collide in the correct orientation for the reaction to occur. The overall kinetics obtained for PM oxidation are given in Table. 4.3.

Table 4.3: Overall Kinetics for Passive Oxidation Experiments with Urea Dosing in Configuration 3

\begin{tabular}{|c|c|c|}
\hline$E_{a}$ & $A$ & $R^{2}$ \\
\hline$[\mathrm{kJ} / \mathrm{gmol}]$ & {$[1 / \mathrm{ppm} / \mathrm{s}]$} & {$[-]$} \\
\hline 97.4 & 27.5 & 0.990 \\
\hline
\end{tabular}


Figure 4.2 shows a comparison of the kinetics obtained during Configuration 1 . The kinetics of passive oxidation with urea dosing from Configuration 1 are very similar in terms of the fit lines, activation energies, and pre exponential factors.

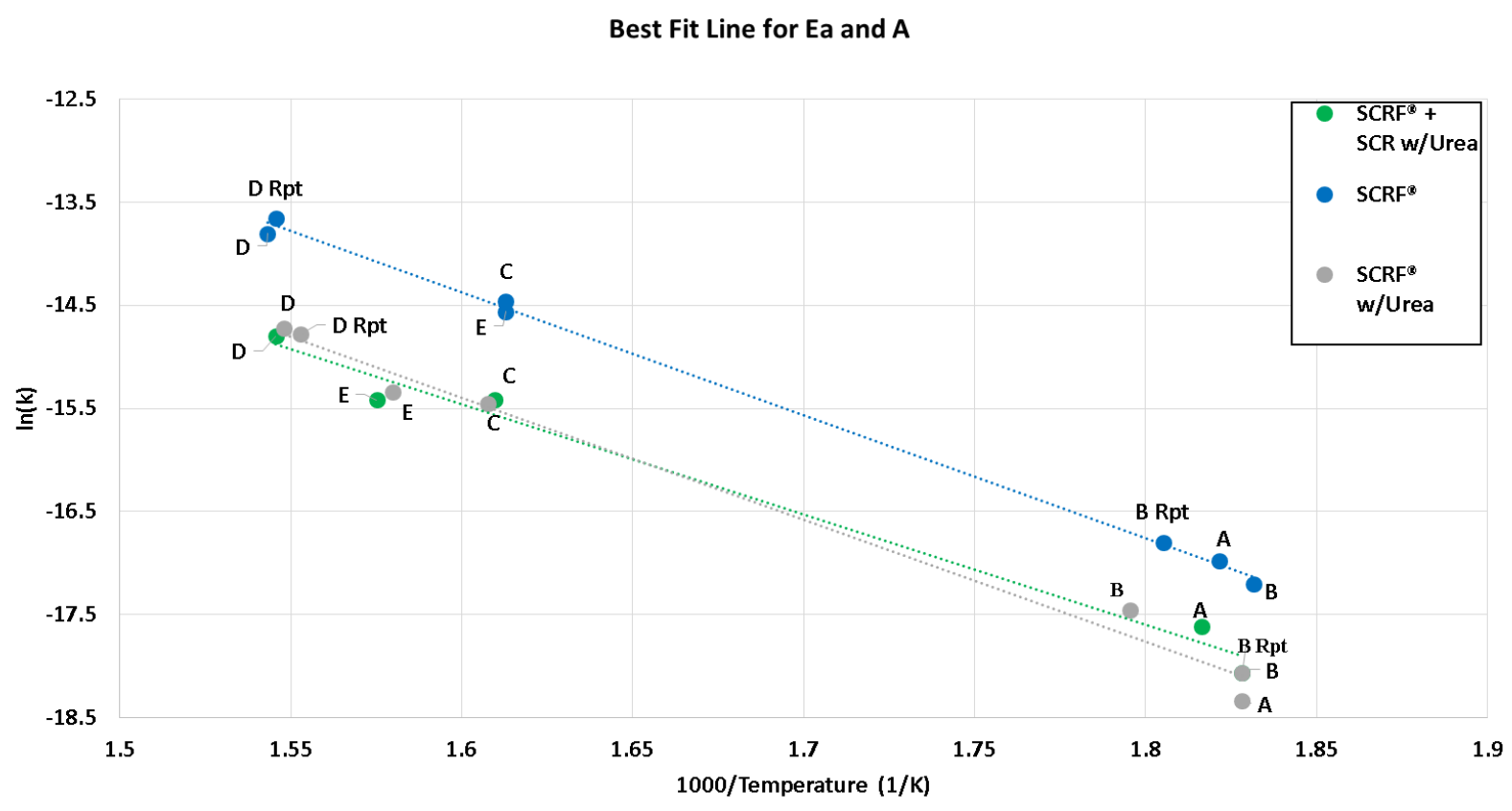

Figure 4.2: Line of Best Fit for In(k) vs 1000/Temperature for Passive Oxidation Experiments Comparison[2,3]

As expected, the difference in ANR ( $\sim 1.0$ for passive oxidation with urea dosing during Configuration 1 versus 1.02-1.10 for passive oxidation with urea dosing during the Configuration 3 tests has an effect on the kinetics, although it is not significant.

Overall the reaction rates were $15 \%$ lower and the rate constant $\mathrm{k}$ were on average $4 \%$ lower when compared to the Configuration 1 with urea dosing.

As can be seen from Table 4.1, the engine conditions for PO stage for Test Point A are a speed of $1301 \mathrm{rpm}$ and a load of $303 \mathrm{Nm}$. Therefore, among the tests performed for Configuration 3, this test point can be classified as a mid-speed mid-load test point. 
The ANR data for this test point is 1.10 (Table 3.4) which is the highest ANR used during the tests in Configuration 3. The standard space velocity is $16.7 \mathrm{k} / \mathrm{hr}$, computed using equation 4.1.

Standard Space Velocity $=\frac{\text { Exhaust mass flow rate }}{\text { Exhaust gas density } * \text { Volume of substrate }}\left(\frac{k}{h r}\right)$

Where exhaust gas density is $1.18 \mathrm{Kg} / \mathrm{m}^{3}$ using the ideal gas equation $(P / \rho=R T)$ at $298 \mathrm{~K}$ and 101.32 KPa with $\mathrm{R}=0.287 \mathrm{KJ} /\left(\mathrm{Kg}^{*} \mathrm{~K}\right)$. This is in alignment with the previous research assumption of considering exhaust gas density equal to that of air for standard space velocity.

The total duration for the Passive Oxidation stage for this test was 551 minutes. This test has the lowest experimental reaction rate of $0.10^{*} 10^{-4} / \mathrm{s}$ as shown in Table 4.2. The low reaction rate for this test is accounted by low $(215 \mathrm{ppm}) \mathrm{NO}_{2}$ into the $\mathrm{SCRF}^{\oplus}$ and the low $\left(278^{\circ} \mathrm{C}\right)$ substrate temperatures at this engine condition. The PM oxidized is $14 \%$ in Configuration 3 as compared to $11 \%$ in Configuration 1 (which was run for 601 minutes and had a reaction rate of $0.04 * 10^{-4} / \mathrm{s}$ ), which is still very low as the target was $30-70 \%$. This can be accounted for by the same reasons as are for the low reaction rate. Also, due to urea dosing, the tests were longer and yet it was difficult to reach the target oxidation percentage.

These results are in accordance with the results found in Configuration 1 [2] for passive oxidation with urea for Test Point $A$, in which the experimental reaction rate was calculated to be $0.04 * 10^{-4} / \mathrm{s}$. The slight difference in reaction rates can be accounted for by the difference in the ANR values injected into the exhaust stream (1.1 v/s 1.03). Since there is a competition for $\mathrm{NO}_{2}$ between the passive oxidation reactions and the SCR reactions within the substrate, hence the difference in the amounts of urea injected into the exhaust stream, urea conversion and temperature can alter the amount of $\mathrm{NO}_{2}$ available for $\mathrm{PO}$ reactions which causes a change in the PM oxidation reaction rate. Other causes of differences are the difference in PM retained during these tests, day to day variation in the experimentation and experimental error related to instrumentation and measurements. 
Figure 4.3 represents the pressure drop curve for Test Point $A$ in configuration 3 vs configuration 1 for PO with urea dosing. As can be seen, the pressure drop during the PO stage has a low slope depicting a low reaction rate. The nature of both the curves is same. A comparison for other test points for Configuration 1 vs Configuration 3 is provided in Appendix F.

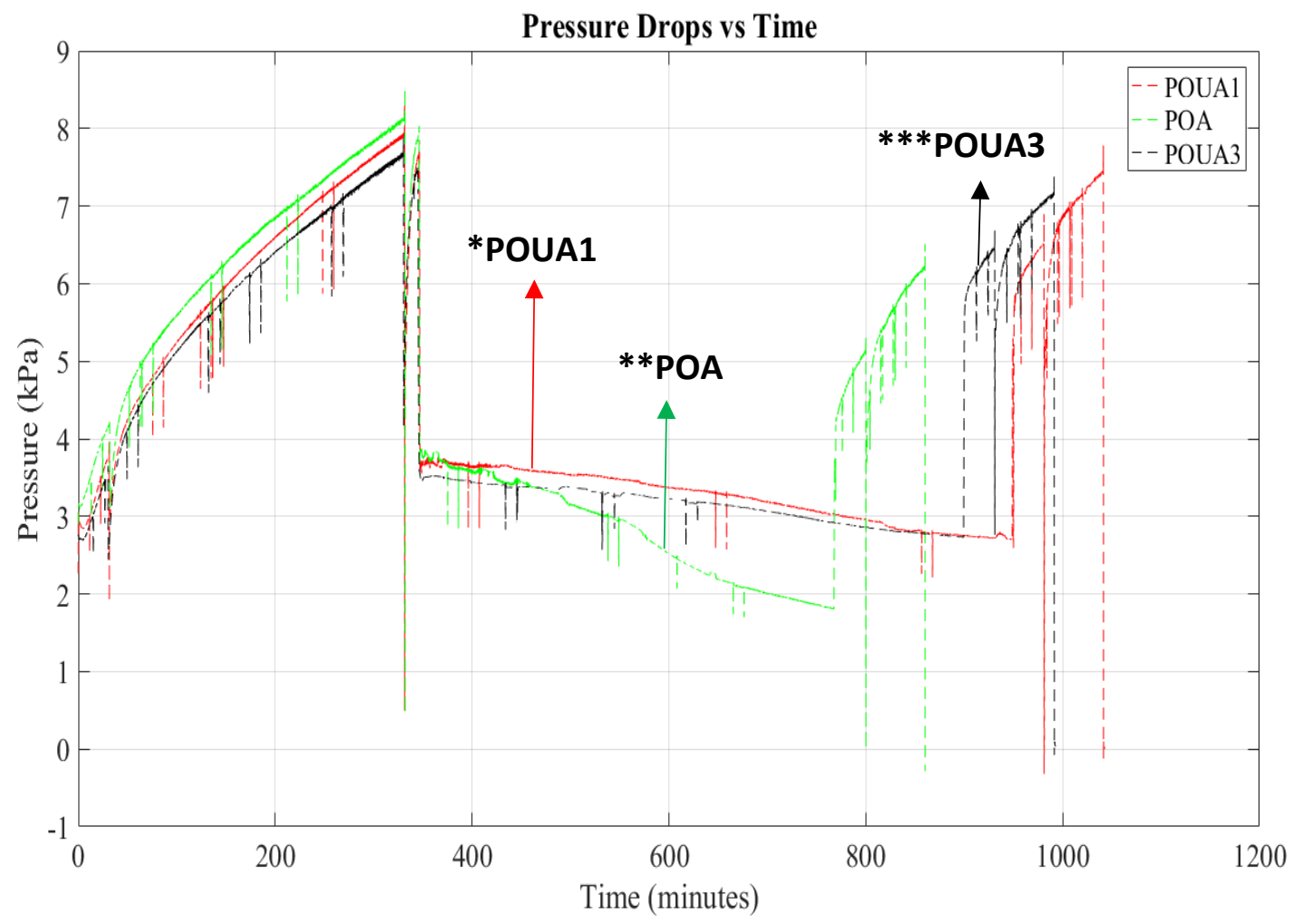

Figure 4.3. Stage-wise Pressure Drop - Test Point A.

* POUA1: Passive Oxidation with Urea Test Point A Configuration 1

** POA: Passive Oxidation without Urea Test Point A Configuration 1

***POUA3: Passive Oxidation with Urea Test Point A Configuration 3

Appendices A, B, C and F contain the Stage 1 and 2 PM Mass Balances, the Pressure Drop across the $\mathrm{SCRF}^{\circledR}$, the Gas Temperature Distribution in the $\mathrm{SCRF}^{\circledR}$ and the comparison between Configuration 3 and Configuration 1 and 2 data respectively. 


\section{2 $\mathrm{NO}_{\mathrm{x}}$ Reduction Emission Data}

This section discusses the $\mathrm{NO}_{\mathrm{x}}$ reduction performance of the $\mathrm{SCRF}^{\circledR}$ only and the $\mathrm{SCRF}^{\circledR}$ and the downstream SCR components together.

\section{NO $\mathrm{x}_{\mathbf{x}}$ Reduction during Passive Oxidation with Urea Injection}

Urea injection was performed during the PO stage at a predetermined ANR between 1.02-1.10 (Table 3.4). The plot of ANR, emission concentrations measured using sensors and emission concentrations measured using the MS during the PO stage for Test Point A is shown in Figure 4.4. It can be observed that the $\mathrm{NH}_{3}$ slip at the outlet of the SCR substrate (orange and yellow lines, measured using the MS and a sensor respectively) decreases with time from 40 ppm to 1 ppm. However, the $\mathrm{NO}_{x}$ concentration at the outlet of the $\mathrm{SCRF}^{\circledR}$ and at the outlet of the SCR (grey line, measured using the MS) increases with time from less than 5 ppm to $20-25 \mathrm{ppm}$. Hence, the concentrations were recorded and analyzed for two different times, one at the beginning of the PO stage and the other towards the end of the PO stage. The emission concentrations at the inlet and outlet of the $\mathrm{SCRF}^{\circledR}$ and SCR-A substrate during the passive oxidation stage for Test Point A are shown in Table 4.4 and 4.5. The number 2(18) indicates the average $\mathrm{NO}_{x}$ concentrations at the beginning (average of first half of PO stage) and the end (average time of second half of PO stage) of the PO stage at the outlet of the $\mathrm{SCRF}^{\circledR}$. Similarly, 30(1) indicates the average $\mathrm{NH}_{3}$ concentrations at the beginning and the end of the $\mathrm{PO}$ stage at the outlet of the $\mathrm{SCRF}^{\circledR}$. 

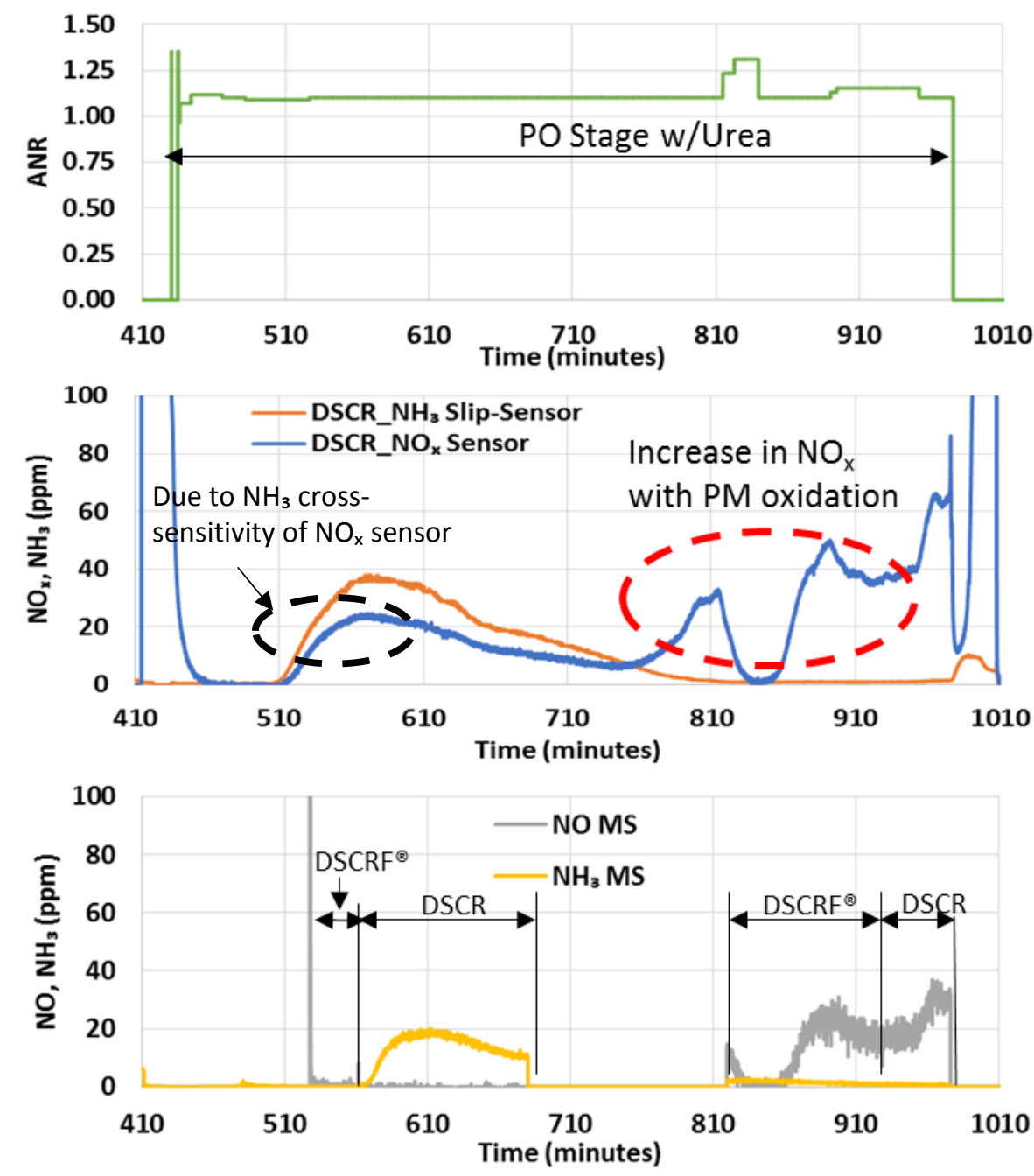

Figure 4.4 Emission Concentrations at Inlet and Outlet of the $\mathrm{SCRF}^{\circledR}$ and SCR-A during Passive Oxidation Stage for Test Point A.

Table 4.6: Emission Concentrations - Test Point A

\begin{tabular}{|c|c|c|c|c|c|c|c|}
\hline \multirow{2}{*}{$\begin{array}{c}\text { SCRF }^{\circledR} \\
\text { Inlet } \\
\text { Temp }\end{array}$} & \multicolumn{3}{|c|}{ USCRF $^{\circledR}$} & \multicolumn{2}{c|}{ DSCRF $^{\circledR}$} & \multicolumn{2}{c|}{ DSCR } \\
\cline { 2 - 8 } & $\mathrm{NO}_{\mathbf{x}}$ & $\mathrm{NO}_{2} / \mathrm{NO}_{\mathbf{x}}$ & $\mathrm{ANR}$ & $\mathrm{NO}_{\mathbf{x}}$ & $\mathrm{NH}_{3}$ & $\mathrm{NO}_{\mathbf{x}}$ & $\mathrm{NH}_{3}$ \\
\hline$\left[{ }^{\circ} \mathrm{C}\right]$ & {$[\mathrm{ppm}]$} & {$[-]$} & {$[-]$} & {$[\mathrm{ppm}]$} & {$[\mathrm{ppm}]$} & {$[\mathrm{ppm}]$} & {$[\mathrm{ppm}]$} \\
\hline 264 & 485 & 0.44 & 1.03 & $2(18)^{*}$ & $30(1)^{*}$ & $1(24)^{*}$ & $28(1)^{*}$ \\
\hline
\end{tabular}

\# : The number $2(18)$ indicates the average $\mathrm{NO}_{x}$ concentrations at the beginning and the end of the PO stage at the outlet of the $\mathrm{SCRF}^{\circledR}$. Similarly, $30(1)$ indicates the average $\mathrm{NH}_{3}$ concentrations at the beginning and the end of the PO stage at the outlet of the $\mathrm{SCRF}^{\circledR}$. 
Table 4.5 SCRF ${ }^{\circledR}$-SCR System Emissions - Test Point A

SCRF $^{\circledR}$ Standard Space Velocity $: 15.3 \mathrm{k} / \mathrm{hr}$

ANR : 1.10

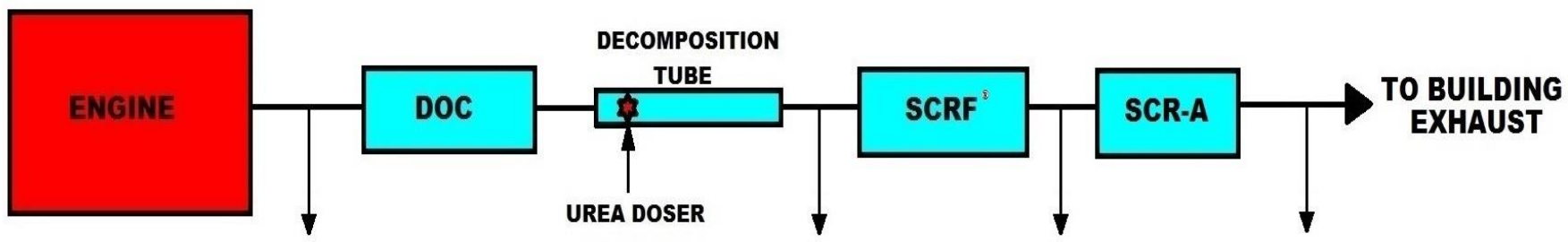

$\begin{array}{lcccc}\text { Parameter } & \text { UDOC } & \text { USCRF }^{\circledR} & \text { DSCRF }^{\circledR} & \text { DSCR } \\ \text { Temperature }\left({ }^{\circ} \mathbf{C}\right) & 277 & 267 & 266 & 266 \\ \text { NO }(\mathbf{p p m}) & 453 & 270 & 1(18)^{\#} & ---- \\ \mathbf{N O}_{2}(\mathbf{p p m}) & 21 & 215 & 1 & --- \\ \mathbf{N O}_{\mathbf{x}}(\mathbf{p p m}) & 474 & 485 & 2(18)^{\#} & 1(24)^{\#} \\ \mathbf{N H}_{3}(\mathbf{p p m}) & ---- & 534 & 30(1)^{\#} & 28(1)^{\#} \\ \mathbf{N O}_{2} / \mathbf{N O} & ---- & 0.44 & ---- & --- \\ \text { NO}_{\mathbf{x}} \text { Reduction }(\%) & ---- & --- & 100 & 100(95)^{\#}\end{array}$

\# : The values in the bracket represent average values at a different time interval which were observed for $\mathrm{NH}_{3}$ slip and $\mathrm{NO}_{x}$ as shown in Figure 4.4. 
The plot of ANR, emission concentrations measured using sensors and emission concentrations measured using the MS during the PO stage for Test Point E is shown in Figure 4.5. It can be observed that the $\mathrm{NH}_{3}$ slip at the outlet of the SCR substrate (orange and yellow lines, measured using the MS and a sensor respectively) decreases with time, similar to Test Point A. However, the $\mathrm{NO}_{\mathrm{x}}$ concentration at the outlet of the SCR (grey line, measured using the MS) increases with time from less than $5 \mathrm{ppm}$ to $25-30 \mathrm{ppm}$. The emission concentrations at the inlet and outlet of the $\mathrm{SCRF}^{\circledR}$ and SCR-A substrate during the PO stage for Test Point $\mathrm{E}$ are shown in Tables 4.6 and 4.7. The number $9(-)$ indicates the average $\mathrm{NO}_{x}$ concentration at the beginning of the PO was 9 ppm. However, the $\mathrm{NO}_{\mathrm{x}}$ concentration towards the end of PO was not available due to measurement issues. Similarly, 6(25) indicates the average $\mathrm{NO}_{x}$ concentrations at the beginning (average of first half of PO stage) and the end (average of second half of PO stage) of the PO stage at the outlet of the SCR. Appendix E contains the tables of the SCRF ${ }^{\circledR}$ - SCR System Emissions for Test Points A,B,C,D,E and 1. 

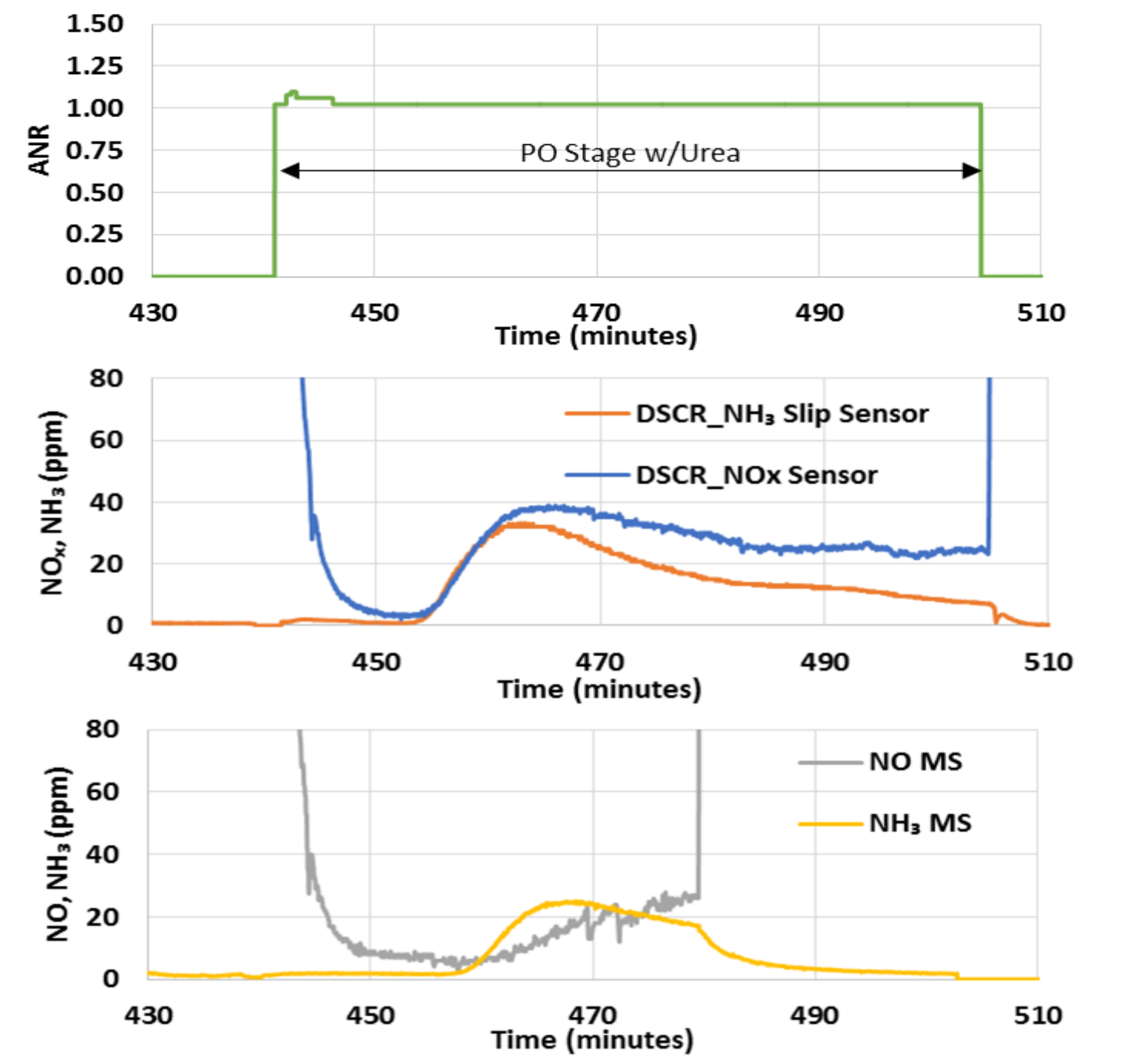

Figure 4.5: Emission Concentrations at Inlet and Outlet of the SCRF ${ }^{\circledR}$ and SCR-A during Passive Oxidation Stage for Test Point E.

Table 4.6: Emission Concentrations - Test Point E

\begin{tabular}{|c|c|c|c|c|c|c|c|}
\hline \multirow{2}{*}{$\begin{array}{c}\text { SCRF }^{\circledR} \\
\text { Inlet } \\
\text { Temp. }\end{array}$} & \multicolumn{3}{|c|}{ USCRF $^{\circledR}$} & \multicolumn{2}{|c|}{ DSCRF $^{\circledR}$} & \multicolumn{2}{|c|}{ DSCR } \\
\hline & $\mathrm{NO}_{\mathrm{x}}$ & $\mathrm{NO}_{2} / \mathrm{NO}_{\mathbf{x}}$ & ANR & $\mathrm{NO}_{\mathrm{x}}$ & $\mathrm{NH}_{3}$ & $\mathrm{NO}_{\mathrm{x}}$ & $\mathrm{NH}_{3}$ \\
\hline$\left[{ }^{\circ} \mathrm{C}\right]$ & [ppm] & {$[-]$} & {$[-]$} & [ppm] & [ppm] & [ppm] & [ppm] \\
\hline 342 & 1584 & 0.37 & 1.03 & $9(-)^{\#}$ & $29(-)^{\#}$ & $6(25)^{*}$ & $32(9)^{\#}$ \\
\hline
\end{tabular}

\# : The number $6(25)$ indicates the average $\mathrm{NO}_{\mathrm{x}}$ concentrations at the beginning and the end of the PO stage at the outlet of the $\mathrm{SCRF}^{\circledR}$. Similarly, 32(9) indicates the average $\mathrm{NH}_{3}$ concentrations at the beginning and the end of the PO stage at the outlet of the $\mathrm{SCRF}^{\circledR}$. 
Table 4.7 SCRF ${ }^{\circledR}$-SCR System Emissions - Test Point E

SCRF $^{\circledR}$ Space Velocity : $19.3 \mathrm{k} / \mathrm{hr}$

ANR : 1.03
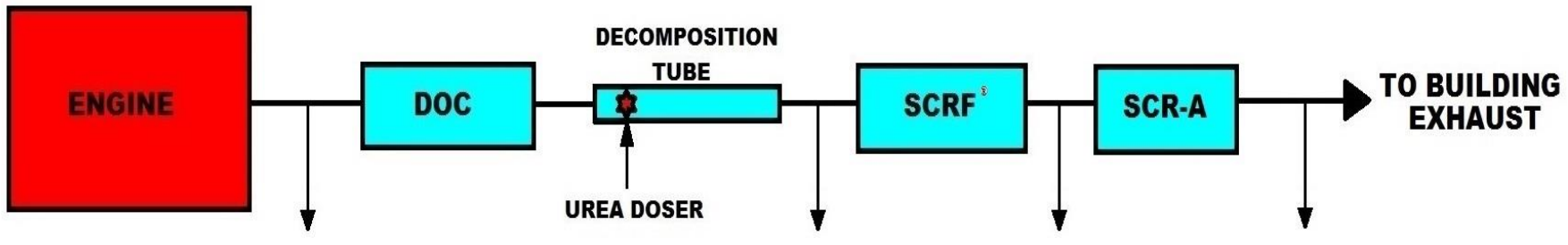

Parameter

UDOC

Temperature $\left({ }^{\circ} \mathbf{C}\right)$

369

USCRF $^{\circledR}$

DSCRF $^{\circledR}$

DSCR

NO (ppm)

1543

$\mathrm{NO}_{2}(\mathbf{p p m})$

14

NO $_{\mathbf{x}}(\mathbf{p p m})$

1557

351

358

357

1001

8

584

1584

1

$---$

$\mathrm{NH}_{3}(\mathbf{p p m})$

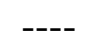

1627

9

$96(25)^{\#}$

$\mathrm{NO}_{2} / \mathrm{NO}_{\mathbf{x}}$

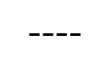

0.37

NO Reduction (\%)

$$
---
$$

---

29

32(9) \#

$99100(98)^{\#}$

\# : The values in the bracket represent average values at a different time interval which were observed for $\mathrm{NH}_{3}$ slip and $\mathrm{NO}_{x}$ as shown in Figure 4.5. 
The $\mathrm{NO}, \mathrm{NO}_{2}$ and $\mathrm{NO}_{\mathrm{x}}$ concentrations at the inlet and outlet of the $\mathrm{SCRF}^{\circledR}$ and the $\mathrm{NO}_{\mathrm{x}}$ conversion efficiency for the six passive oxidation test conditions with urea dosing are given in Table 4.8. It is observed that the $\mathrm{NO}_{\mathrm{x}}$ conversion efficiency, calculated based on concentrations at the beginning of the PO stage is greater than $98 \%$ for all the test conditions with $\mathrm{NH}_{3}$ slip at the outlet of the $\mathrm{SCRF}^{\circledR}$ less than 50 ppm for ANR's varying between $1.02-1.10$. The NO, $\mathrm{NO}_{2}$ and $\mathrm{NO}_{x}$ concentrations at the inlet and outlet of the SCR (downstream of the $\mathrm{SCRF}^{\circledR}$ ), system $\mathrm{NO}_{\mathrm{x}}$ conversion efficiency (SCRF ${ }^{\circledast}$ and the SCR together) and nitrogen balance for the SCRF ${ }^{\circledR}$ and the SCR together are given in Table 4.9. It is observed that the SCR outlet $\mathrm{NO}_{x}$ concentrations increase as the PM in the $\mathrm{SCRF}^{\circledR}$ is oxidized. System $\mathrm{NO}_{x}$ conversion efficiency (SCRF ${ }^{\circledR}$ and SCR together) was greater than $99 \%$ based on concentrations measured at the beginning of the PO stage. However, the $\mathrm{NO}_{x}$ conversion efficiency greater than $95 \%$ was observed for concentrations measured at the end of the PO stage. Nitrogen balance was observed to be higher than $90 \%$ for all the Test Points which indicates consistency in the experimental data.

It is also seen that the $\mathrm{NO}_{\mathrm{x}}$ conversion efficiencies across the $\mathrm{SCRF}^{\circledR}$ only in Configuration 3 are very high $99-100 \%$. Also, it is observed that the $\mathrm{SCRF}^{\circledR}$ outlet $\mathrm{NO}_{\mathrm{x}}$ is very low and the concentrations are much lower as compared to Configuration 1 data as described in Appendix F. This may be due to inaccuracies in the measurement of $\mathrm{NO}_{\mathrm{x}}$ values downstream the $\mathrm{SCRF}^{\circledR}$ which can happen if the heated filter or the Mass Spectrometer gets clogged due to PM. It is hypothesized that the high $\mathrm{NO}_{\mathrm{x}}$ conversion may be an inaccurate value due to these measurement inaccuracies. A more detailed discussion on $\mathrm{NO}_{\times}$conversion efficiencies along with a comparison to previous Configurations is presented in Appendix F. 
Table 4.8: Engine and Exhaust Conditions, Emission Concentrations and $\mathrm{NO}_{x}$ Conversion Efficiency of the $\mathrm{SCRF}^{\circledR}-\mathrm{Configuration} 3$

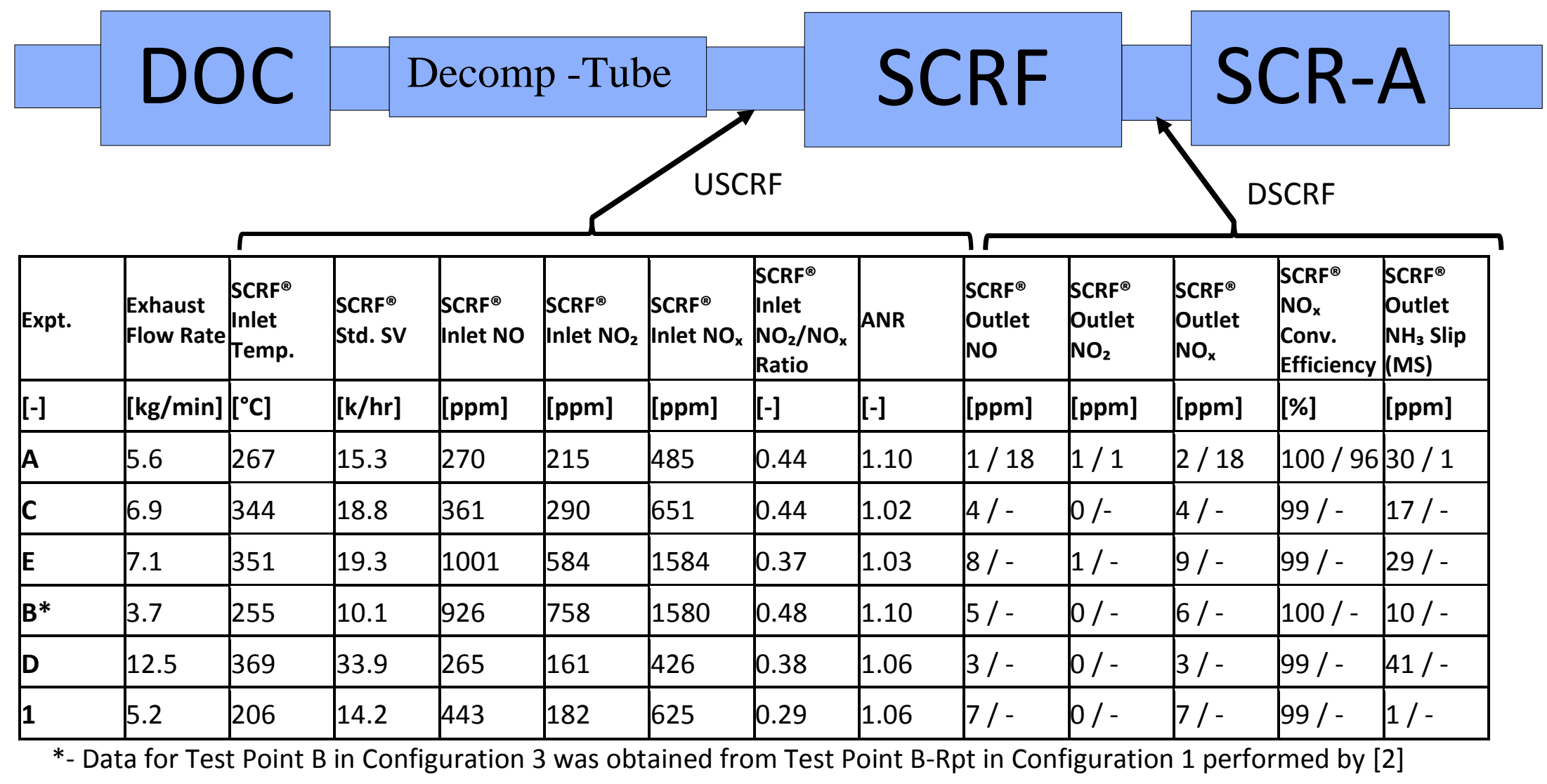


Table 4.9: Emission Concentrations at Inlet and Outlet of the SCR and $\mathrm{NO}_{\mathrm{x}}$ Conversion Efficiency of the SCRF ${ }^{\circledR}$ and SCR TogetherConfiguration 3

\begin{tabular}{|c|c|c|c|c|c|c|c|}
\hline & Decomp- & -Tube & & & & & \\
\hline Test Point & $\begin{array}{l}\text { SCR Inlet } \\
\text { Temp. } \\
\text { (production } \\
\text { sensor) }\end{array}$ & $\begin{array}{l}\text { SCR Inlet } \\
\mathrm{NO}_{\mathrm{x}}\end{array}$ & $\begin{array}{l}\text { SCR Inlet } \\
\mathrm{NH}_{3} \\
(\mathrm{MS})\end{array}$ & $\begin{array}{l}\text { SCR Outlet } \\
\mathrm{NO}_{\mathrm{x}}\end{array}$ & $\begin{array}{l}\text { SCR Outlet } \\
\mathrm{NH}_{3} \text { Slip } \\
\text { (sensor) }\end{array}$ & $\begin{array}{l}\text { System NO } \\
\text { Conv. } \\
\text { Efficiency }\end{array}$ & $\begin{array}{l}\text { Nitrogen } \\
\text { Balance }\end{array}$ \\
\hline$[-]$ & [ppm] & [ppm] & [ppm] & [ppm] & [ppm] & [\%] & [\%] \\
\hline$A$ & 267 & $2 / 18$ & $30 / 1$ & $1 / 24$ & $28 / 1$ & $100 / 95$ & 92 \\
\hline C & 344 & $4 /-$ & $17 /-$ & $1 / 17$ & $18 / 1$ & 100 / 97 & 99 \\
\hline $\mathbf{E}$ & 358 & $9 /-$ & $29 /-$ & $6 / 25$ & $32 / 9$ & $100 / 98$ & 98 \\
\hline $\mathrm{B}^{*}$ & 268 & $5 /-$ & $10 /-$ & $9 /-$ & $4 /-$ & $99 /-$ & 91 \\
\hline$D$ & 371 & $3 /-$ & $41 /-$ & $1 / 13$ & $36 / 15$ & $100 / 97$ & 94 \\
\hline 1 & 211 & $7 /-$ & $1 /-$ & $8 /-$ & $2 /-$ & 99 / - & 93 \\
\hline
\end{tabular}

*- Data for Test Point B in Configuration 3 was obtained from Test Point B-Rpt in Configuration 1 performed by [2] 
Considering the $\mathrm{NO}_{\mathrm{x}}$ reduction across the $\mathrm{SCRF}^{\oplus}$ only, a NO conversion efficiency of $100 \%$ is observed at an ANR of 1.10 for Test Point A as is shown in Table 4.8. When compared to the results from Configuration 1, in which the $\mathrm{NO}_{x}$ conversion was $91 \%$ for Test Point $A$ for an ANR of 1.03, the $\mathrm{NO}_{x}$ conversion efficiency is $9 \%$ higher due to higher ANR. The $\mathrm{NH}_{3}$ slip however increased from $12 \mathrm{ppm}$ in Configuration 1 to $30 \mathrm{ppm}$ in Configuration 3, again accounted for by the higher ANR values in Configuration 3. Although the $\mathrm{NH}_{3}$ slip increased across the $\mathrm{SCRF}^{\circledast}$, it is still less than 50 ppm for the SCRF ${ }^{\oplus}$ - SCR system, which was the desired target and one of the objectives of Configuration 3.

A nitrogen balance was used to check the consistency of data by ensuring that the mass of species was conserved. The nitrogen balance is given by equation 4.2 , which is similar to the one used in reference [2]. For Configuration 3, the nitrogen balance across the SCRF ${ }^{\circledast}$ was calculated to be $96 \%$ which is higher as compared to a value of $90 \%$ computed during Configuration 1 , thus showing a higher confidence in terms of accuracy of data obtained during this configuration.

$$
\text { Nitrogen Balance }=1-\frac{\mathrm{NH}_{3, \text { Injected }}-\left(\mathrm{NO}_{X, \text { Inlet }}-\mathrm{NO}_{X, \text { Outlet }}\right)-\mathrm{NH} \mathrm{H}_{3, \text { Slip }}}{N H_{3, \text { Injected }}}
$$

Where,

$\mathrm{NH}_{3, \text { Injected }}$ : is ammonia injected in ppm assuming complete dissociation of urea.

$\mathrm{NO}_{x}$, Inlet : is the NOx at the inlet of $\mathrm{SCRF}^{\oplus}$ in $\mathrm{ppm}$.

$\mathrm{NO}_{\mathrm{x}}$, Outlet : is the NOx at the outlet of $\mathrm{SCRF}^{\oplus}$ in $\mathrm{ppm}$.

$\mathrm{NH}_{3, \text { Slip }}$ : is the ammonia slip at the outlet of $\mathrm{SCRF}^{\oplus}$ in ppm.

The $\mathrm{NH}_{3}$, Injected can be computed using Equation 4.3.

$$
\mathrm{NH}_{3} \text { Injected }=\frac{2 * \text { Urea injection rate } * 0.325 * \text { MWexhaust } * \text { Urea Density }}{\text { Exhaust Flow rate } * \text { MWurea }} \ldots \ldots \ldots \ldots . . . .4
$$

Considering the $\mathrm{NO}_{\mathrm{x}}$ reduction across the $\mathrm{SCRF}^{\oplus}-\mathrm{SCR}$ system as a whole, a $\mathrm{NO}_{\mathrm{x}}$ conversion efficiency of $100 \%$ is observed. The species concentration input to the SCR is the same as the species concentration output from the $\mathrm{SCRF}^{\circledast}$. As evident from Table 4.5, the $\mathrm{NO}_{\mathrm{x}}$ coming out of the $\mathrm{SCRF}^{\circledast}$ is $2 \mathrm{ppm}$ and the $\mathrm{NO}_{\mathrm{x}}$ coming out of the $\mathrm{SCR}$ is $1 \mathrm{ppm}$, therefore the $\mathrm{NO}_{\mathrm{x}}$ conversion 
efficiencies across the $\mathrm{SCRF}^{\oplus}$ only and the $\mathrm{SCRF}^{\oplus}$-SCR system is same for this Test Point. The $\mathrm{NH}_{3}$ slip when compared to SCRF only case from Configuration 1 increased from 12 ppm to 28 ppm for the SCRF ${ }^{\circledast}$-SCR system of Configuration 3 (Appendix F). The SCR in this case decreased the ammonia slip from 30 ppm to 28 ppm as shown in Table 4.1, which could be a measurement error since the instrument resolution is not high enough to measure $2 \mathrm{ppm}$ accurately or the 2 ppm $\mathrm{NH}_{3}$ could have been adsorbed in the SCR. Besides, there was just 2 ppm of $\mathrm{NO}_{x}$ going into the SCR, thus we don't expect the SCR reactions in the SCR brick to be active due to lack of reactant species. The SCR brick just acts as a passive device in this case so that any $\mathrm{NO}_{\mathrm{x}}$ not reduced by $\mathrm{NH}_{3}$ to $\mathrm{N}_{2}$ and $\mathrm{H}_{2} \mathrm{O}$ within the $\mathrm{SCRF}^{\oplus}$ is reduced in the SCR.

Again a nitrogen mass balance was used to ensure that the mass of species was conserved. It is given by equation 4.2 with the only difference that $\mathrm{NO}_{x}$, Outlet and $\mathrm{NH}_{3, \text { Slip }}$ are at the outlet of SCR, when considering the SCRF ${ }^{\oplus}-\mathrm{SCR}$ system. The $\mathrm{N}_{2}$ balance is $92 \%$ for Test Point A. For other test points, the values are provided in Appendix F. 


\section{Chapter 5. Summary and Conclusions}

This chapter summarizes important findings and conclusions of the research presented in this report.

\subsection{Summary}

Five passive oxidation Test Points from Configuration 1 and one $\mathrm{NO}_{\mathrm{x}}$ reduction Test Point from Configuration 2 were completed in Configuration 3. During testing the $\mathrm{SCRF}^{\circledR}$ inlet temperatures varied from $200-370^{\circ} \mathrm{C}$, space velocities varied from $10-34 \mathrm{k} / \mathrm{hr}, \mathrm{NO}_{2}$ varied from $160-750$ ppm and $\mathrm{NO}_{2} / \mathrm{NO}_{x}$ ratio varied from $0.29-0.48$.

Experimental data obtained from Configuration 3 were analyzed to determine the kinetics for $\mathrm{NO}_{2}$ assisted $\mathrm{PM}$ oxidation performance of the $\mathrm{SCRF}^{\circledR}$ at a constant ANR between $1.02-1.10$ during different tests. $\mathrm{NO}_{x}$ reduction and $\mathrm{NH}_{3}$ slip performance of the $\mathrm{SCRF}^{\circledR}$, and the $\mathrm{SCRF}^{\circledR}$ and SCR together as a system, were also determined. It was observed that the SCR along with the $\mathrm{SCRF}^{\circledR}$ had a measured $99-100 \% \mathrm{NO}_{\mathrm{x}}$ conversion efficiency with a ANR slightly $>1$ while maintaining a low $<50 \mathrm{ppm} \mathrm{NH}$ slip. The higher values of ANR produce similar $\mathrm{NO}_{x}$ conversion efficiencies but also produce a higher $\mathrm{NH}_{3}$ slip which is undesirable. However, the $\mathrm{NO}_{x}$ conversion efficiency across the $\mathrm{SCRF}^{\circledR}$ only was measured to be $99-100 \%$. This meant that there was negligible $\mathrm{NO}_{x}$ conversion across the SCR. The reason for the SCR acting as a passive device in these tests is very low concentration of reactants $\left(\mathrm{NO}_{\mathrm{x}}\right.$ and $\left.\mathrm{NH}_{3}\right)$ going into it because of very low concentration of these reactants out of the $\mathrm{SCRF}^{\circledR}$. There may be an error in the emission concentrations at the outlet $\mathrm{SCRF}^{\circledR}$ due to measurement inaccuracies which could be the cause of observing very high $\mathrm{NO}_{x}$ conversion across the $\mathrm{SCRF}^{\circledR}$. It is possible that a higher concentration of the reactants enters the SCR in these tests and the SCR is converting more $\mathrm{NO}_{\mathrm{x}}$ than is apparent in the data that has been acquired.

The procedure used for calculation of the target ANR for Configuration 3 was found to have an error. It did not consider the effect of the SCR downstream the SCRF ${ }^{\circledR}$. This lead to a slightly incorrect approximation of the target ANR to be used during Configuration 3 tests. These values were corrected and more closely approach the actual ANR dozed. Appendix G provides a detailed calculation for the calculation of the corrected ANR and a comparison with values predicted in reference 3 and the actual values dosed.

\subsection{Conclusions}

1) The kinetics for $\mathrm{NO}_{2}$ assisted $\mathrm{PM}$ oxidation with urea dosing for Configuration 3 were found with an activation energy of $97.4 \mathrm{~kJ} / \mathrm{gmol}$ and pre exponential factor of 27.5 $1 / \mathrm{ppm} / \mathrm{s}$. 
2) The reaction rates for $\mathrm{NO}_{2}$ assisted $\mathrm{PM}$ oxidation with urea dosing were $15 \%$ lower with rate constants $\mathrm{k}$ being $4 \%$ lower, when compared to the values obtained in Configuration 1 with urea dosing.

3) $\mathrm{NO}_{x}$ reduction across the $\mathrm{SCRF}^{\circledR}$ only (with PM loading) $>98 \%$ was observed between ANR $1.02-1.10$, with $\mathrm{NH}_{3}$ slip $<50$ ppm. The high $\mathrm{NO}_{x}$ Conversion efficiencies observed across the $\mathrm{SCRF}^{\circledR}$ only in Configuration 3 could be due to measurement inaccuracies in the $\mathrm{NO}_{\mathrm{x}}$ values obtained downstream of the $\mathrm{SCRF}^{\circledR}$.

4) $\mathrm{NH}_{3}$ slip from the $\mathrm{SCRF}^{\circledR}$ decreases and $\mathrm{NO}_{\mathrm{x}}$ concentration downstream of the $\mathrm{SCRF}^{\circledR}$ increases with passive oxidation of PM in the $\mathrm{SCRF}^{\circledR}$.

5) $\mathrm{NO}_{\mathrm{x}}$ concentrations downstream of the SCR were $<10 \mathrm{ppm}$ at the beginning of urea injection and increased to $<40 \mathrm{ppm}$ with passive oxidation of PM.

6) $\mathrm{NH}_{3}$ concentrations downstream of the SCR were $<40 \mathrm{ppm}$ at the beginning of urea injection and decreased to $<15$ ppm with $\mathrm{NO}_{2}$ assisted oxidation of PM.

7) The procedure for the target ANR calculation used in this configuration was found to overestimate the ANR value to be dosed because it does not consider the effect of the SCR downstream the $\mathrm{SCRF}^{\circledR}$. A more accurate procedure is presented in Appendix G.

\subsection{Future Research}

1) Tests should be performed to check the accuracy of the emission data from between the $\mathrm{SCRF}^{\circledR}$ and the SCR. This will also help address the concern from Tenneco that the data from between the $\mathrm{SCRF}^{\circledR}$ and the SCR location may be inconsistent.

2) Repeat tests must be performed to validate the data acquired in Configuration 3. This will help to determine if the $\mathrm{NO}_{x}$ and $\mathrm{NH}_{3}$ data measured downstream of the $\mathrm{SCRF}^{\circledR}$ is accurate. The new data will also help analyze what lead to high $\mathrm{NO}_{\mathrm{x}}$ conversion efficiencies across the $\mathrm{SCRF}^{\circledR}$.

3) A further investigation into the soot morphological analysis is required. The nature of soot may change with fuel rail pressure at lower (fractal) dimensions which may then affect the oxidation kinetics of soot. 


\section{References}

[1] Song, X., "A SCR Model based on Reactor and Engine Experimental Studies for a Cu-zeolite Catalyst," PhD Dissertation, Michigan Technological University, 2013.

[2] Gustafson, E., "An Experimental Investigation into $\mathrm{NO}_{2}$ Assisted Passive Oxidation With and Without Urea Dosing and Active Regeneration of Particulate Matter for a SCR Catalyst on a DPF," MS Thesis, Michigan Technological University, 2016.

[3] Kadam,V., "An Experimental Investigation of the Effect of Temperature and Space Velocity on the Performance on a Cu-Zeolite Flow-Through SCR and a SCR on a DPF with and without PM Loading," MS Thesis, Michigan Technological University, 2016.

[4] Raghavan, K., "An Experimental Investigation into the Effect of $\mathrm{NO}_{2}$ and Temperature on the Passive Oxidation and Active Regeneration of Particulate Matter in a Diesel Particulate Filter," MS Thesis, Michigan Technological University, 2015.

[5] López - De Jesús, Y., Chigada, P., Watling, T., Arulraj, K. et al., "NOx and PM Reduction from Diesel Exhaust Using Vanadia SCRF ${ }^{\circledR}, "$ SAE Int. J. Engines 9(2): doi:10.4271/2016-01-0914, 2016.

[6] Balland, J., Parmentier, M., and Schmitt, J., "Control of a Combined SCR on Filter and UnderFloor SCR System for Low Emission Passenger Cars," SAE Int. J. Engines 7(3): doi:10.4271/2014-01-1522, 2014.

[7] Johansen, K., Widd, A., Zuther, F., and Viecenz, H., "Passive $\mathrm{NO}_{2}$ Regeneration and NOx Conversion for DPF with an Integrated Vanadium SCR Catalyst," SAE Technical Paper 01-0915, 2016, doi:10.4271/2016-01-0915, 2016.

[8] Johansen, K., Bentzer, H., Kustov, A., Larsen, K. et al., "Integration of Vanadium and Zeolite Type SCR Functionality into DPF in Exhaust Aftertreatment Systems - Advantages and Challenges," SAE Technical Paper 2014-01-1523, doi:10.4271/2014-01-1523, 2014. 
[9] Czerwinski, J., Zimmerli, Y., Mayer, A., Lemaire, J. et al., "Investigations of SDPF -Diesel Particle Filter with SCR Coating for HD-Applications," SAE Technical Paper 2015-01-1023, doi:10.4271/2015-01-1023, 2015.

[10] Ye, P., Sun, C., Lapuerta, M. et al, "Impact of Rail Pressure and Biodiesel Fueling on the Particulate Morphology and Soot Nanostructures from a Common-Rail Turbocharged Direct Injection Diesel Engine", International J of Engine Research, DOI: 10.1177/1468087414564229, 2014.

[11] Qurashi, K., "The Impact of Carbon Dioxide and Exhaust Gas Recirculation on the Oxidative Reactivity of Soot from Ethylene Flames and Diesel Engines", Ph.D. Dissertation, The Pennsylvania State University, 2007.

[12] Iwata, H., Konstandopoulos, A., Nakamura, K., Ogyu, K. et al., "Experimental Study of Physical and Chemical Properties of Soot under Several EGR Conditions," SAE Technical Paper 201401-1593, DOI:10.4271/2014-01-1593, 2014.

[13] Lapuerta, M., Martos, F., Herreros, J., "Effect of Engine Operating Conditions on the Size of Primary Particles Composing Diesel Soot Agglomerates", Aerosol Science, doi:10.1016/j.jaerosci.2007.02.001, 2007.

[14] Pou Ng,I., Ma, H., Kittelson, D., Miller, A., "Comparing Measurements of Carbon in Diesel Exhaust Aerosols Using Aethalometer, NIOSH Method 5040, and SMPS", SAE Technical Paper 2007-01-0334, April 16-19, 2007.

[15] Warner, J., Johnson J., Bagley, S., Huynh, C., "Effects of a Catalyzed Particulate Filter on Emissions from a Diesel Engine: Chemical Characterization Data and Particulate Emissions Measured with Thermal Optical and Gravimetric Methods", SAE Technical Paper 2003-010049, 2003. 
Table A.1: Stage 1 PM Mass Balance

\begin{tabular}{|c|c|c|c|c|c|c|c|c|c|c|c|}
\hline Expt. & Duration & $P M_{1 n}$ & $\begin{array}{l}\text { Filtration } \\
\text { Efficiency }\end{array}$ & PMout & PMstart & PM $M_{\text {Retained }}$ & PMLoading & PM $_{\text {Added }}$ & PMAvailable & PMoxidized & $\begin{array}{l}\text { Percent } \\
\text { Oxidized }\end{array}$ \\
\hline$[-]$ & [min] & [g] & [\%] & [g] & [g] & [g] & {$[\mathrm{g} / \mathrm{L}]$} & [g] & [g] & [g] & [\%] \\
\hline A & 29.8 & 3.4 & 58.6 & 1.4 & 0 & 1.2 & 0.1 & 1.2 & 3.4 & 0.8 & 23.3 \\
\hline C & 32.2 & 3.6 & 58.6 & 1.5 & 0 & 1.1 & 0.1 & 1.1 & 3.6 & 1.0 & 28.4 \\
\hline$E$ & 31.1 & 3.3 & 58.6 & 1.4 & 0 & 1.4 & 0.1 & 1.4 & 3.3 & 0.5 & 16.6 \\
\hline B & 30.8 & 3.0 & 58.6 & 1.3 & 0 & 1.1 & 0.1 & 1.1 & 3.0 & 0.6 & 20.7 \\
\hline D & 30.2 & 3.2 & 58.6 & 1.3 & 0 & 1.2 & 0.1 & 1.1 & 3.2 & 0.7 & 22.2 \\
\hline 1 & 30.3 & 3.34 & 58.6 & 1.4 & 0 & 1.0 & 0.1 & 1.0 & 3.3 & 1.0 & 28.6 \\
\hline
\end{tabular}


Table A.2: Stage 2 PM Mass Balance

\begin{tabular}{|c|c|c|c|c|c|c|c|c|c|c|c|}
\hline Expt. & Duration & $P M_{1 n}$ & $\begin{array}{l}\text { Filtration } \\
\text { Efficiency }\end{array}$ & PM & $\mathbf{P M}_{\text {start }}$ & PM $M_{\text {Retained }}$ & PMLoading & PM $_{\text {Added }}$ & $\mathrm{PM}_{\text {Available }}$ & PMoxidized & $\begin{array}{l}\text { Percent } \\
\text { Oxidized }\end{array}$ \\
\hline$[-]$ & [min] & [g] & [\%] & [g] & [g] & [g] & {$[\mathrm{g} / \mathrm{L}]$} & [g] & [g] & [g] & [\%] \\
\hline A & 299.6 & 35.5 & 98.3 & 0.59 & 1.2 & 27.8 & 1.6 & 26.6 & 36.7 & 8.3 & 22.5 \\
\hline C & 300.1 & 33.4 & 98.4 & 0.53 & 1.1 & 24.5 & 1.4 & 23.4 & 34.5 & 9.5 & 27.5 \\
\hline$E$ & 300.8 & 29.5 & 98.4 & 0.47 & 1.4 & 25.5 & 1.5 & 24.2 & 30.9 & 4.9 & 15.8 \\
\hline B & 299.9 & 31.7 & 97.6 & 0.76 & 1.1 & 25.5 & 1.5 & 24.4 & 32.9 & 6.6 & 20.0 \\
\hline D & 300.0 & 31.8 & 95.7 & 1.36 & 1.2 & 24.6 & 1.4 & 23.4 & 33.0 & 7.1 & 21.4 \\
\hline 1 & 300.7 & 33.5 & 98.4 & 0.53 & 1.0 & 24.4 & 1.4 & 23.4 & 34.5 & 9.6 & 27.8 \\
\hline
\end{tabular}


Table A.3: Variables to Compare Loading Stage 1+2

\begin{tabular}{|c|c|c|c|c|c|c|c|c|c|}
\hline Expt. & $\begin{array}{c}\text { SCRF }^{\circledast} \text { Inlet } \\
\text { Temp. }\end{array}$ & $\begin{array}{c}\mathrm{NO}_{2} \text { Into } \\
\text { SCRF }^{\circledast}\end{array}$ & PMoxidized,S1 & PMoxidized,S2 & PMstart,s1 & $\mathrm{PM}_{\text {Retained,S2 }}$ & $\begin{array}{c}\Delta \mathrm{P} \text { at Stage } \\
\text { Start S1 }\end{array}$ & $\begin{array}{c}\Delta P \text { at Stage } \\
\text { End } S 2\end{array}$ & $\begin{array}{c}\Delta \Delta \mathrm{P} \text { for } \\
\text { Stage } 1+2\end{array}$ \\
\hline$[-]$ & {$\left[{ }^{\circ} \mathrm{C}\right]$} & [ppm] & [g] & [g] & [g] & [g] & {$[\mathrm{kPa}]$} & {$[\mathrm{kPa}]$} & {$[\mathrm{kPa}]$} \\
\hline$A$ & 276 & 58 & 0.8 & 8.3 & 0 & 27.8 & 2.7 & 7.7 & 5.0 \\
\hline C & 275 & 59 & 1.0 & 9.5 & 0 & 24.5 & 2.7 & 7.9 & 5.2 \\
\hline$E$ & 273 & 62 & 0.5 & 4.9 & 0 & 25.5 & 2.7 & 7.8 & 5.1 \\
\hline B & 275 & 66 & 0.6 & 6.6 & 0 & 25.5 & 2.9 & 8.5 & 5.6 \\
\hline D & 277 & 69 & 0.7 & 7.1 & 0 & 24.6 & 2.8 & 7.5 & 4.7 \\
\hline 1 & 271 & 62 & 1.0 & 9.6 & 0 & 24.4 & 2.7 & 7.2 & 4.5 \\
\hline
\end{tabular}




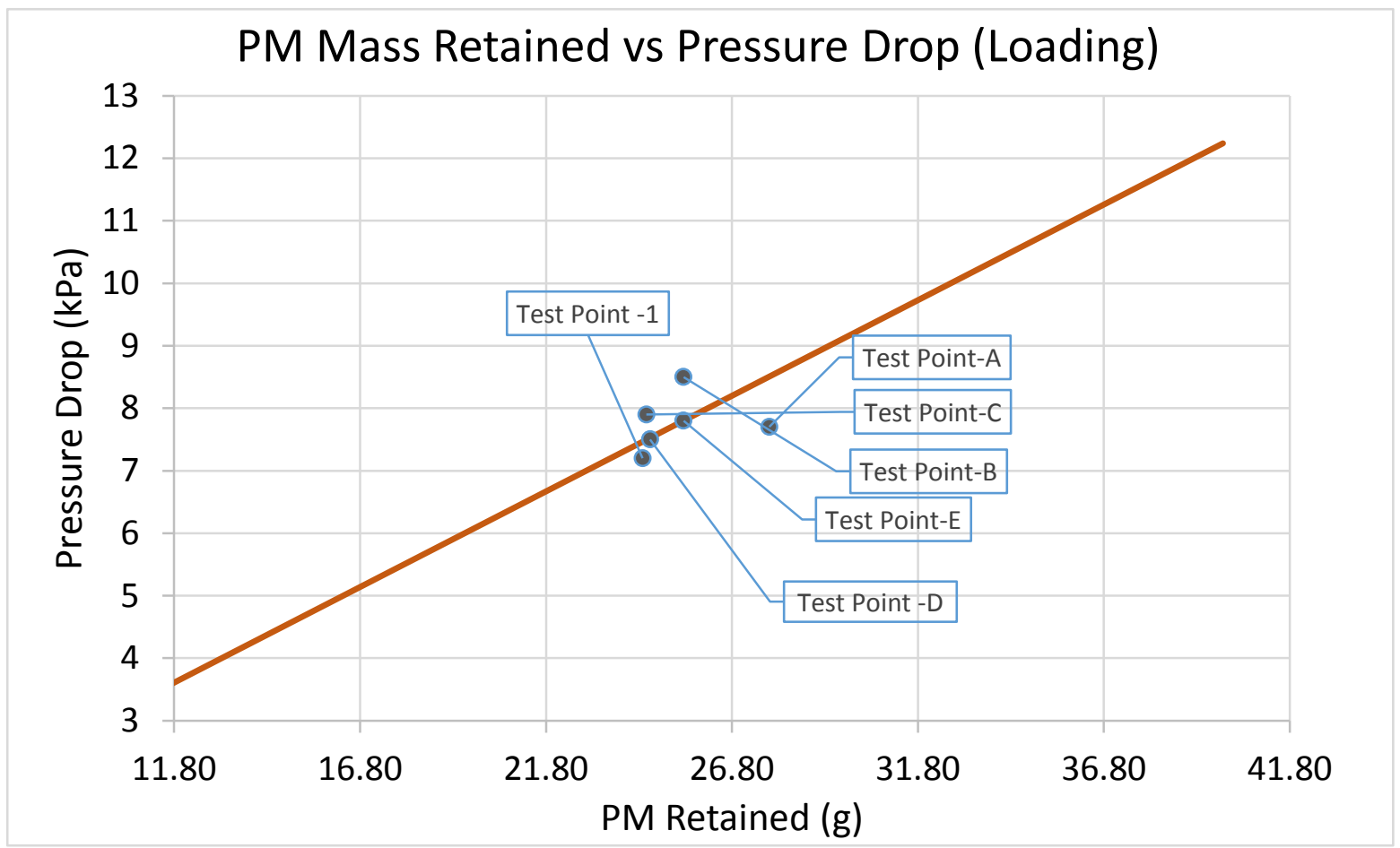

Figure A.1. PM Mass Retained vs Pressure Drop for Loading Stage S1 and S2

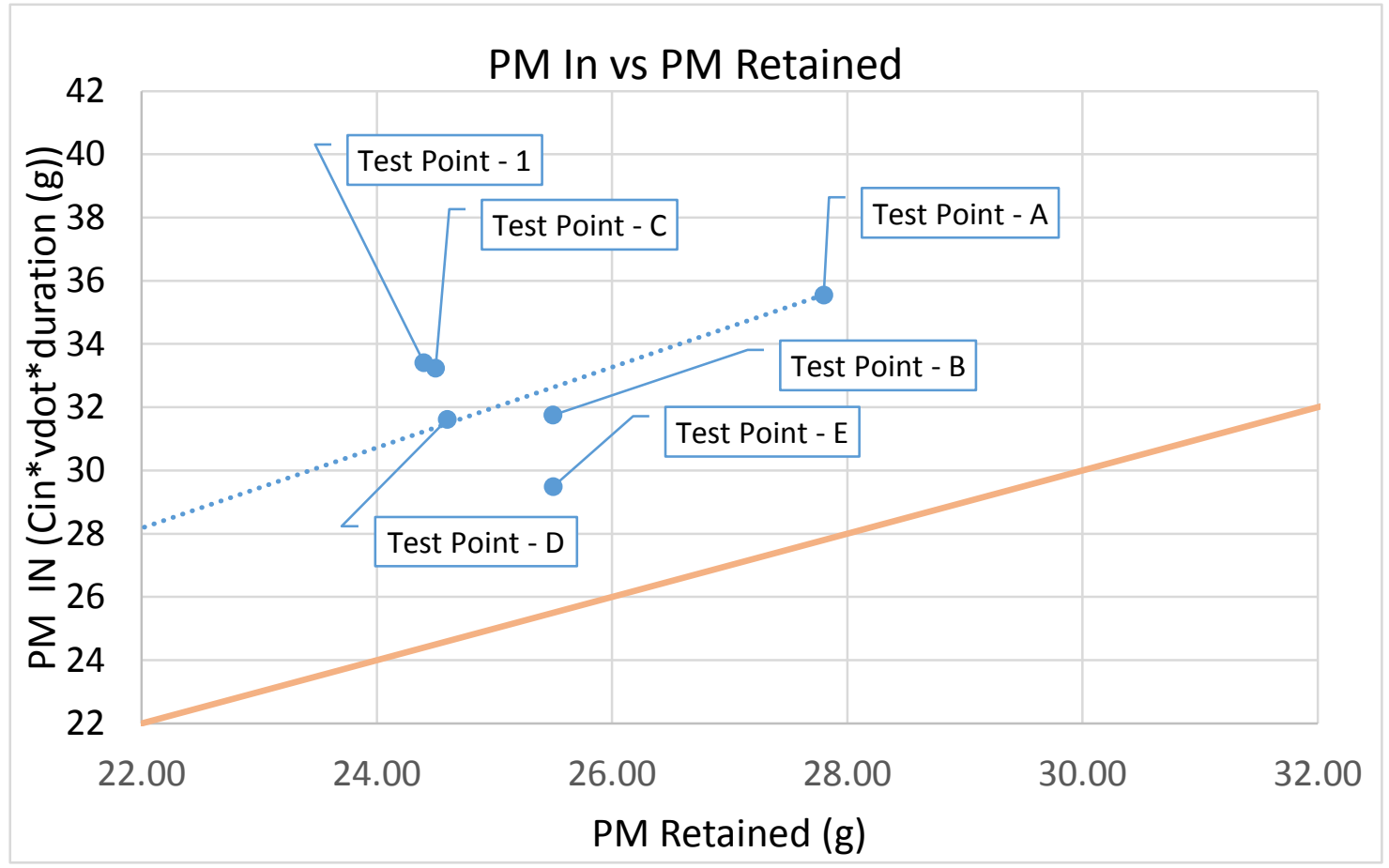

Figure A.2. PM Mass into the $\mathrm{SCRF}^{\circledR}$ vs PM Mass Retained for Loading Stage S1 and S2

*: Figures A.1 and A.2 are discussed in Appendix B. 


\section{Appendix B. Pressure Drop across SCRF}

This appendix presents the pressure drop curves across the $\mathrm{SCRF}^{\oplus}$ for all the six tests conducted in the DOC - SCRF ${ }^{\oplus}$ - SCR Configuration 3 - Figures B.1 to B.6. As can be seen from these plots, the pressure at the beginning of Stage 1 (S1), which is the stage after clean out stage (performed at $600^{\circ} \mathrm{C}$ ), is within $\pm 0.1 \mathrm{KPa}$ for all the Test Points. Hence, it can be assumed that most of the PM in the substrate was oxidized during the clean out stage or that they had the same PM present. Thus the initial mass of the substrate is same for all these Test Points i.e. the mass at the beginning of Stage 1.

Another thing that can be observed in these plots is that the pressure rise during the Ramp Up (RU) stage has not been able to reach the same value as that during the end of Stage 2 (S2). The reason for this is that since the RU stage was run only for 15 minutes, (which is as per the defined test procedure) therefore, the pressure drop across the $\mathrm{SCRF}^{\circledR}$ did not get sufficient time to reach the same value as that during the end of S2.

It is also observed that the Passive Oxidation stage in various Test Points have different slopes. This can be accounted for by the difference in the $\mathrm{SCRF}^{\circledR}$ inlet temperatures, $\mathrm{PM}$ concentrations and the $\mathrm{NO}_{2}$ concentrations for these Test Points. The higher the $\mathrm{SCRF}^{\oplus}$ inlet temperature, the lesser is the slope of PO curve.

Also, it can be seen that Test Point 1 does not have a Stage 4 (S4). This is due to malfunctioning of the equipment in the lab. Since, S4 data are required only from modelling perspective, it did not affect the test in any way, thus, this Test Point was not repeated.

Figure B.7 shows the pressure drops across the $\mathrm{SCRF}^{\circledR}$ during the stage 1 and stage 2 loading for all the experiments. It can be seen from the figure that the pressure drops across the filter are not the same at the end of stage 2 loading although the loading conditions were same in all these tests $-2400 \mathrm{rpm}$ and $200 \mathrm{Nm}$.

From Appendix A (Figures A.1 and A.2), it is seen that the mass deposited at the end of stage 2 is slightly different in different test points. This shows that the variation in pressure drop is related to the PM masses retained and the pressure drops do not fall on a straight line in Figure A1. This is because of 
likely measurement errors in measuring the PM mass retained. This variation can also be a result of different exhaust temperature and $\mathrm{NO}_{2}$ concentration that would result in different amount of PM mass being oxidized for each experiment.

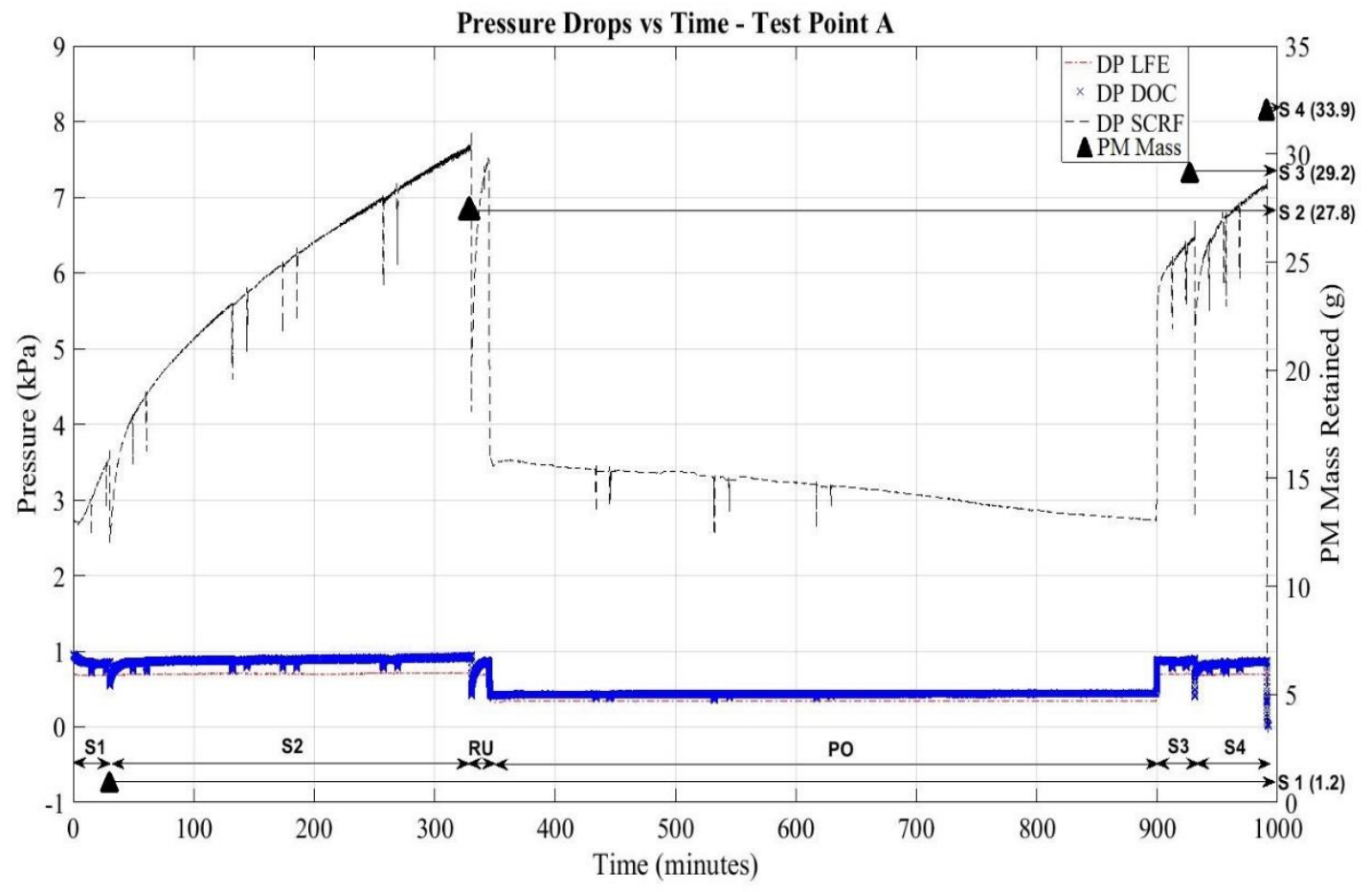

Figure B.1: Pressure Drop across SCRF ${ }^{\circ}$ for Test Point A 


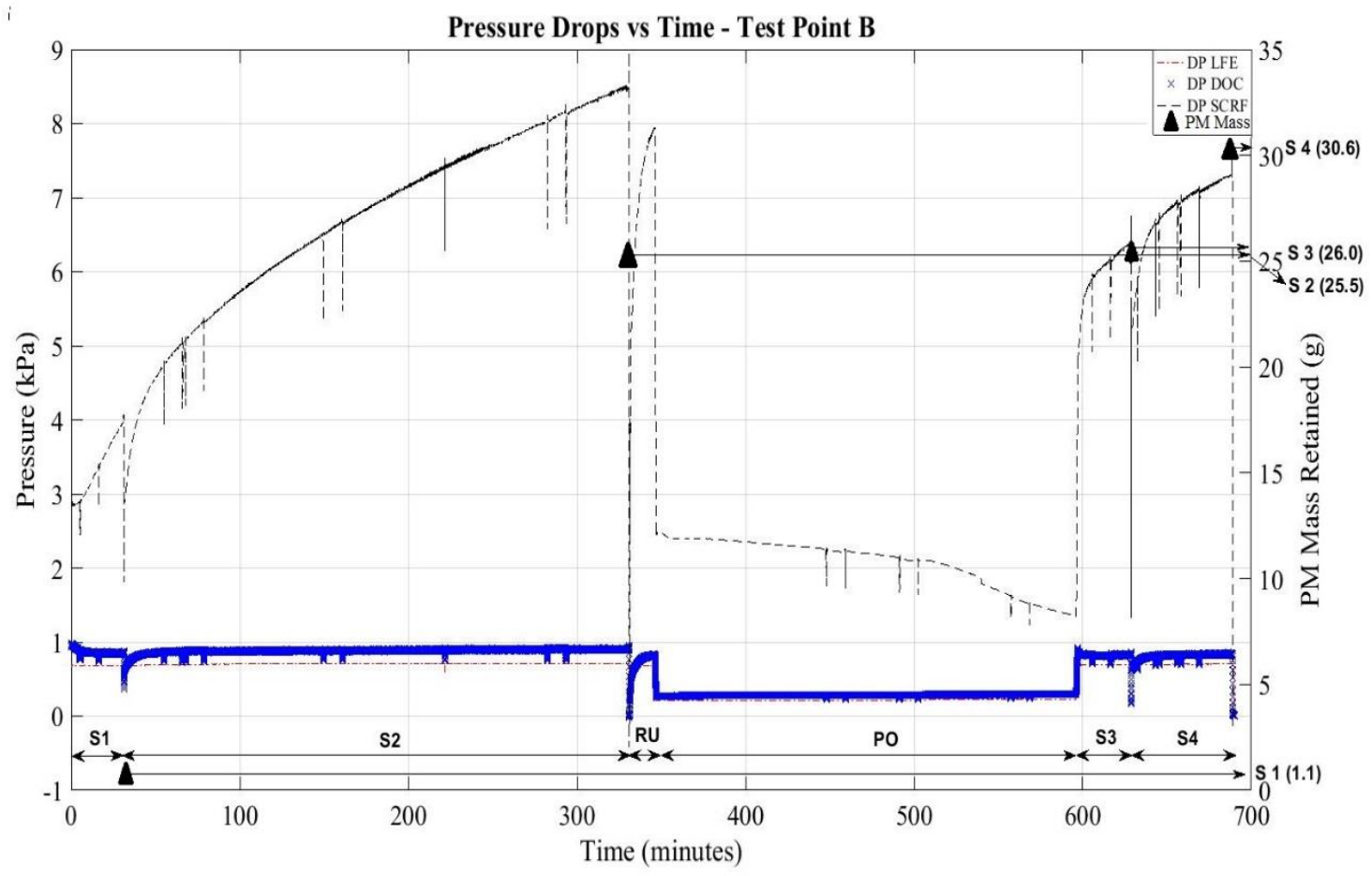

Figure B.2: Pressure Drop across $\mathrm{SCRF}^{\circledast}$ for Test Point B

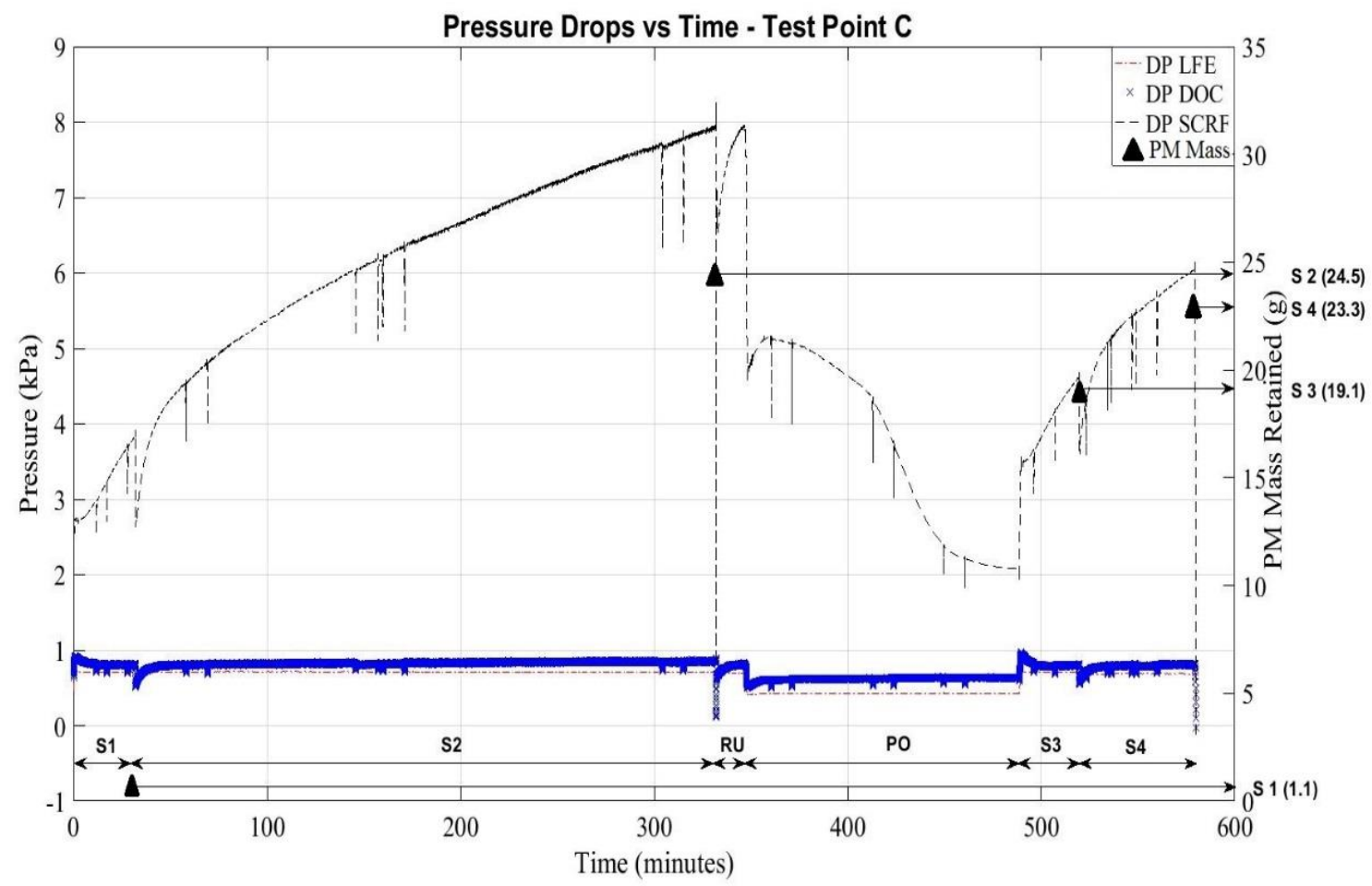

Figure B.3: Pressure Drop across SCRF ${ }^{\circledast}$ for Test Point C 


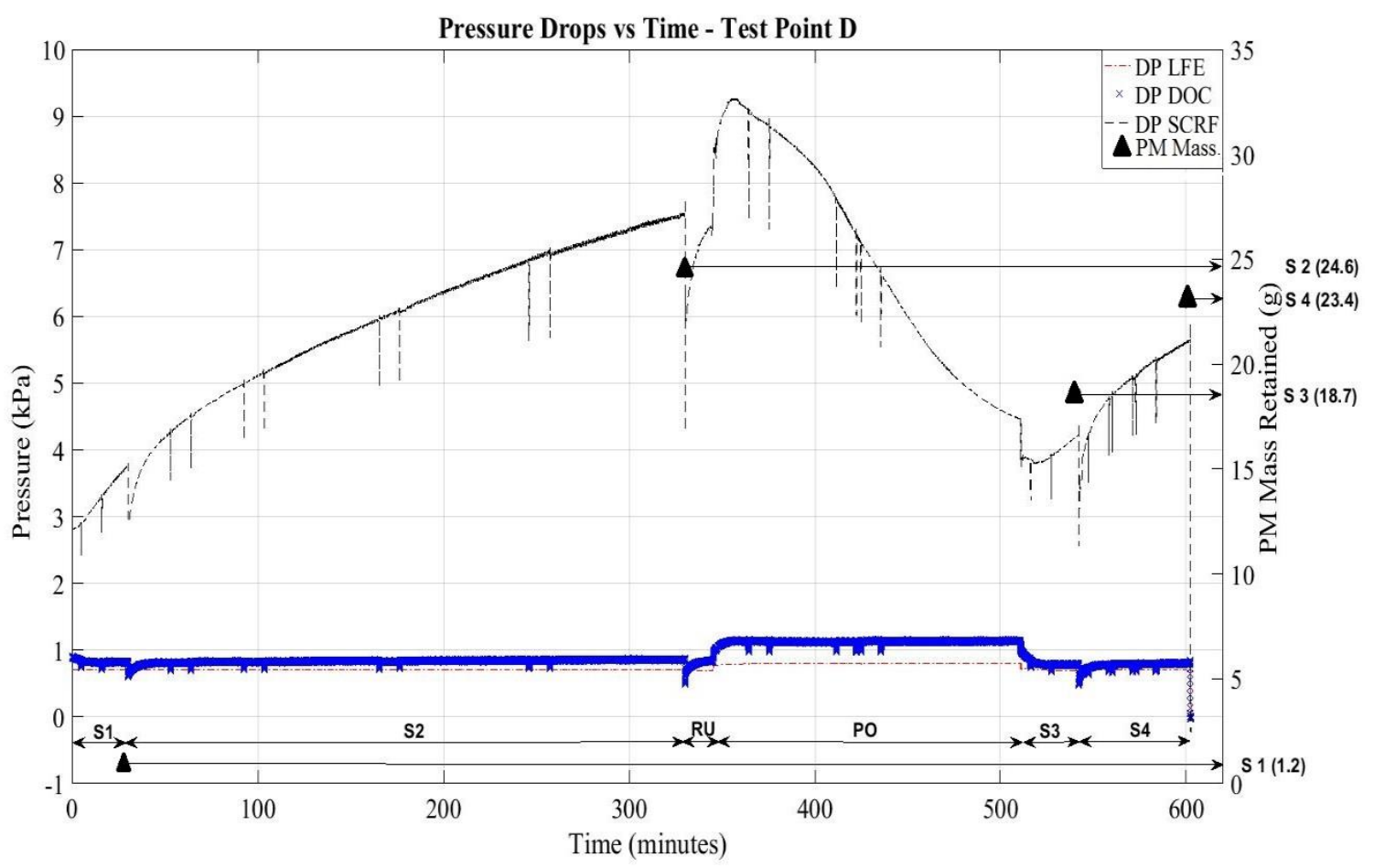

Figure B.4: Pressure Drop across SCRF ${ }^{\circledast}$ for Test Point D

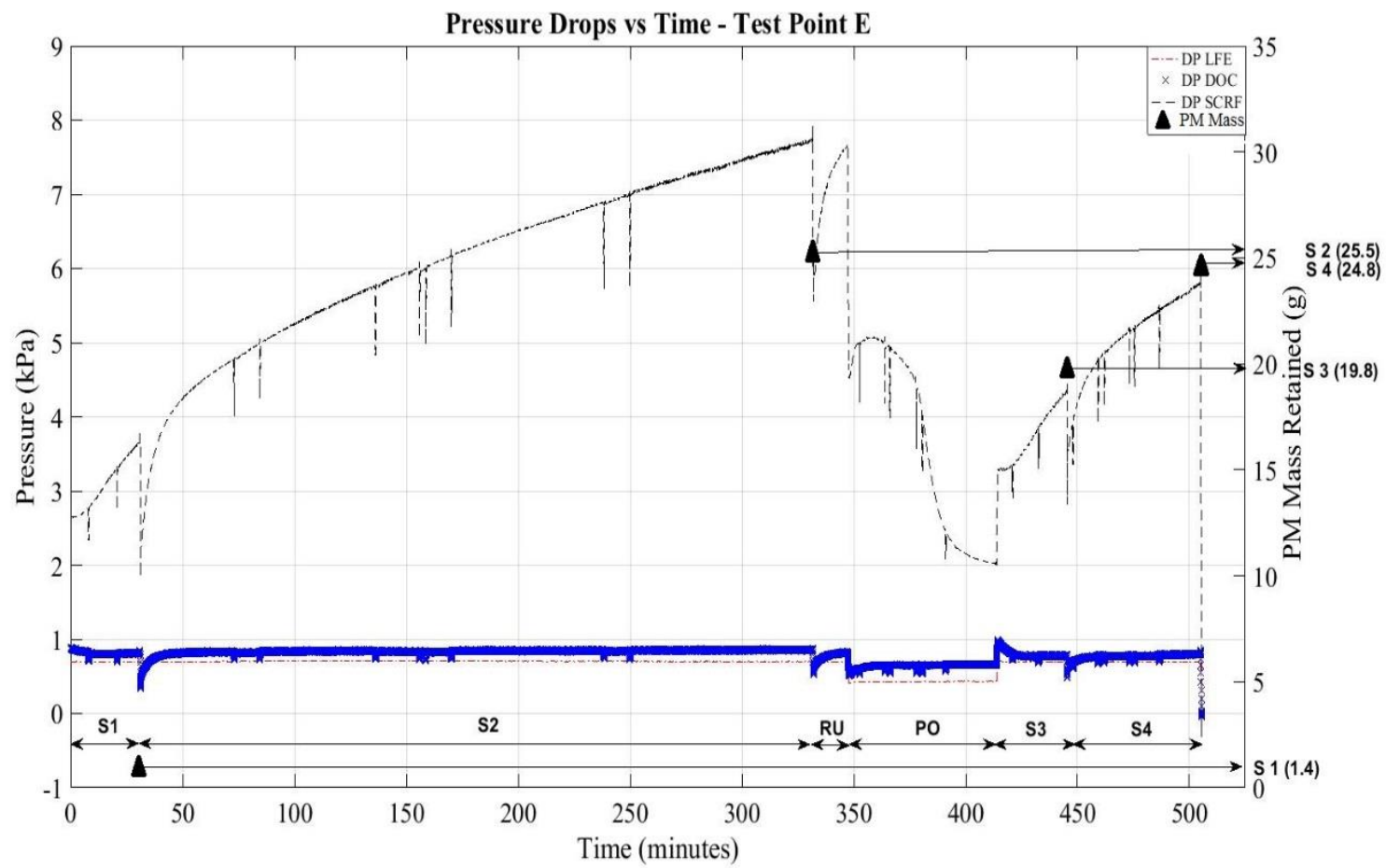

Figure B.5: Pressure Drop across $\mathrm{SCRF}^{\oplus}$ for Test Point E 


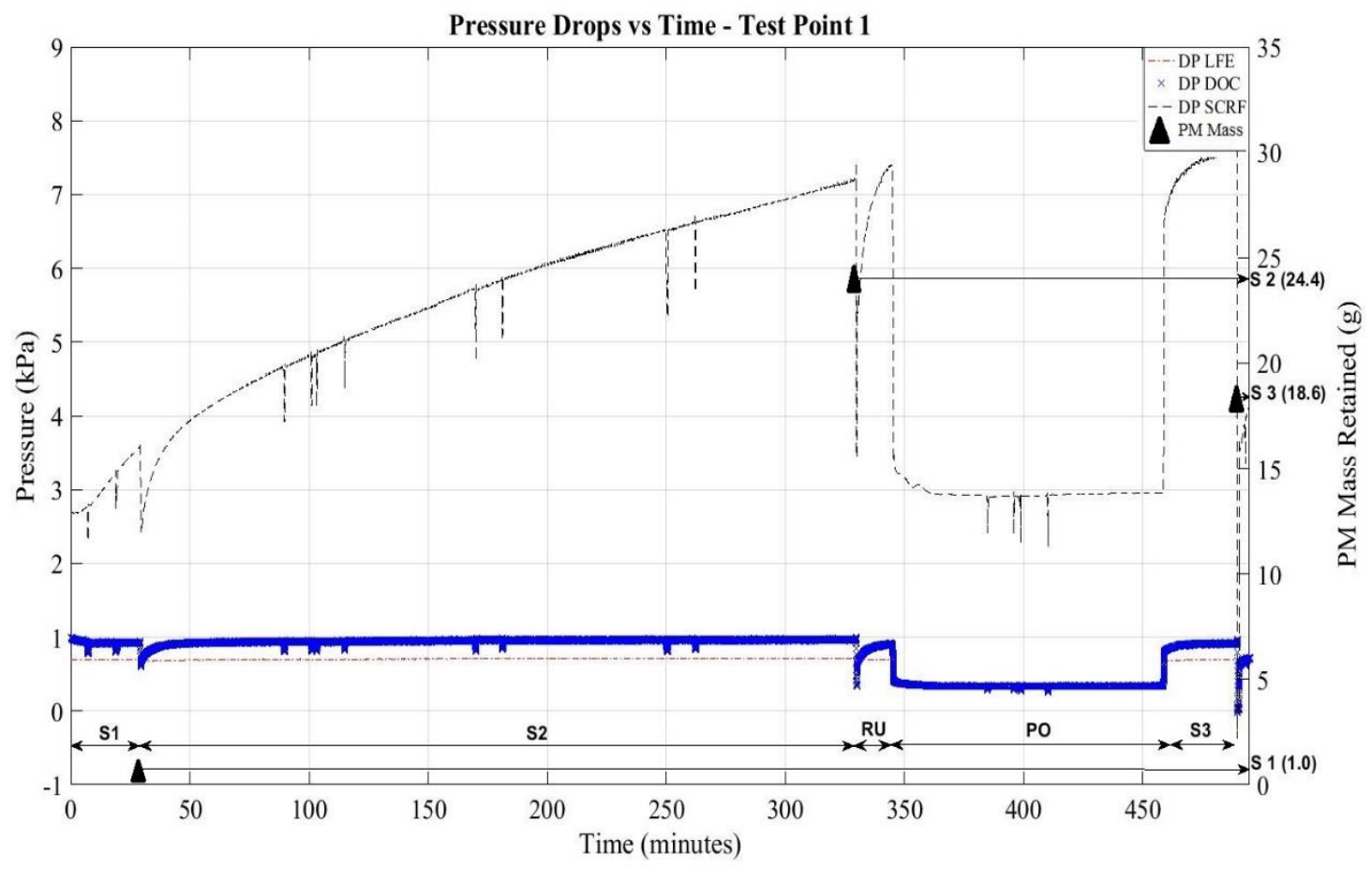

Figure B.6: Pressure Drop across SCRF ${ }^{\oplus}$ for Test Point 1

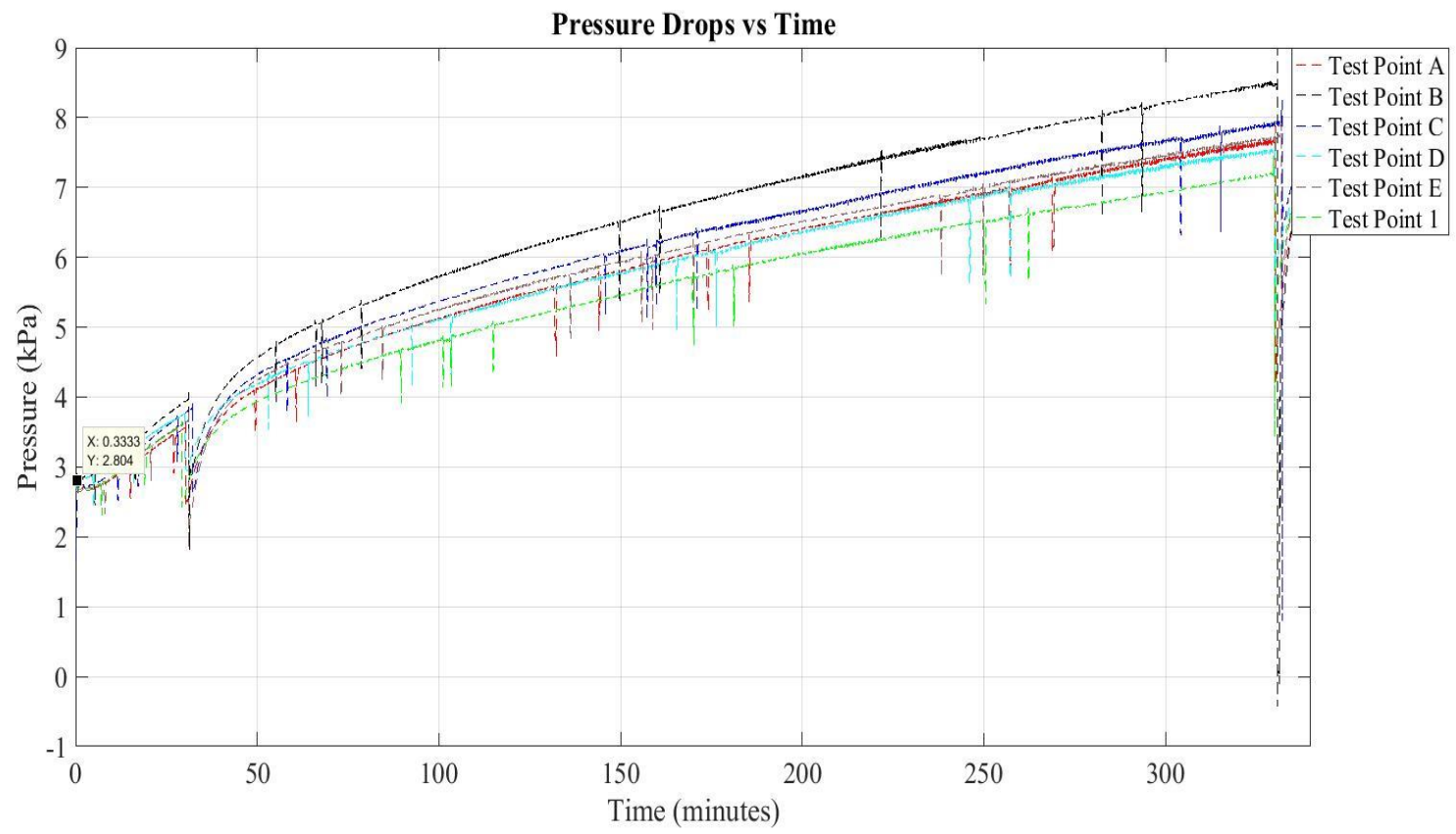

Figure B.7: Combined Pressure Drops across SCRF ${ }^{\oplus}$ for Loading - Stage 1 and Stage 2 


\section{Appendix C. Gas Temperature Distribution in the SCRF ${ }^{\oplus}$ During PO}

This appendix presents the gas temperature distribution plots across the $\mathrm{SCRF}^{\oplus}$ at a time somewhere between 10 to 20 minutes into the Passive Oxidation stage, where the temperatures have just stabilized. As can be seen from Figures C.1 to C.6, the general trend of temperature distribution (increasing temperature in the axial direction) is similar in all these plots.

In all these plots, the X-Axis represents the axial length of the filter in $\mathrm{mm}$ while the Y-Axis represents the radial distance from the center of the SCRF ${ }^{\circledR}$. The figures plotted here represent only half of the $\mathrm{SCRF}^{\oplus}$. Lines inside the plot represent isotherms, which divide the plot into various zones with different temperature ranges. The white circles represent the broken thermocouples at various locations, temperature data for which has been estimated using linear interpolation within the axial zone.

The trend in temperature distribution in all these plots with urea injection is similar to that found in reference [2]. It is thought that the rise in temperature inside the filter occurs due to exothermic reactions taking place. Thus, relatively higher temperatures towards the second half of the SCRF ${ }^{\oplus}$ axially are shown by the data. However, the increase in temperature observed for the first half of the filter is also due to some other effect, as the SCR reactions and PM oxidation only generate a few degree exotherm each. One possibility may be due to how these thermocouples are instrumented in the filter. Of the 20 instrumented thermocouples, 10 are inserted in the inlet channels and 10 are instrumented in the outlet channels. Therefore, the distribution of temperature shown in the figure may be affected because of differences between the inlet and outlet channels.

The temperature decrease trend from the center to the edge of the substrate is due to heat transfer occurring radially within the substrate of the $\mathrm{SCRF}^{\circ}$. A detailed explanation of the temperature distribution plots with urea dosing is in reference [2].

The temperature distribution for Test Point C (Figure C.6) is from reference [2] due to lack of temperature data available on account of 6 broken thermocouples during experimentation. A temperature distribution plot for a Test Point with the same engine conditions but a different ANR value can be found in reference [2]. 


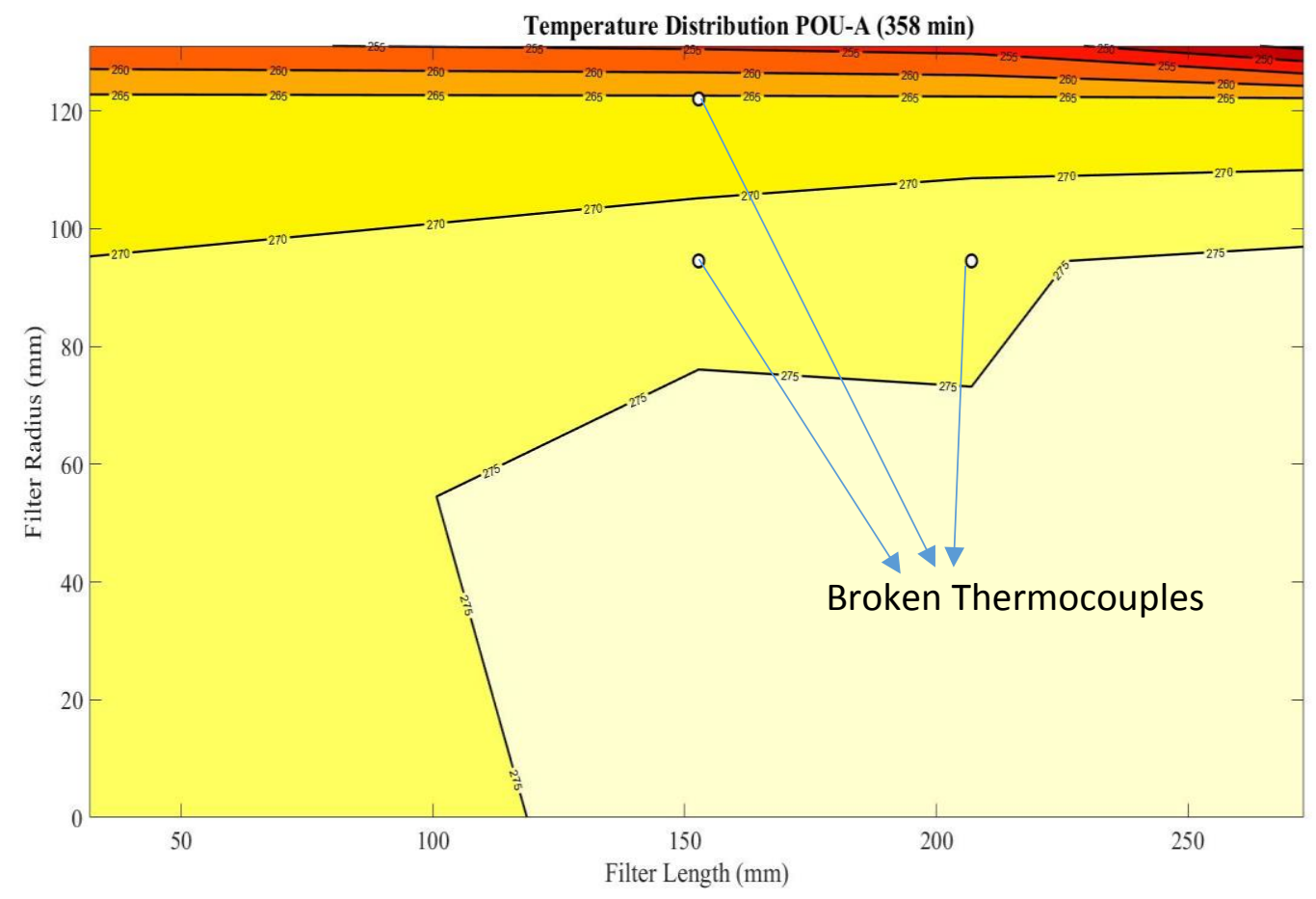

Figure C.1: Temperature Distribution Test Point A (12 minutes into PO)

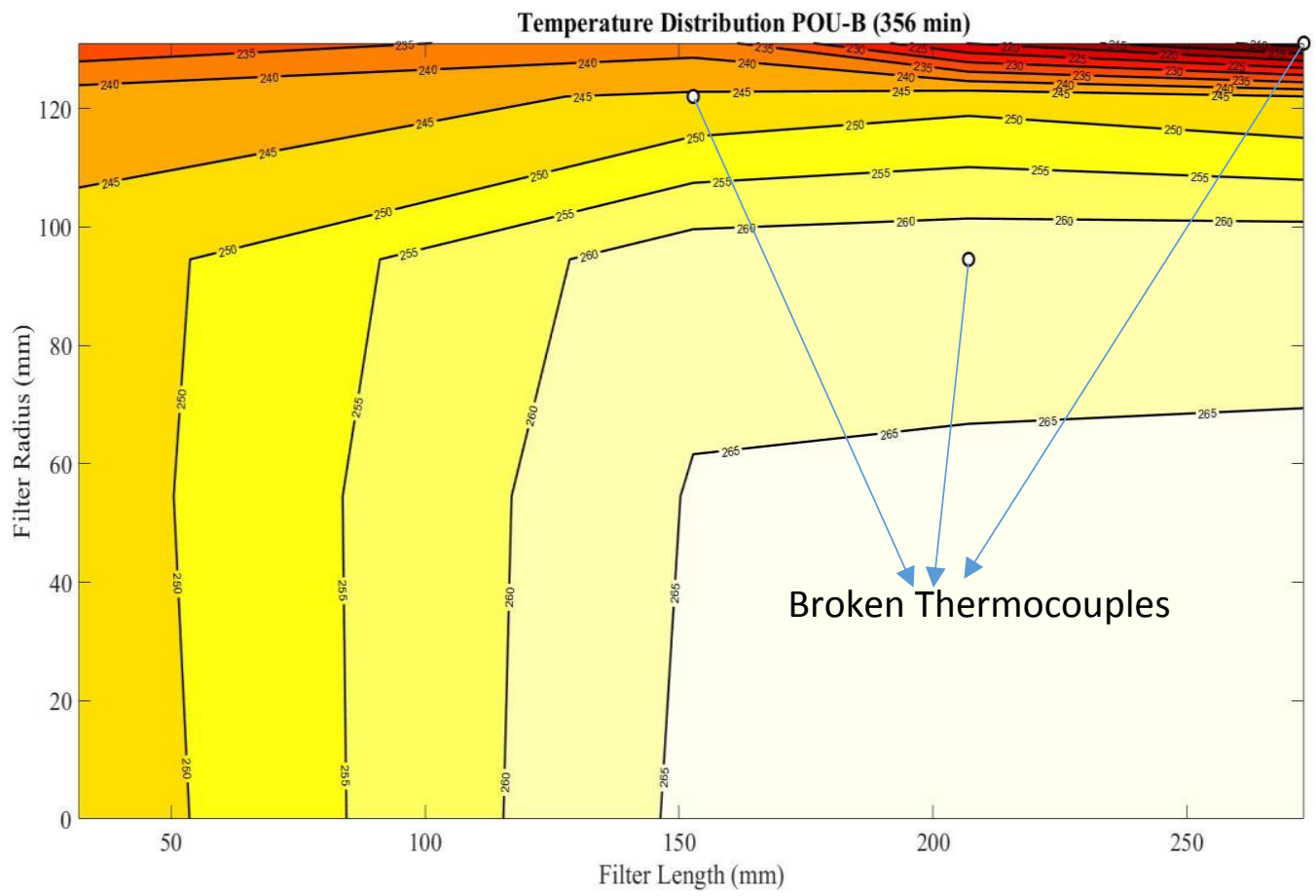

Figure C.2: Temperature Distribution Test Point B (9 minutes into PO) 


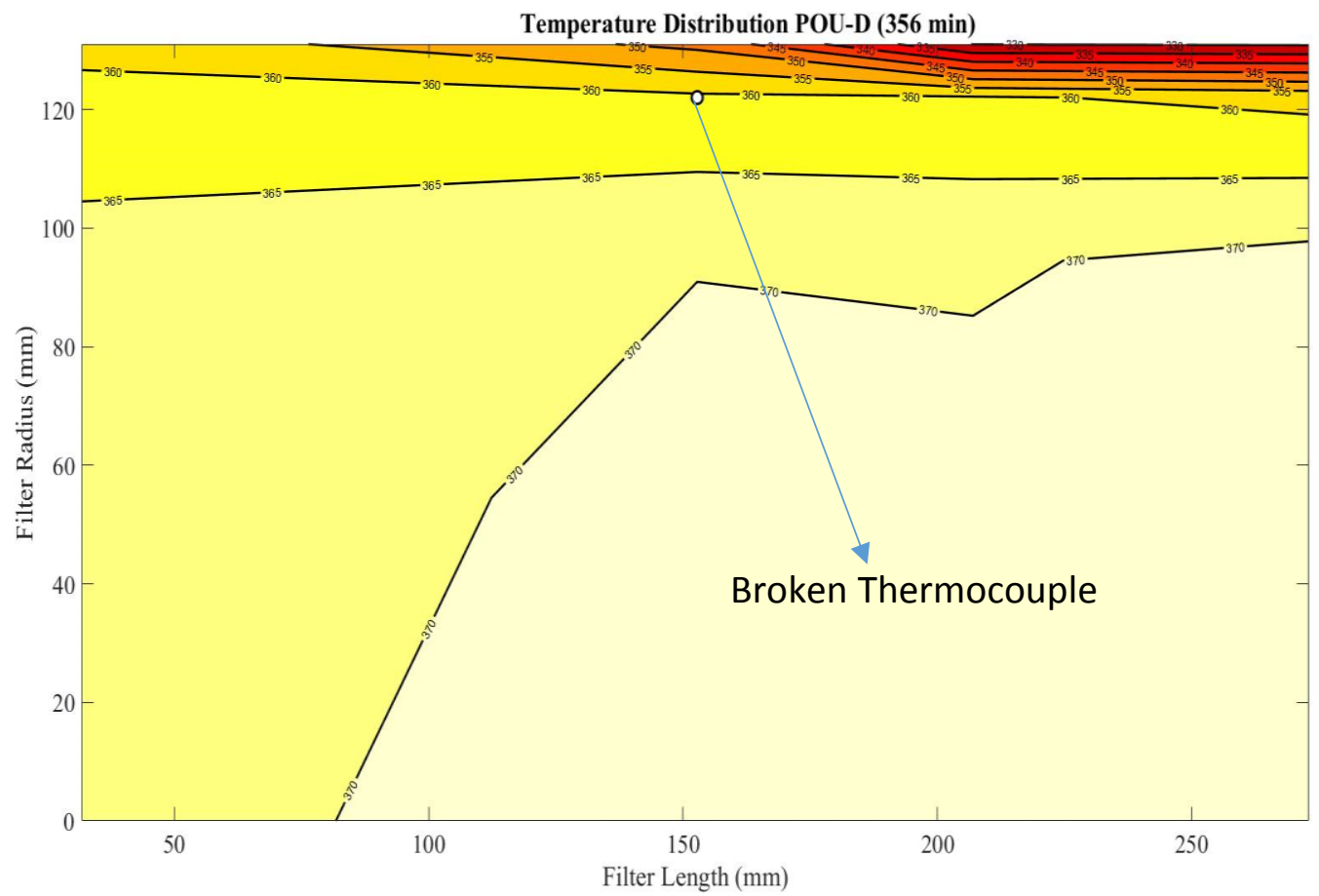

Figure C.3: Temperature Distribution Test Point D (13 minutes into PO)

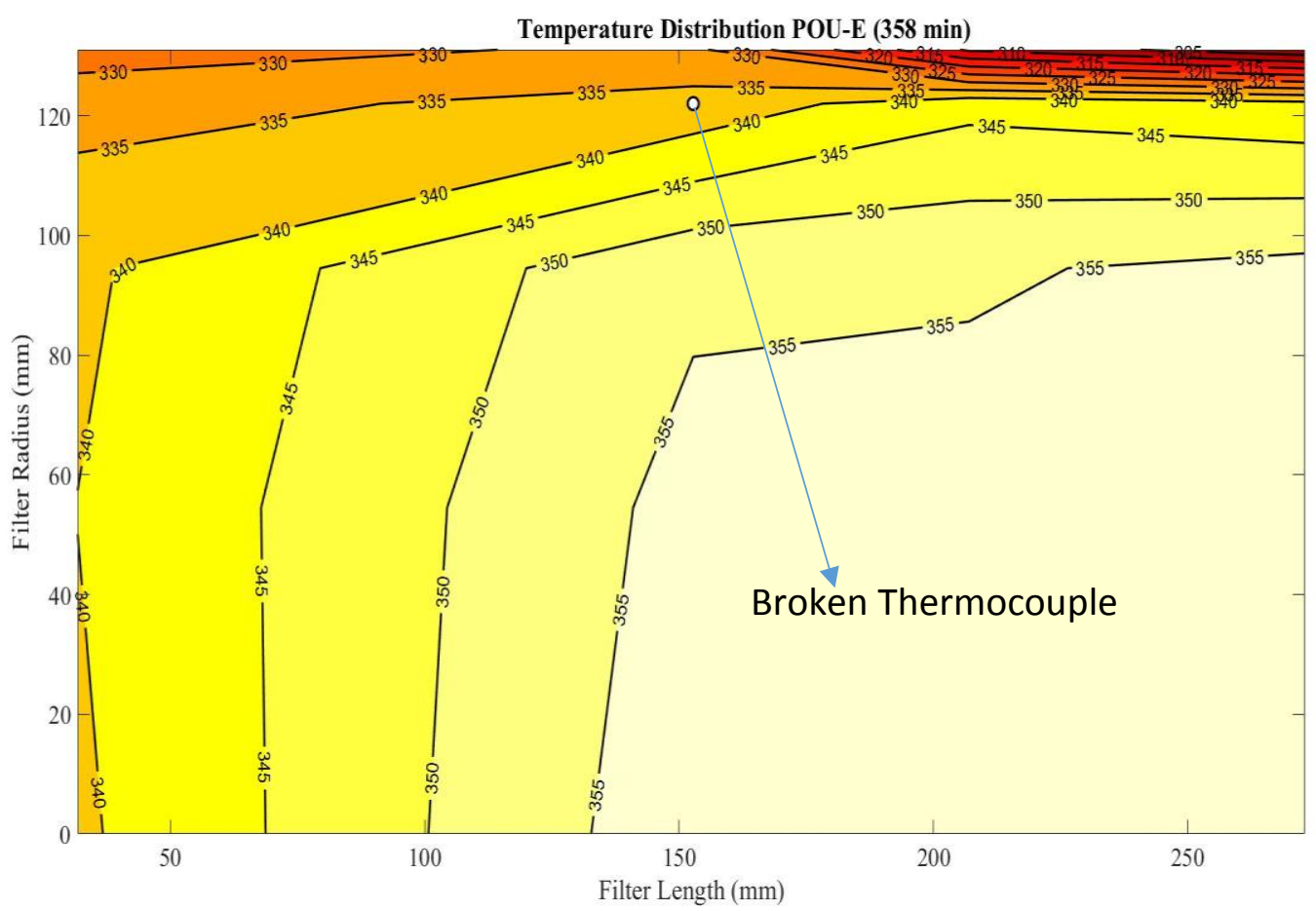

Figure C.4: Temperature Distribution Test Point E (10 minutes into PO) 


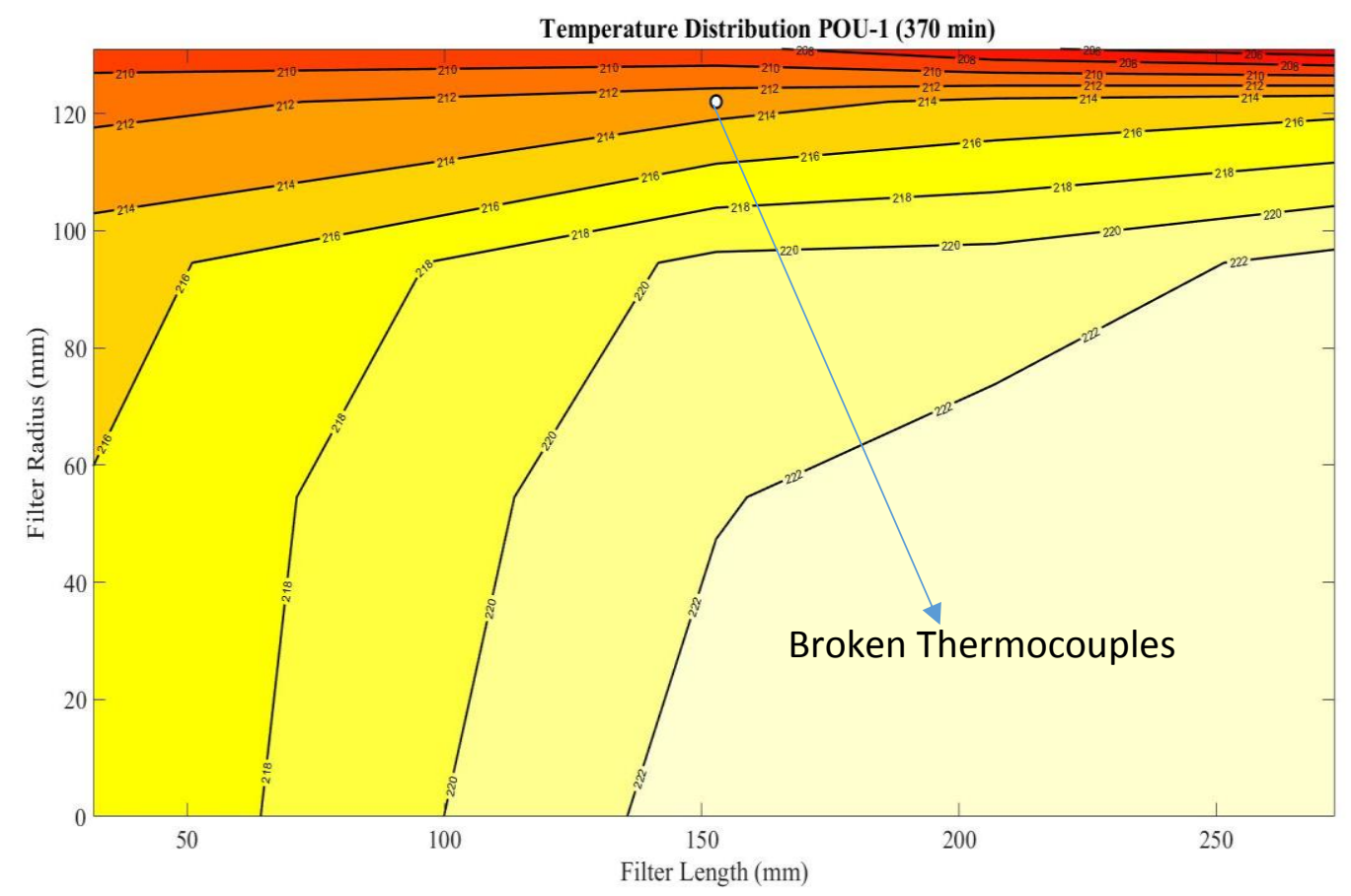

Figure C.5: Temperature Distribution Test Point 1 (22 minutes into PO)

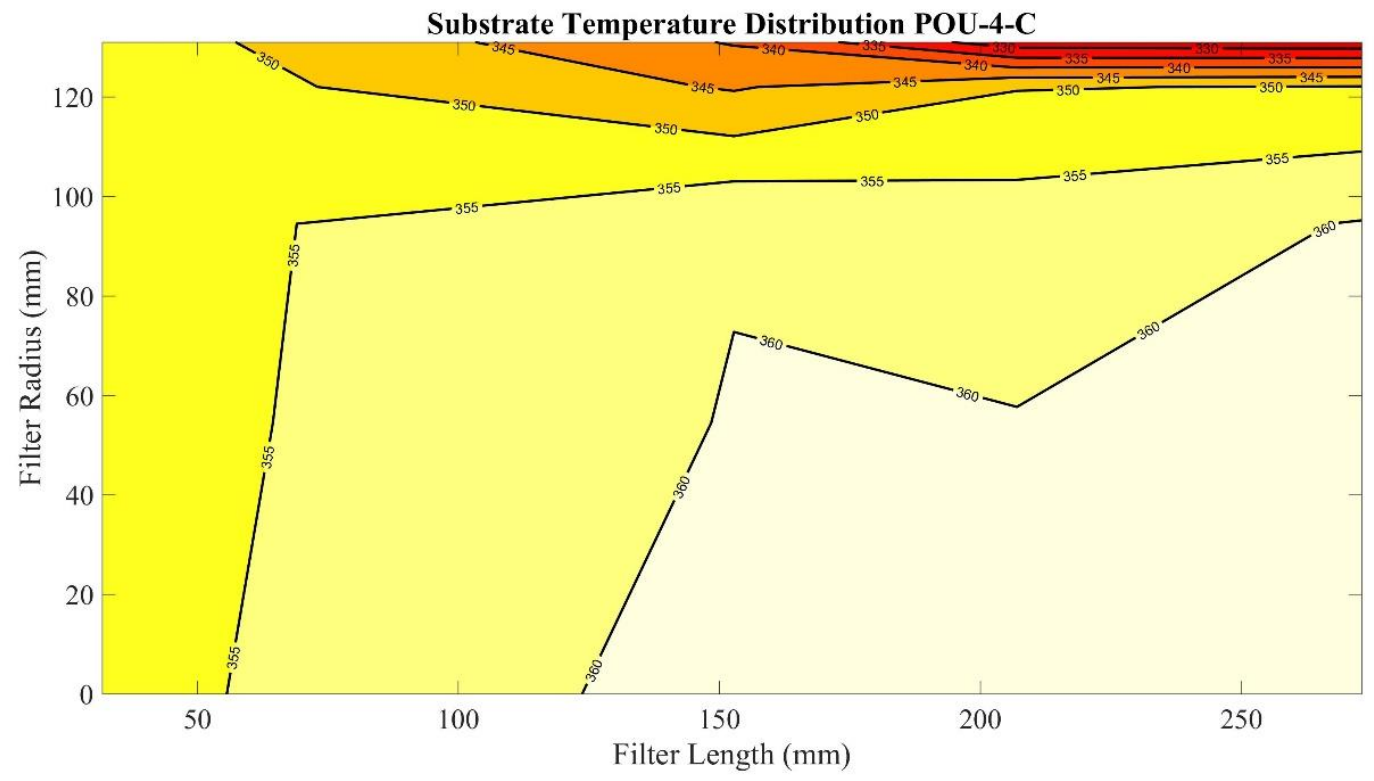

Figure C.6: Temperature Distribution Test Point C [2] *

*: This figure has been directly used from refernce [2] due to lack of data available on account of 6 broken thermocouples. The temperatures are similar and are within a range of $\pm 5^{\circ} \mathrm{C}$ for the Test Point $\mathrm{C}$ in Configuration 1 and Configuration 3. 


\section{Appendix D. Particulate Morphology}

This appendix presents a brief discussion from literature regarding the Primary Particle Size and Elemental Carbon/Organic Carbon analysis. This is then followed by the presentation of data found in the study conducted at MTU.

\section{D.1 Primary Particle Size - Literature}

Ye et al. [10] studied the effect of fuel rail pressure on particulate morphology. The tests were conducted on a 6.4L Ford diesel engine with $30 \%$ load and $60 \%$ load and different fuel rail pressures. Transmission Electronic Microscopy (TEM) imaging was used to observe the primary particles. It was observed that there is no significant effect of engine load and fuel rail pressure on primary particle diameter. It was also concluded that the impact of fuel rail pressure is on larger length scales than primary particle lengths. They found the primary particle size to range between 24 and $28 \mathrm{~nm}$ for ULSD fuel. It was also observed that the number of primary particles increases with engine load and decreases with increase in fuel rail pressure as shown in Figure D.1.

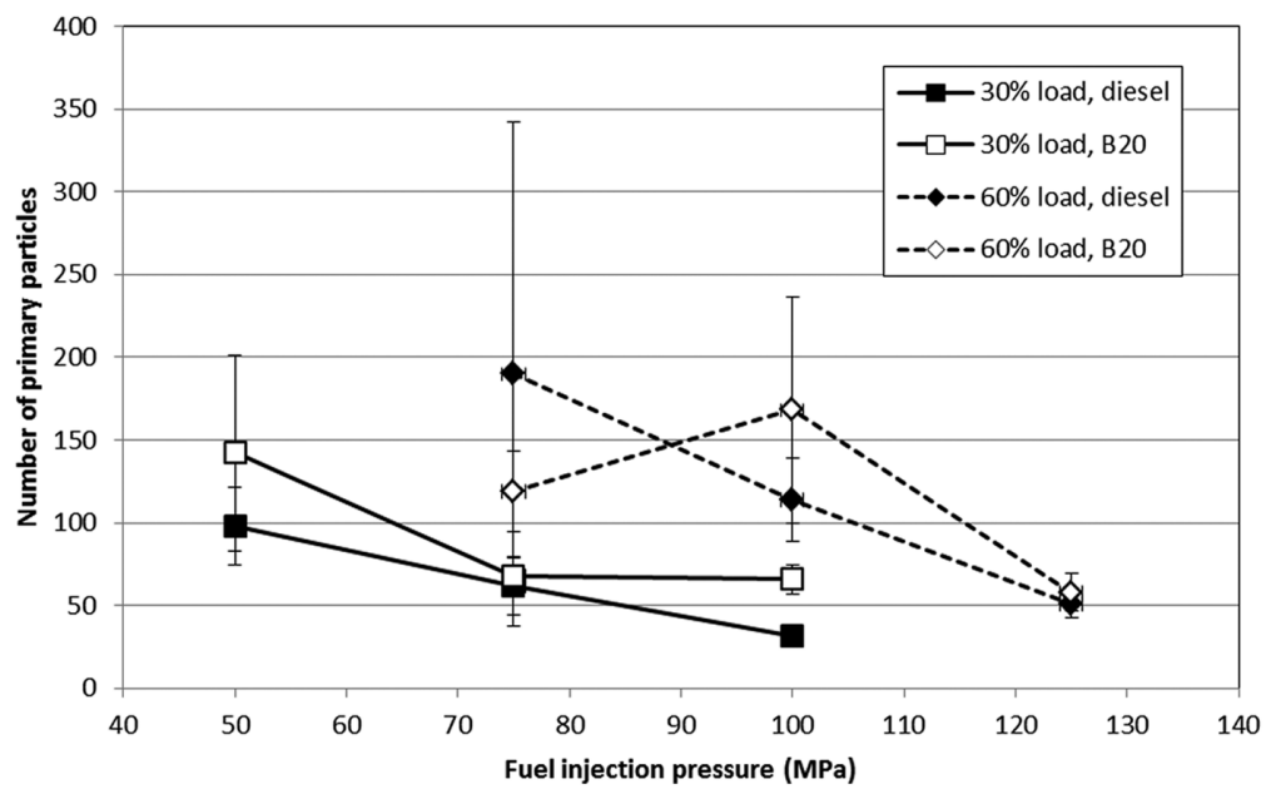

Figure D.1: Number of Primary particles vs Fuel Injection Pressure for Diesel and B 20 Fuel [10] 
Qurashi [11] studied the effect of EGR on primary particle diameter. His study used a $2.5 \mathrm{~L}$ light duty diesel engine to produce particulate matter (PM) and Transmission Electronic Microscopy (TEM) imaging for visual inspection of the PM. The primary particle diameter was estimated to be around $30 \mathrm{~nm}$ taking an average of 70 particles at a fuel injection pressure of 1600 bar for an EGR rate of $0 \%$ and $20 \%$. It was concluded that there is no significant impact of EGR on the primary particle diameter.

Iwata et al [12] conducted a study on soot reactivity using a $1.6 \mathrm{~L}$ diesel engine and varying the EGR rate. They found out that the primary particle size does not vary with EGR rate and is around $22 \mathrm{~nm}$ as shown in Figure D.2. TEM imaging was used to estimate the size. The also concluded that more reactive soot is produced at lower EGR rate and less reactive soot is produced at high EGR rates.

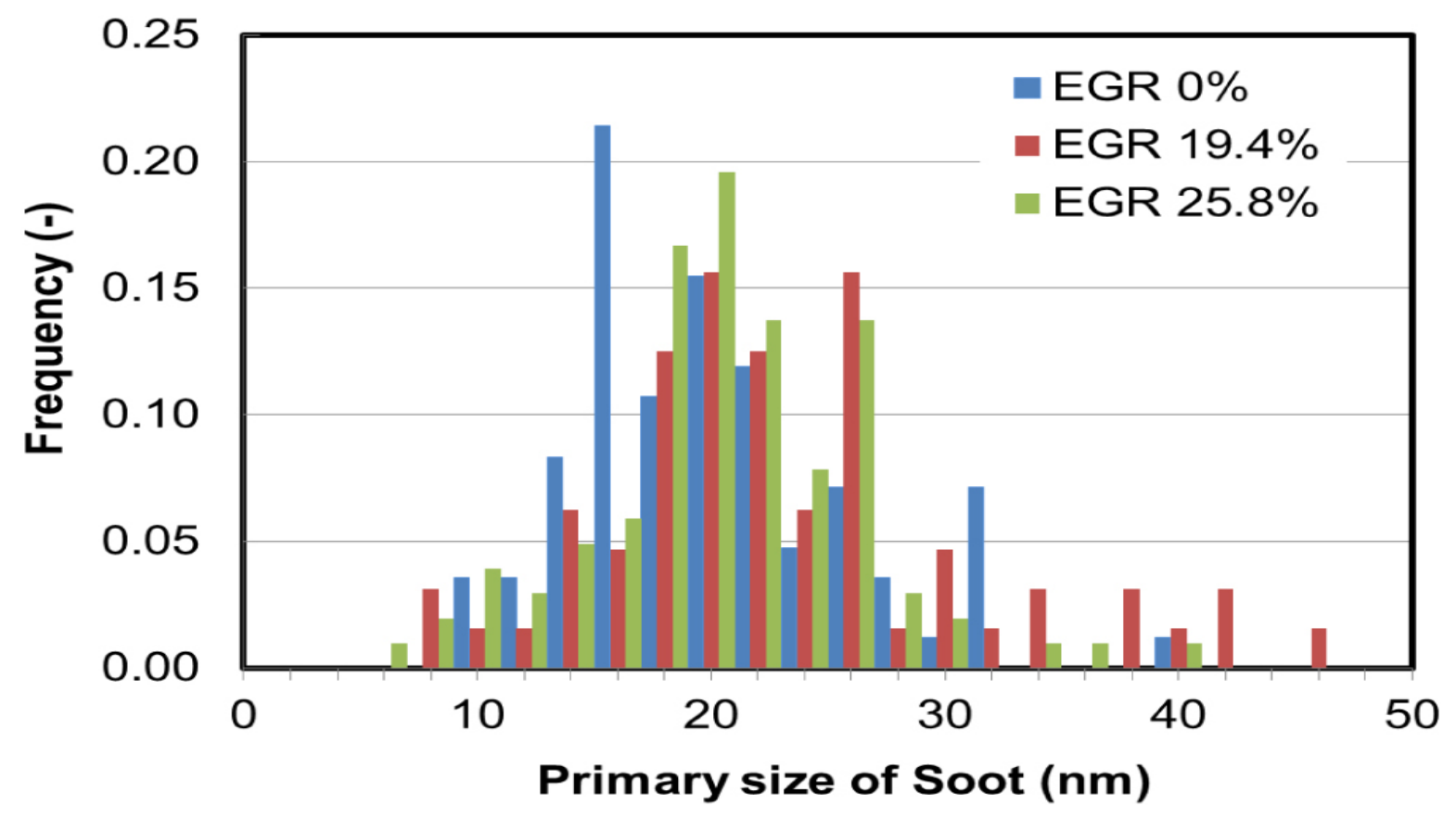

Figure D.2: Primary Particle Size Distribution at Different EGR Rates. [12]

Lapuerta et al. [13] used a 2.2 L Nissan YD22 engine to produce PM. His studies found the primary particle diameter to be $25 \mathrm{~nm}$. His investigations also showed that decreasing the air to fuel ratio as well as engine speed have a significant impact on the primary particle diameter. The primary 
particle diameter was seen to increase with decrease in both these parameters and a variation range of $32 \%$ with AFR and $36 \%$ with Engine speed was observed.

\section{D.2 Effect of Decreased Fuel Rail Pressure on Particulate Morphology}

This section discusses the results obtained from the study of the effect of decreased fuel rail pressure on primary particle diameter from the study conducted at MTU.

Morphology analysis of diesel soot agglomerates generally comprises studying the primary particle diameter, the fractal dimension of the agglomerates and the particle size distribution of the exhaust gases. The analysis depicts the ability of the diesel soot agglomerate to adsorb the unburned hydrocarbons on their surface. This absorption is directly related to the oxidation characteristics and reactivity of the soot [10]. Diesel soot fundamentally comprises primary particles which are composed of elemental carbon [11]. The knowledge of the diameter of these primary particles is of importance since it varies the surface area which then affects the oxidative reactivity as more (or less) adsorption of hydrocarbons may occur which promotes (or demotes) oxidation rate [10]. The primary particles have a very complex geometry but can be assumed to resemble spheres. A large amount of useful information can be found from the knowledge of primary particle diameter which is discussed in reference [13].

In this study, three PM samples each were collected at three different fuel rail pressures of 750 (50\% reduced), 1050(30\% reduced) and 1500 bar (nominal). SEM imaging was used to take multiple images of the samples at different locations on the filter paper for each sample to attain high accuracy. The images were taken at different zoom values such as 100x, 150x and 200x. The 200x images were used in this study to measure the primary particle diameter. The primary particle diameter was then determined by measuring individual particles using image processing software and then averaging these measurements of 20 randomly selected particles for each sample. The results from the study are presented in Table D.1. Figure D.3, D.4 and D.5 show the SEM images at different fuel rail injection pressure at 200x zoom. Table D. 2 presents the diameter of the 20 randomly sampled particles from different images of the same sample at different locations on the filter paper. The data are presented at different fuel rail injection pressures. 


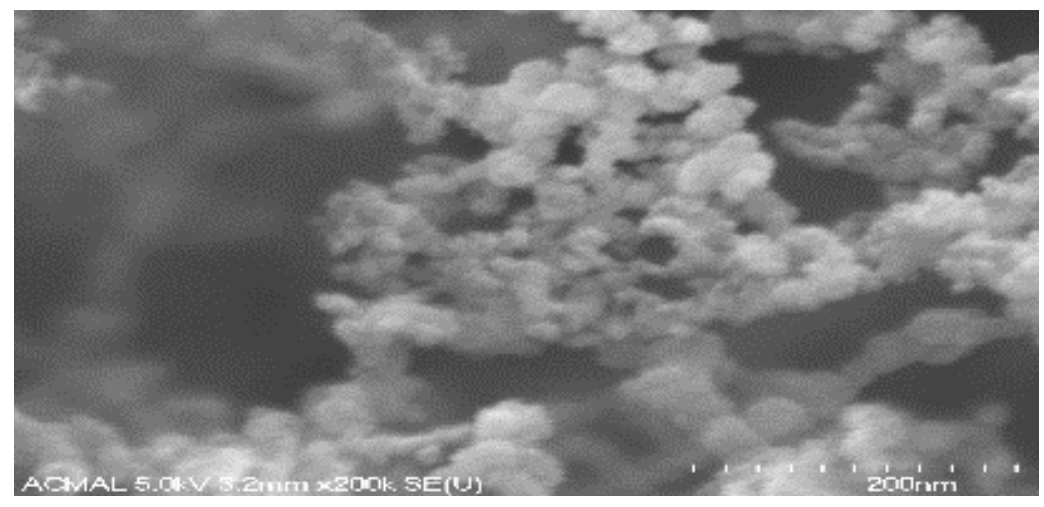

Figure D.3. SEM image of Primary Particle agglomerate at 750 bar fuel rail Injection pressure

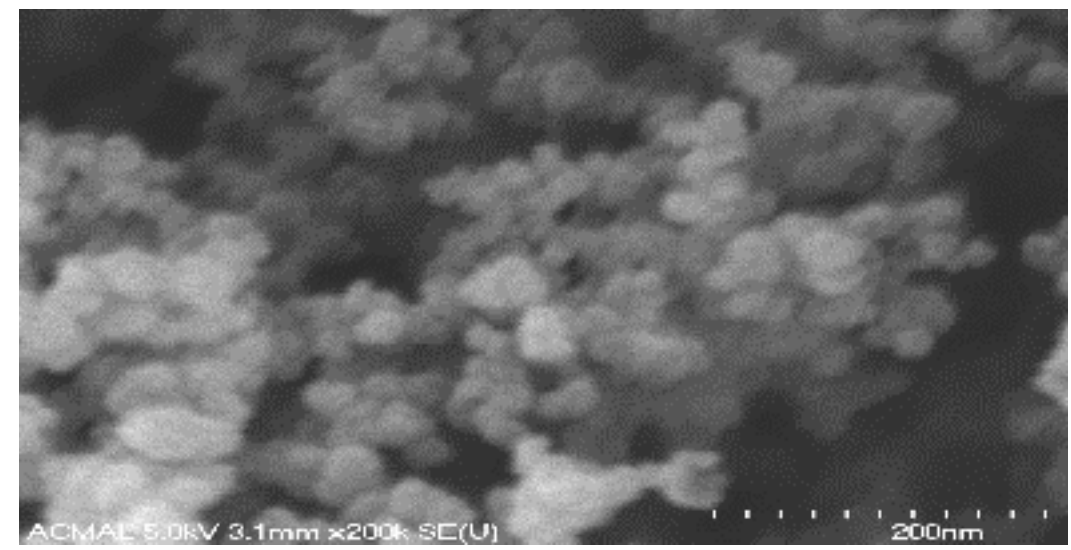

Figure D.4. SEM image of Primary Particle agglomerate at 1050 bar fuel rail Injection pressure

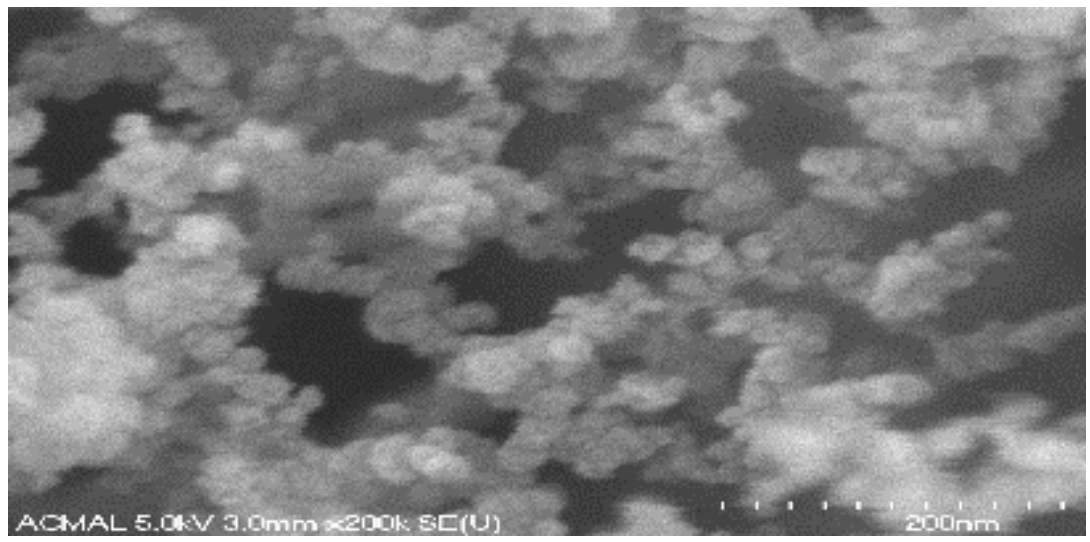

Figure D.5. SEM image of Primary Particle agglomerate at 1500 bar fuel rail Injection pressure 
The results for the primary particle diameter are shown in Figure D.6. It can be seen that the primary particle diameter for different rail pressures is determined to be is in the range of 15 and $46 \mathrm{~nm}$ with average values of 28 to $30 \mathrm{~nm}$. The data for the measurements for primary particle diameter are presented in Table D.1. It is seen that there is no significant effect of fuel injection pressure on the primary particle size. Figure D.7 shows the primary particle diameter determined in reference [10] at different fuel rail pressures and engine load conditions. A comparison shows that values obtained in this study are in close agreement to the ones found by [10] (28-30 nm vs 25-27 nm). The slight difference in values can be accounted for by the difference in engines used to produce PM and difference in engine running conditions such as EGR rate, Speed, load etc.

Table D.1 Primary Particle Diameter at Different Fuel Rail Injection Pressures

\begin{tabular}{|c|c|c|c|}
\hline $\begin{array}{c}\text { Injection } \\
\text { Pressure (bar) }\end{array}$ & $\begin{array}{c}\text { Average } \\
\text { Size(nm) }\end{array}$ & $\begin{array}{c}\text { Maximum } \\
\text { Size (nm) }\end{array}$ & $\begin{array}{c}\text { Minimum } \\
\text { Size (nm) }\end{array}$ \\
\hline 1500 & 28 & 35 & 19 \\
\hline 1050 & 30 & 46 & 20 \\
\hline 750 & 29 & 46 & 15 \\
\hline
\end{tabular}




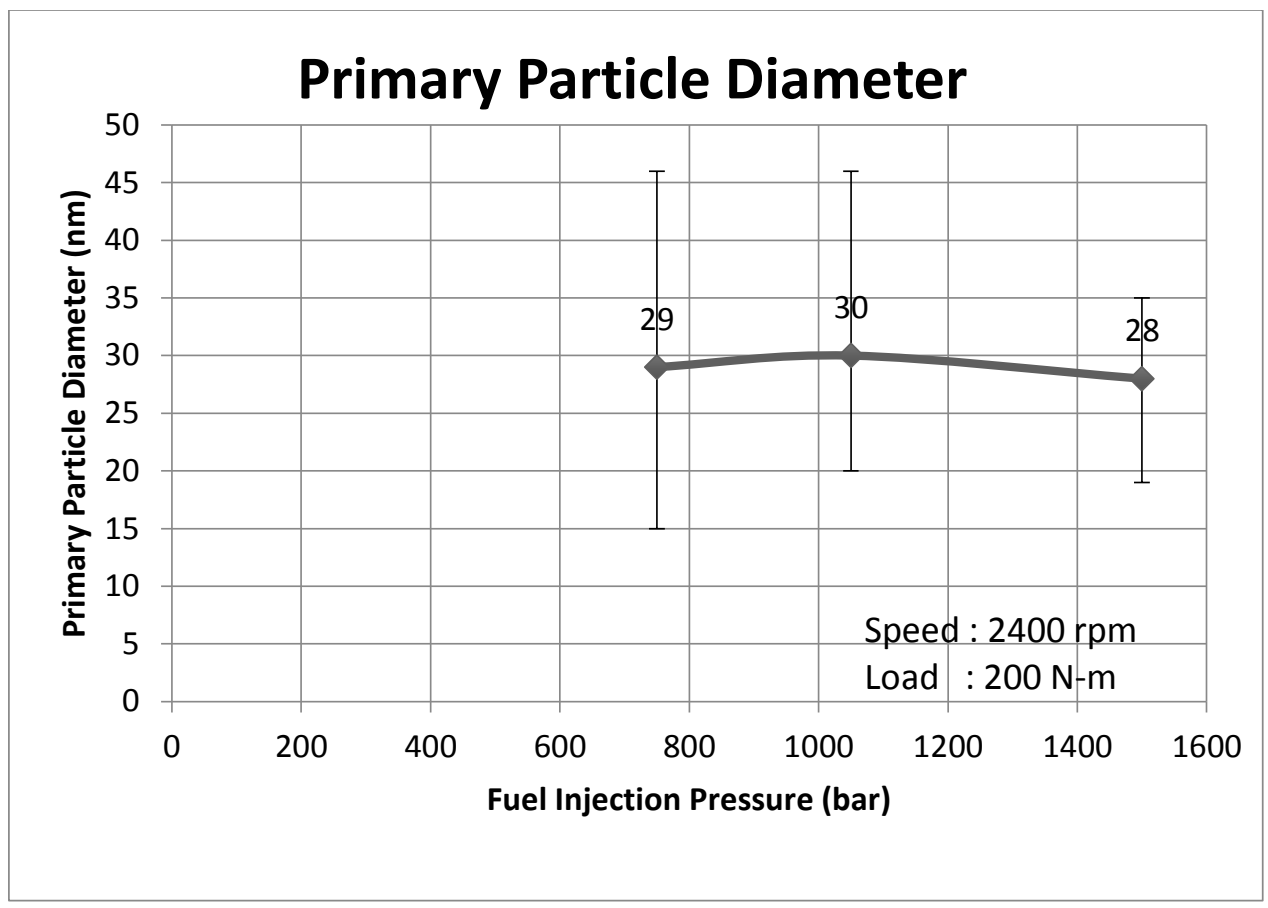

Figure D.6: Primary Particle Diameter at Different Fuel Rail Injection Pressures

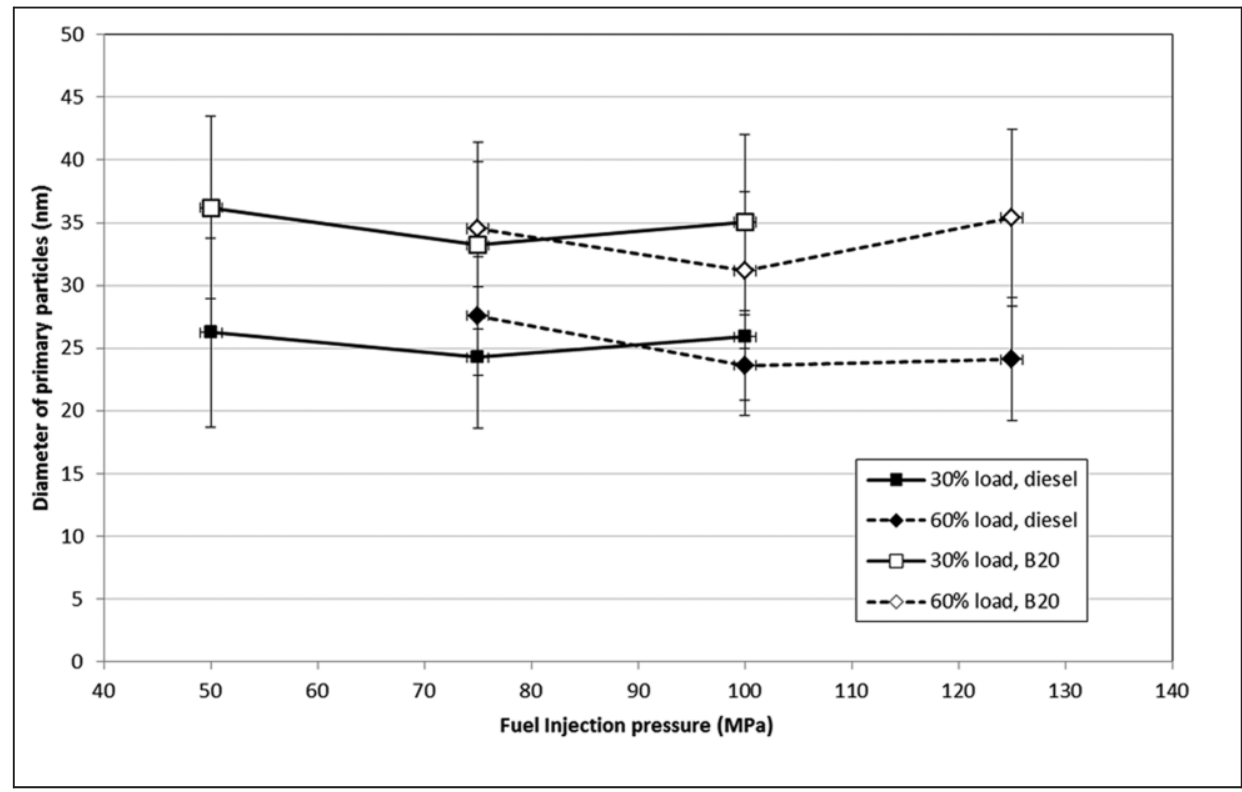

Figure D.7: Primary Particle Diameter for Diesel and B20 soot from

TEM image at different fuel injection pressures [10] 
From Figure D.3 to D.5, it can be seen that bright white spheres are the primary particles. These are disposed in the agglomerates as irregular clusters. These agglomerates have different apparent densities due to the difference in their compactness [13]. The primary particle diameter also appears to be slightly different in these clusters. The bright images are the particles which are closer to the microscope and are focused (which is the top of the cluster) while the relatively dark particles are the ones that are away from the microscope (towards the base of the cluster). The dark portion represents the interstices between the agglomerates. 
Table D.2: Primary Particle Diameter of 20 randomly chosen particles at different fuel injection rail pressure

\begin{tabular}{|c|c|c|c|c|c|c|c|c|c|c|c|c|c|c|c|c|c|c|c|c|}
\hline $\begin{array}{c}\text { Pressure } \\
\text { (Bar) }\end{array}$ & \multicolumn{20}{|c|}{$\begin{array}{l}\text { Size } \\
(\mathrm{nm})\end{array}$} \\
\hline 750 & 31.8 & 43.2 & 25.8 & 38.6 & 31.7 & 28.7 & 31.7 & 17.9 & 27.8 & 33.7 & 30.8 & 18.8 & 25.7 & 3.05 & 28.7 & 33.3 & 42.8 & 28.8 & 20.2 & 14.9 \\
\hline 1050 & 45.5 & 29.7 & 24.8 & 42.6 & 29.9 & 22.8 & 37.5 & 36.7 & 27.0 & 32.7 & 33.7 & 3.47 & 27.8 & 2.33 & 23.8 & 19.8 & 23.8 & 32.6 & 28.8 & 32.2 \\
\hline 1500 & 23.8 & 30.3 & 30.7 & 39.6 & 23.8 & 28.6 & 3.54 & 31.3 & 32.9 & 35.1 & 24.3 & 2.67 & 18.8 & 2.63 & 24.3 & 21.0 & 31.5 & 25.7 & 19.2 & 23.9 \\
\hline
\end{tabular}




\section{D.3 Elemental Carbon (EC) / Organic Carbon (OC) - Literature Review}

Pou Ng et al. [14] studied the EC/OC in diesel exhaust produced using a John Deere 4045 engine. The various methods for measurement used were National Institute of Occupation Safety and Health (NIOSH) method 5040, Aethalometer and Scanning Mobility Particle Sizer (SMPS) which all use different principles. NIOSH 5040 is considered to be the reference method to measure $\mathrm{EC} / \mathrm{OC}$. They conducted experiments at different engine load conditions and found out that both Black Carbon (BC) measured using the Aethalometer and EC concentrations measured using NIOSH method 5040 are high at high engine loads. BC concentration is almost the same as EC concentration suggesting that BC can be approximated as EC. It was also seen that the OC concentration decreased as engine load increased.

Warner et al. [15] compared the gravimetric and Thermal Optical Methods to understand the effect of the CPF on particulate emissions at various engine operating conditions. They found that increasing the engine load increases EC and OC. They also concluded that there is a good agreement between the solids portion(SOL) of the Total Particulate Matter (TPM) and the EC. At low engine loads, Organic Carbon and Soluble Organic Fraction (SOF) of TPM showed good agreement but at high loads, it did not. The study also showed that the EC on average comprised $69 \%$ of Total Carbon (TC $=\mathrm{EC}+\mathrm{OC})$ while the rest was OC.

\section{F.4 Elemental Carbon (EC) -Organic Carbon (OC) Analysis}

The EC-OC analysis is an indicative of the oxidative reactivity of the particulate matter and the rate at which the filter is loaded. As discussed, NIOSH method 5040, which is a Thermal Optical Method, was used to determine the EC-OC fractions of TC from diesel particulate matter. The analysis was performed as Cummins. Figure D.8 shows the results obtained from this analysis. It can be seen from the figure that the $\mathrm{OC}$ content is consistent with the variation in fuel rail injection pressure except for one sample with 1500 rail pressure. EC content on the other hand varies with fuel rail injection pressure. It is seen that EC is much higher for lower rail pressures and decreases with increase in rail pressure. Table D.3 tabulates the results obtained for various samples at different injection pressures. The highlighted data point seems like an outlier. 
Table D.3: EC/OC Analysis at Different Fuel Rail Injection Pressures using NIOSH Method 5040 (Cummins Inc.)

\begin{tabular}{|c|c|c|c|c|c|c|c|c|c|}
\hline $\begin{array}{c}\text { Injection } \\
\text { Pressure } \\
\text { (bar) }\end{array}$ & \multicolumn{3}{|c|}{750} & \multicolumn{3}{c|}{1050} & \multicolumn{3}{c|}{1500} \\
\hline $\begin{array}{c}\text { OC NIOSH } \\
\mathbf{5 0 4 0} \\
\text { ug/Sample }\end{array}$ & 484 & 504 & 493 & 515 & 419 & 429 & 464 & 422 & 596 \\
\hline $\begin{array}{c}\text { EC NIOSH } \\
\mathbf{5 0 4 0} \\
\text { ug/Sample }\end{array}$ & 2588 & 2742 & 2632 & 1410 & 1551 & 1555 & 829 & 858 & 666 \\
\hline $\begin{array}{c}\text { TC NIOSH } \\
\mathbf{5 0 4 0} \\
\text { ug/Sample }\end{array}$ & 3073 & 3246 & 3125 & 1926 & 1970 & 1984 & 1294 & 1280 & 1263 \\
\hline
\end{tabular}




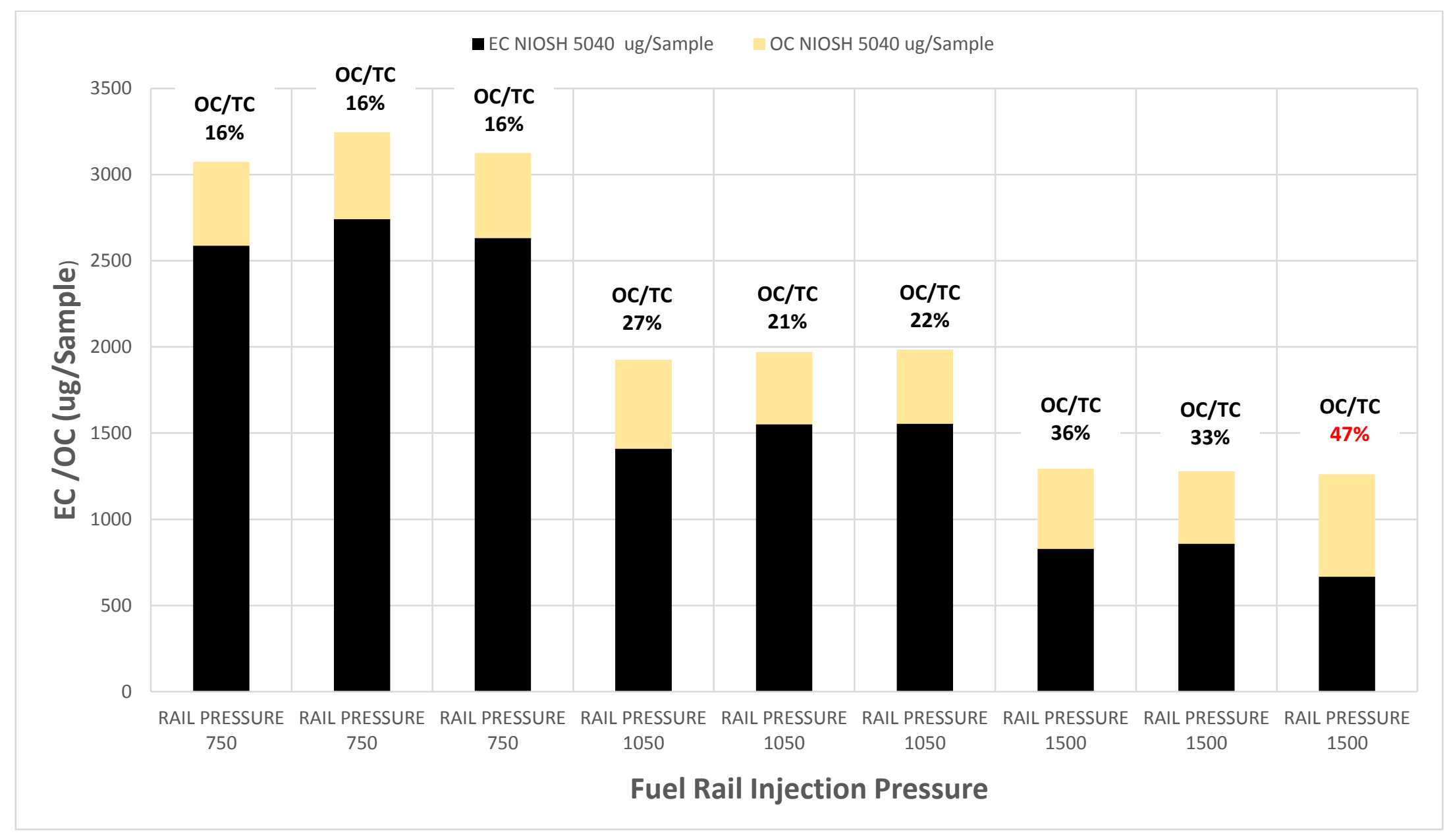

Figure D.8: EC/OC analysis of PM at Different Fuel Rail Injection Pressure (Cummins Inc.) 
Table E.1 SCRF ${ }^{\circledR}$-SCR System Emissions - Test Point A

$\mathrm{SCRF}^{\circledast}$ Standard Space Velocity $: 15.3 \mathrm{k} / \mathrm{hr}$

ANR : 1.10

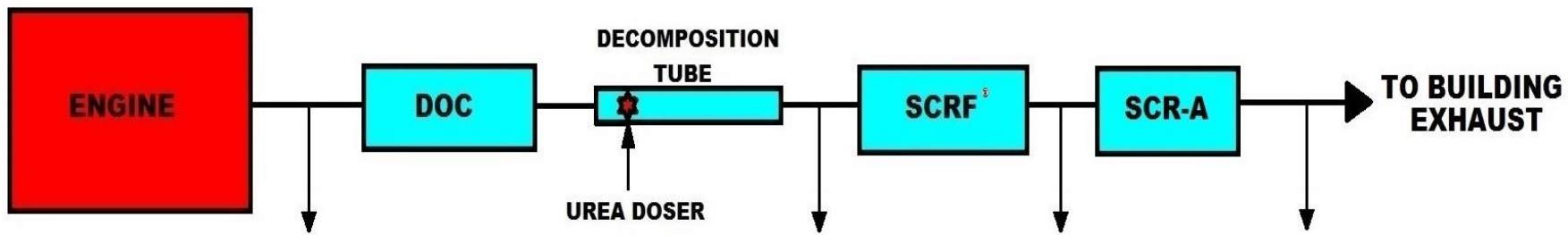

Parameter

$\begin{array}{lcccc} & \text { UDOC } & \text { USCRF }^{\circledR} & \text { DSCRF }^{\circledR} & \text { DSCR }^{\circledR} \\ \text { Temperature }\left({ }^{\circ} \mathbf{C}\right) & 277 & 267 & 266 & 266 \\ \text { NO }(\mathbf{p p m}) & 453 & 270 & 1(18)^{\#} & ---- \\ \text { NO2 }(\mathbf{p p m}) & 21 & 215 & 1 & ---- \\ \text { NOx }(\mathbf{p p m}) & 474 & 485 & 2(18)^{\#} & 1(24)^{\#} \\ \text { NH3 }(\mathbf{p p m}) & ---- & 534 & 30(1)^{\#} & 28(1)^{\#} \\ \text { NO2/NOx } & ---- & 0.44 & ---- & --- \\ \text { NOx } & ---- & --- & 100 & 100(95)^{\#}\end{array}$

\# : The number $2(18)$ indicates the average $\mathrm{NO}_{x}$ concentrations at the beginning and the end of the PO stage at the outlet of the $\mathrm{SCRF}^{\circledR}$. Similarly, $30(1)$ indicates the average $\mathrm{NH}_{3}$ concentrations at the beginning and the end of the PO stage at the outlet of the $\mathrm{SCRF}^{\circledR}$.

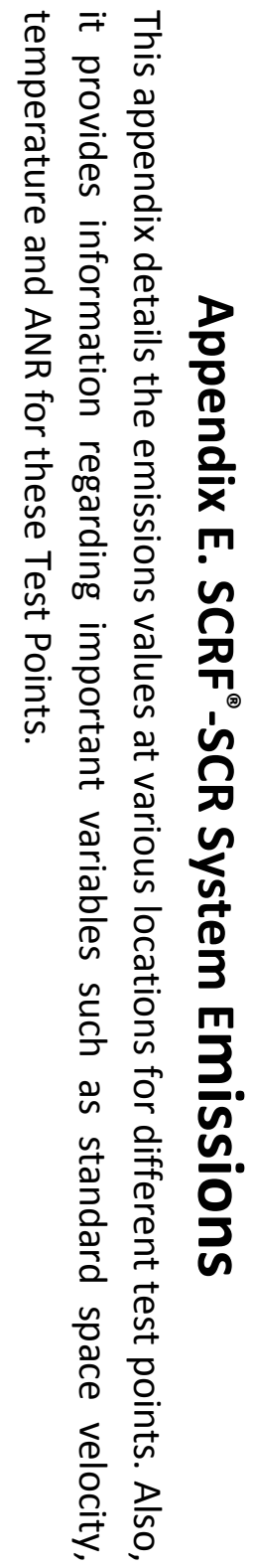


Table E.2 SCRF ${ }^{\circledR}$-SCR System Emissions - Test Point B

SCRF $^{\circledR}$ Space Velocity : $10.1 \mathrm{k} / \mathrm{hr}$

ANR : 1.10

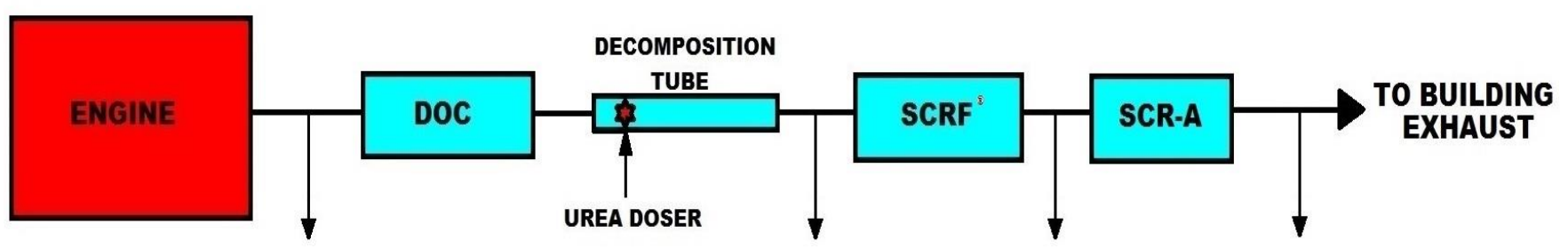

Parameter

Temperature $\left({ }^{\circ} \mathrm{C}\right)$

NO (ppm)

$\mathrm{NO}_{2}(\mathbf{p p m})$

NO $_{\mathbf{x}}(\mathbf{p p m})$

$\mathrm{NH}_{3}$ (ppm)

$\mathrm{NO}_{2} / \mathrm{NO}_{\mathrm{x}}$

NO ${ }_{x}$ Reduction (\%)

UDOC
279
1559
24
1583
----
----
----

USCRF $^{\circledR}$

255

822

758

1580

1742

0.48

$----$
DSCRF

268

6

0

6

10

$----$

100
DSCR

267

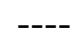

9

4

$---$

99 


\section{Table E.3 SCRF ${ }^{\circledR}$-SCR System Emissions - Test Point C}

\section{SCRF ${ }^{\circledR}$ Space Velocity : $18.8 \mathrm{k} / \mathrm{hr}$}

ANR : 1.02

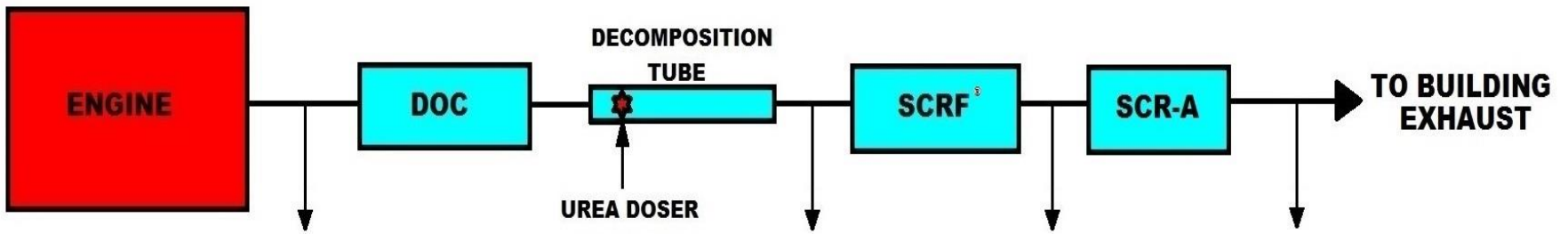

\begin{tabular}{|c|c|c|c|c|}
\hline Parameter & UDOC & $\mathbf{U S C R F}^{\circledR}$ & DSCRF $^{\circledR}$ & DSCR \\
\hline Temperature $\left({ }^{\circ} \mathbf{C}\right)$ & 355 & 344 & 344 & 343 \\
\hline NO (ppm) & 627 & 361 & 4 & ---- \\
\hline $\mathrm{NO}_{2}(\mathrm{ppm})$ & 5 & 290 & 0 & ---- \\
\hline NOx $(p p m)$ & 632 & 651 & 4 & $1(24)^{\#}$ \\
\hline $\mathrm{NH}_{3}(\mathrm{ppm})$ & --- & 667 & 17 & $28(1)^{\#}$ \\
\hline $\mathrm{NO}_{2} / \mathrm{NO}_{\mathbf{x}}$ & ---- & 0.44 & ---- & ---- \\
\hline NO Reduction (\%) & ---- & ---- & 99 & $100(97)^{\#}$ \\
\hline
\end{tabular}

\# : The number $1(24)$ indicates the average $\mathrm{NO}_{\mathrm{x}}$ concentrations at the beginning and the end of the PO stage at the outlet of the SCRF ${ }^{\circledR}$. Similarly, 28(1) indicates the average $\mathrm{NH}_{3}$ concentrations at the beginning and the end of the PO stage at the outlet of the SCRF ${ }^{\circledR}$. 


\section{Table E.4 SCRF ${ }^{\circledR}$-SCR System Emissions - Test Point D}

SCRF $^{\circledR}$ Space Velocity : $33.9 \mathrm{k} / \mathrm{hr}$

ANR : 1.06

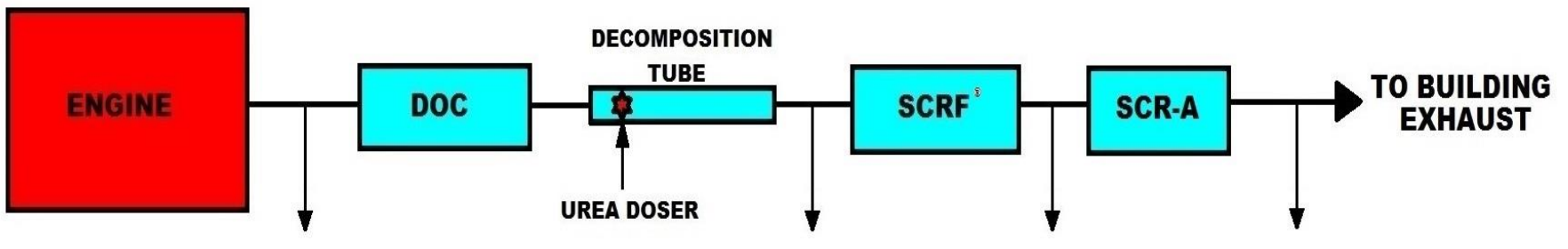

Parameter UDOC

Temperature $\left({ }^{\circ} \mathbf{C}\right) \quad 377$

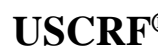

DSCRF $^{\circledR}$

DSCR

NO (ppm)

414

369

371

370

$\mathrm{NO}_{2}(\mathbf{p p m})$

$$
7
$$

265

161

$\mathrm{NO}_{\mathbf{x}}(\mathbf{p p m})$

421

426

3

0

$\mathrm{NH}_{3}$ (ppm)

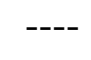

454

3

3
41

$\mathrm{NO}_{2} / \mathrm{NO}_{\mathbf{x}}$

$---$

0.38

----

NOx Reduction (\%)

$---$

99

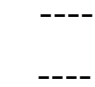




\section{Table E.5 SCRF ${ }^{\circledR}$-SCR System Emissions - Test Point E}

SCRF $^{\circledR}$ Space Velocity : $19.3 \mathrm{k} / \mathrm{hr}$

ANR : 1.03

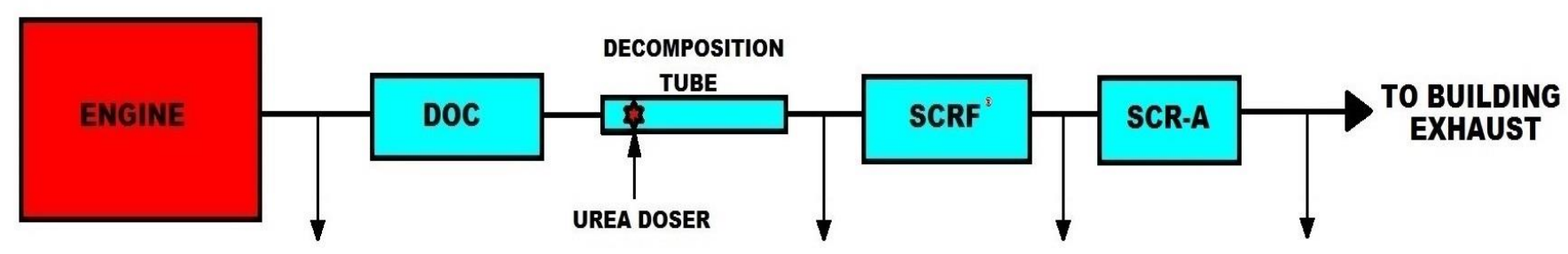

\begin{tabular}{|c|c|c|c|c|}
\hline Parameter & UDOC & $\mathbf{U S C R F}^{\circledR}$ & DSCRF $^{\circledR}$ & DSCR \\
\hline Temperature $\left({ }^{\circ} \mathbf{C}\right)$ & 369 & 351 & 358 & 357 \\
\hline NO (ppm) & 1543 & 1001 & 8 & ---- \\
\hline $\mathrm{NO}_{2}(\mathbf{p p m})$ & 14 & 584 & 1 & ---- \\
\hline NOx $_{x}(\mathbf{p p m})$ & 1557 & 1584 & 9 & $6(25)^{\#}$ \\
\hline $\mathrm{NH}_{3}(\mathbf{p p m})$ & ---- & 1627 & 29 & $32(9) \#$ \\
\hline $\mathrm{NO}_{2} / \mathrm{NO}_{\mathbf{x}}$ & ---- & 0.37 & ---- & ---- \\
\hline NO $_{x}$ Reduction (\%) & ---- & ---- & 99 & $100(98)^{\#}$ \\
\hline
\end{tabular}

\# : The number $6(25)$ indicates the average $\mathrm{NO}_{\mathrm{x}}$ concentrations at the beginning and the end of the PO stage at the outlet of the $\mathrm{SCRF}^{\circledR}$. Similarly, 32(9) indicates the average $\mathrm{NH}_{3}$ concentrations at the beginning and the end of the PO stage at the outlet of the SCRF ${ }^{\circledR}$. 
Table E.6 SCRF ${ }^{\circledR}$-SCR System Emissions - Test Point 1

SCRF $^{\circledR}$ Space Velocity : $14.2 \mathrm{k} / \mathrm{hr}$

ANR : 1.06

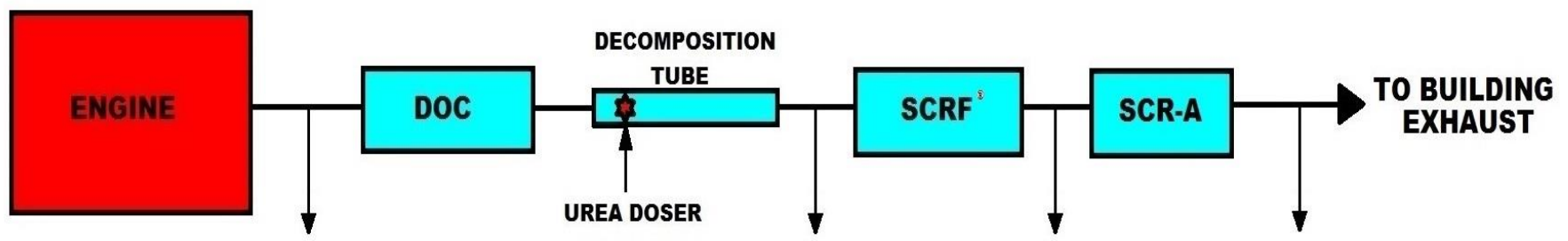

$\begin{array}{lc}\text { Parameter } & \text { UDOC } \\ \text { Temperature }\left({ }^{\circ} \mathrm{C}\right) & 215 \\ \mathrm{NO}(\mathbf{p p m}) & 568 \\ \mathrm{NO}_{2}(\mathbf{p p m}) & 46 \\ \mathrm{NO}_{\mathbf{x}}(\mathbf{p p m}) & 614 \\ \mathrm{NH}_{3}(\mathbf{p p m}) & ---- \\ \mathrm{NO}_{2} / \mathrm{NO} & --- \\ \mathrm{NO}_{\mathbf{x}} \text { Reduction }(\%) & ----\end{array}$

$\begin{array}{ccc}\text { USCRF }^{\circledR} & \text { DSCRF }^{\circledR} & \text { DSCR } \\ 206 & 211 & 212 \\ 443 & 7 & ---- \\ 182 & 0 & ---- \\ 625 & 7 & 8 \\ 664 & 1 & 2 \\ 0.29 & ---- & ---- \\ ---- & 99 & 99\end{array}$




\section{Appendix F. Comaprison of Passive Oxidation with Urea Injection and $\mathrm{NO}_{x}$ Conversion Efficiencies in Configurations 1 and 2 to Configuration 3.}

This appendix presents the comparison of Passive Oxidation with urea tests in Configuration 1 and Configuration 3. It also compares the results of the 3 configurations for $\mathrm{NO}_{\mathrm{x}}$ conversion efficiencies. Pressure drop plots are shown for the two configurations for the PO stage. The plot for Test Point B has not been shown because this test condition had the same ANR as that in Configuration 1 and data for it were obtained from the test performed by reference [2]. Figures F1 to F4 represent the comparison of pressure drops across the SCRF ${ }^{\circledR}$ during the $\mathrm{PO}$ stage.

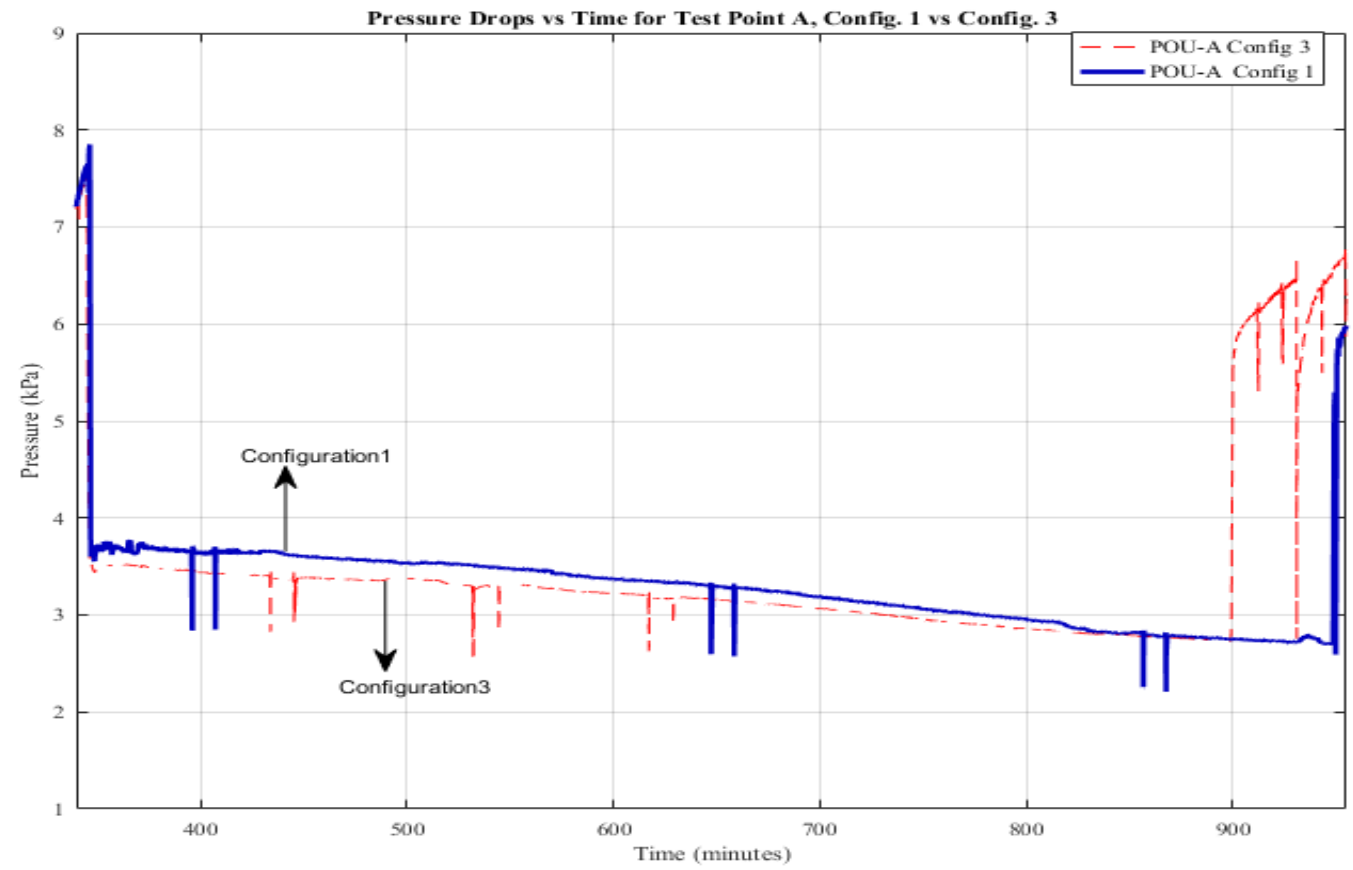

Figure F.1: Pressure drop comparison between Config. 1 and Config. 3 - Test Point A 


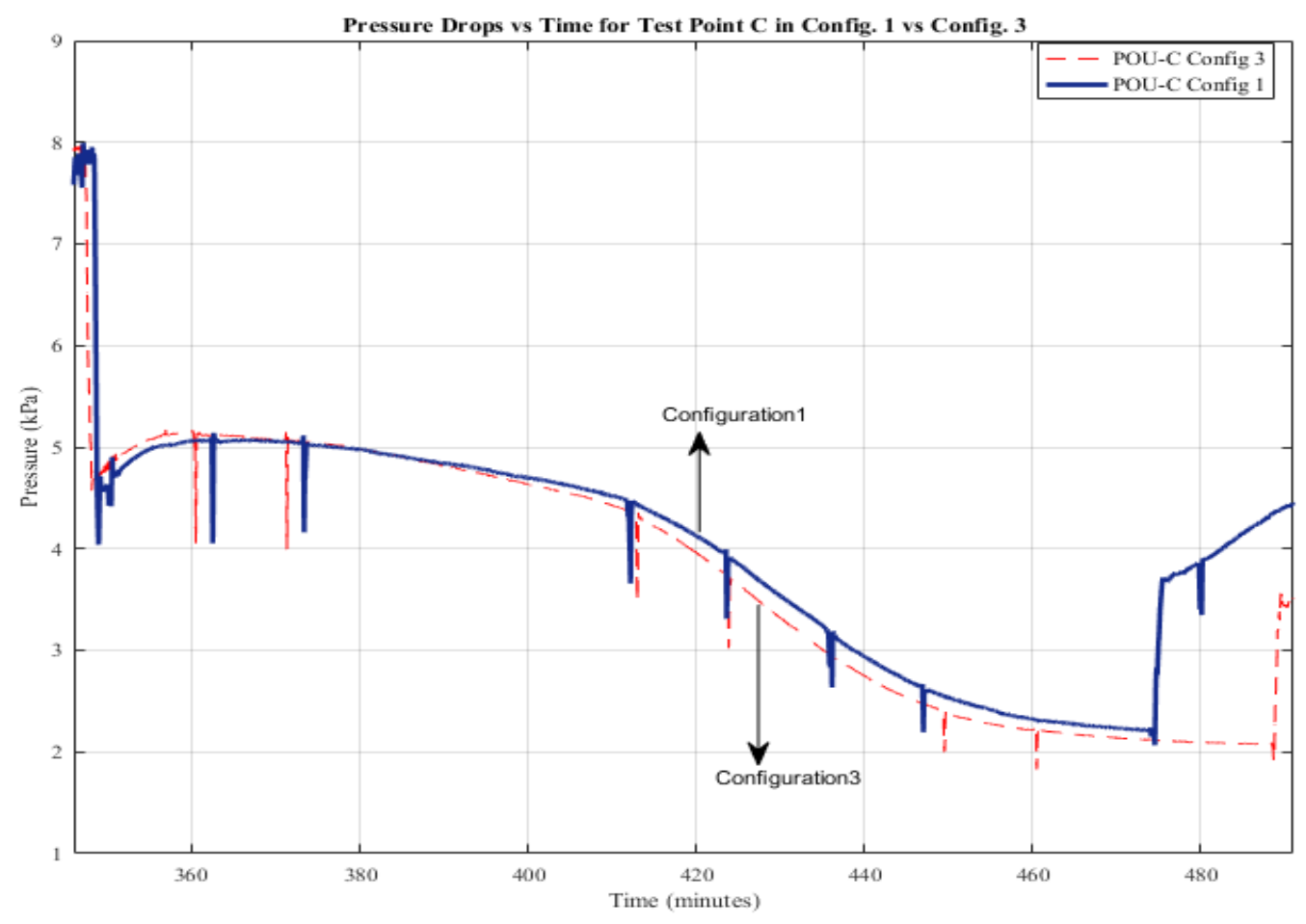

Figure F.2: Pressure drop comparison between Config. 1 and Config. 3 - Test Point C

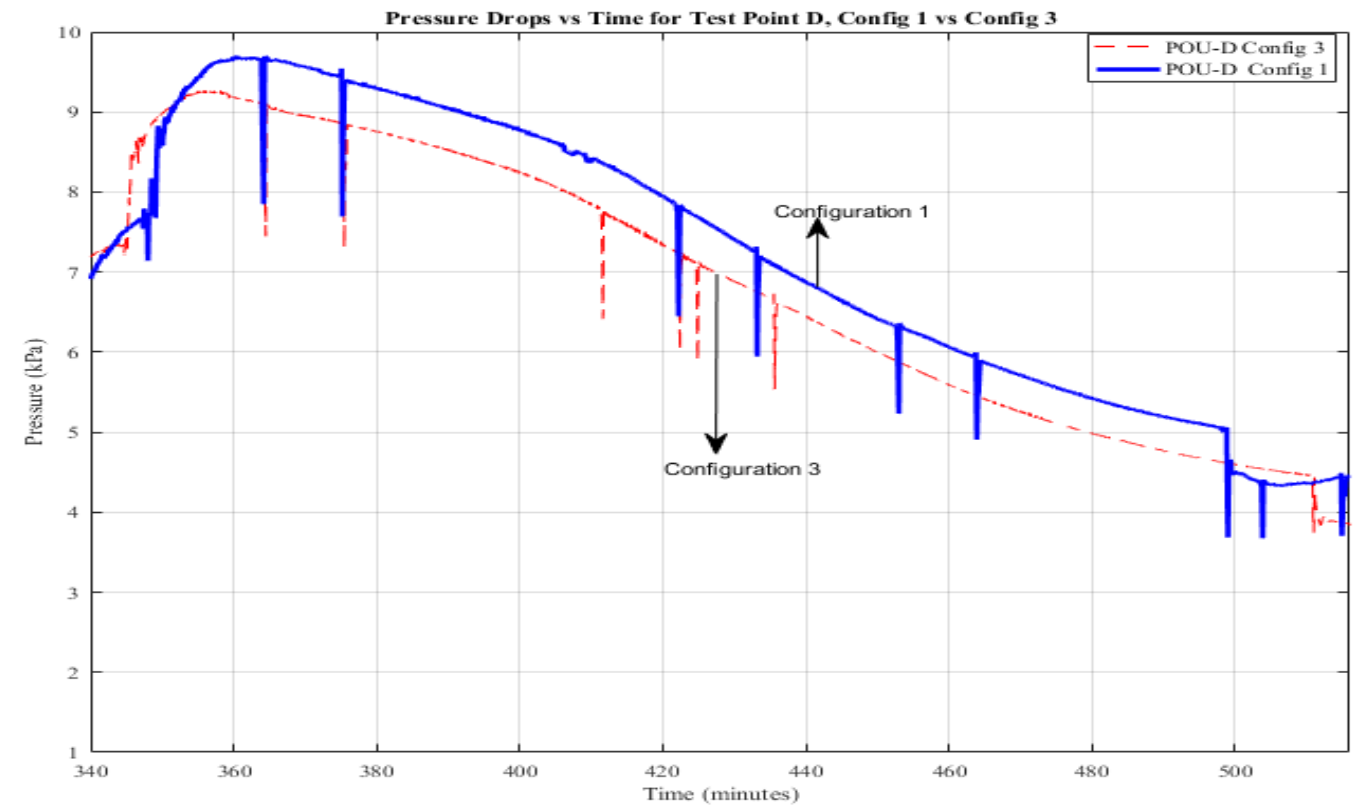

Figure F.3: Pressure drop comparison between Config. 1 and Config. 3 - Test Point D 


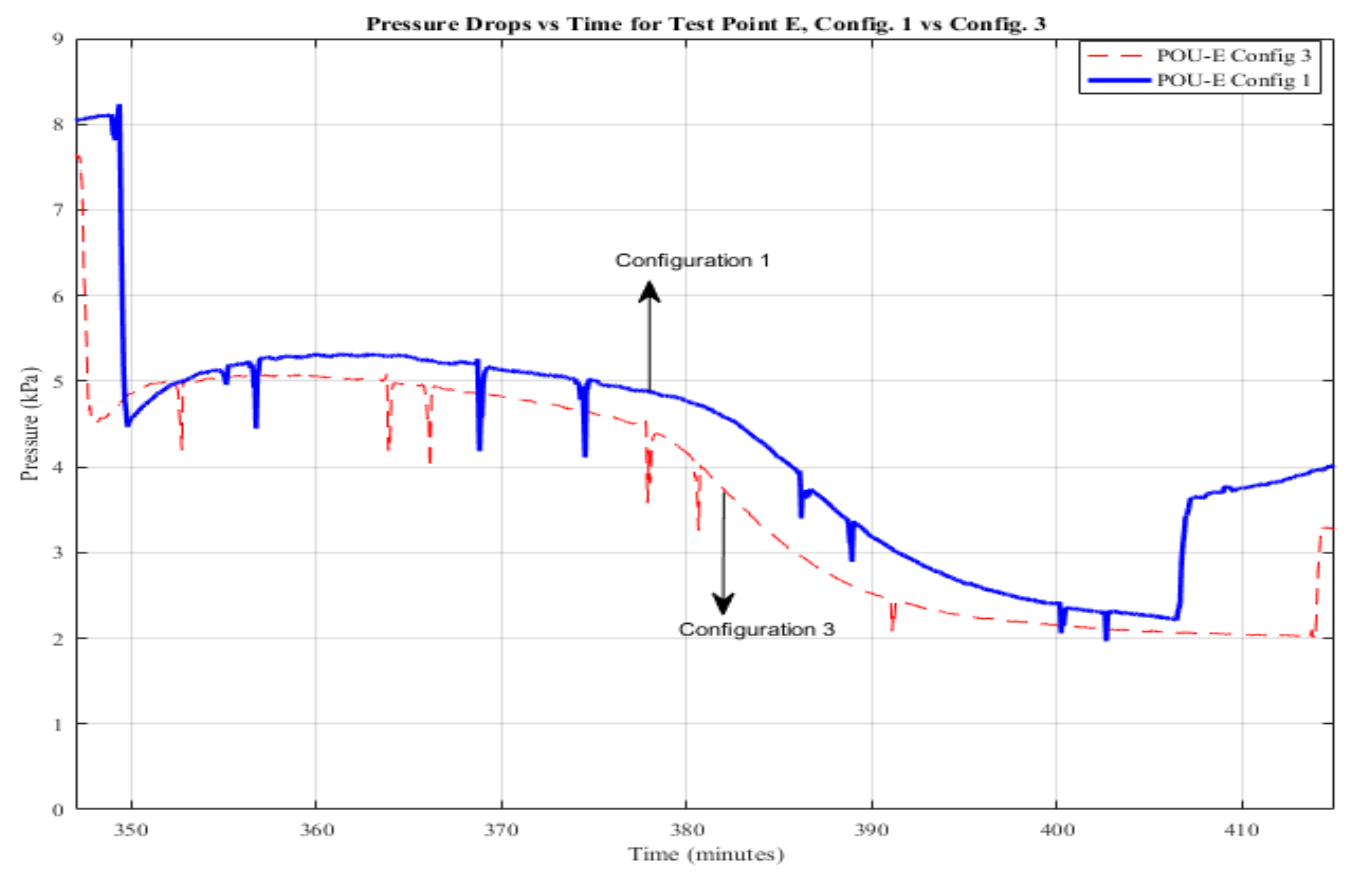

Figure F.4: Pressure drop comparison between Config. 1 and Config. 3 - Test Point E

Table F.1 represents a comparison of the $\mathrm{NO}_{2}$ assisted $\mathrm{PM}$ oxidation reaction rate and $\mathrm{NO}_{\mathrm{x}}$ conversion efficiencies between Configurations 1 and 3. It can be seen from this table that under the same test conditions for speed and load, the reaction rates do not vary significantly (except for Test Point A), which is also evident from Figure 4.2, in chapter 4 . This is expected as the downstream SCR in Configuration 3 acts as a passive device which can store any excess $\mathrm{NH}_{3}$ slipping out of the $\mathrm{SCRF}^{\circledR}$ by adsorption on its surface [1] and use this stored $\mathrm{NH}_{3}$ to reduce any $\mathrm{NO}_{\mathrm{x}}$ that cannot be converted in the $\mathrm{SCRF}^{\circledR}$ to $\mathrm{N}_{2}$ and $\mathrm{H}_{2} \mathrm{O} . \mathrm{NO}_{\mathrm{x}}$ conversion efficiencies are also compared. The $\mathrm{NO}_{x}$ conversion effciencies across the $\mathrm{SCRF}^{\circledR}$ and the system as a whole (SCRF ${ }^{\circledR}$ plus SCR) are found to be much higher than those observed in Configuration 1.

Table F. 2 shows the $\mathrm{NO}_{\mathrm{x}}$ conversion efficiency across the $\mathrm{SCRF}^{\circledR}$ in comparison to that obtained in Configurations 1 and 2 for similar test conditions. It is observed that the $\mathrm{NO}_{\mathrm{x}}$ conversion efficiencies obtained in Configuration 3 across the $\mathrm{SCRF}^{\circledR}$ only are much higher than those obtained in earlier Configurations and approach 99 to $100 \%$. This eliminates the need of a downstream SCR, if such high efficiencies are obtained through the use of a single SCRF ${ }^{\circledR}$ only. In 
Configuration 3, one of the objectives is to find an optimum value of ANR experimentally such that $\mathrm{NO}_{x}$ conversion effeciency maximizes and $\mathrm{NH}_{3}$ slip minimizes simultaneously across the $\mathrm{SCRF}^{\circledR}$ and $\mathrm{SCR}$ system as a whole. Dosing of this optimum ANR caused the $\mathrm{SCRF}^{\circledR} \mathrm{NO}_{\mathrm{x}}$ conversion efficieny to be $99-100 \%$ with a $\mathrm{NH}_{3}$ slip of $<50$ PPM for different test conditions and the SCR did not convert any considerable $\mathrm{NO}_{\mathrm{x}}$. One hypothesis for observing such high efficiencies could be the possible use of an optimum value of ANR such that when this value of ANR is dosed there is a maximum $\mathrm{NO}_{x}$ conversion efficiency of $99-100 \%$ with a $\mathrm{NH}_{3}$ slip of < 50 PPM. Any value of ANR greater than this optimum value produces a $\mathrm{NO}_{x}$ conversion efficiency of $99-100 \%$ but a higher $\mathrm{NH}_{3}$ slip. Any value of ANR less than this optimum value produces a $\mathrm{NO}_{x}$ conversion efficiency of less than $99 \%$ (90-95\% for tests in Config 1) and a lower $\mathrm{NH}_{3}$ slip (<20 PPM for tests in Config 1). This is shown in Figure F.5 for Test Point 1. The procedure to compute this optimum ANR is discussed in appendix G. Also plots similar to Figure F.5 can be found in reference [3] for test conditions that were run during Configuration 2.

Another hypothesis of observing such high $\mathrm{NO}_{\mathrm{x}}$ conversion values may be due to error in downstream data meaurements. As can be observed from Table F.2 that the measured $\mathrm{NO}_{\mathrm{x}}$ concentration out of the $\mathrm{SCRF}^{\circledR}$ in Configuration 3 is $<10$ ppm while it is observed to be between 26 and 86 ppm during Configuration 1 tests. Since we observe that for a very small change in the value of $A N R$, there is a huge rise in $\mathrm{NO}_{x}$ conversion efficiency, as shown in Figures F.6 and F.7, it can be hypothised that there may be an error in the measurements downstream of the SCRF ${ }^{\circledR}$. Since the outlet $\mathrm{NO}_{\mathrm{x}}$ values observed due to this error are too low, this causes a high value of $\mathrm{NO}_{\mathrm{x}}$ conversion efficiencies when the ANR is increased slightly. The measurement inaccuracies may have occurred because of the filter getting choked in the heated filter. This may have caused the Mass Spectrometer to suck the room air from any minute leaks in the joints, since it did not get sample due to the filter getting choked. The air in entering this system may have then caused measurement inaccuracies due to dilution of the little sample that was entering the mass spectrometer.

Table F. 3 shows the $\mathrm{NO}$ and $\mathrm{NO}_{2}$ concentrations entering and exiting the $\mathrm{DOC}$ in all three configurations. Table F.4 shows the NO conversion efficiencies across the DOC. A comparison shows that the NO conversion efficiencies across the DOC have slightly decreased from 
Configuration 1 to Configuration 3. The probable reason of this is the aging of the DOC and thus the slight deterioation in its performance over time. 
Table F.1. Comparison for Configuration 1 and 3 for PM Passive Oxidation with Urea Injection

\begin{tabular}{|c|c|c|c|c|c|c|c|c|c|c|c|c|c|c|c|c|c|c|c|c|}
\hline & \multicolumn{9}{|c|}{ Configuration 1} & \multicolumn{11}{|c|}{ Configuration 3} \\
\hline $\begin{array}{l}\text { Test } \\
\text { Point }\end{array}$ & ANR & $\begin{array}{l}\text { Dura } \\
\text {-tion }\end{array}$ & $\begin{array}{l}\text { PM } \\
\text { Oxid } \\
\text {-ized }\end{array}$ & $\begin{array}{l}\text { Avg. } \\
\text { Subs. } \\
\text { Temp }\end{array}$ & $\begin{array}{l}\text { Expt } \\
\text { RRo }\end{array}$ & $\begin{array}{l}\text { k= } \\
\mathrm{NO}_{2} / \mathrm{RR} \\
0\end{array}$ & $\begin{array}{l}\text { SCRF® } \\
\text { NOx } \\
\text { Conv. } \\
\text { Eff. }\end{array}$ & $\begin{array}{l}\mathrm{NH}_{3} \\
\text { Slip }\end{array}$ & $\begin{array}{l}\mathbf{N}_{2} \\
\text { Bal. }\end{array}$ & ANR & $\begin{array}{l}\text { Dura } \\
\text {-tion }\end{array}$ & $\begin{array}{l}\text { PM } \\
\text { Oxid } \\
\text {-ized }\end{array}$ & $\begin{array}{l}\text { Avg. } \\
\text { Subs. } \\
\text { Temp }\end{array}$ & $\begin{array}{l}\text { Expt } \\
\text { RRo }\end{array}$ & $\begin{array}{l}\mathrm{k}= \\
\mathrm{NO}_{2} / \mathrm{RR} \\
\mathrm{O}\end{array}$ & $\begin{array}{l}\text { SCRF® } \\
\text { NOx } \\
\text { Conv. } \\
\text { Eff. }\end{array}$ & $\begin{array}{l}\text { Sys. } \\
\text { NOx } \\
\text { Conv. } \\
\text { Eff. }\end{array}$ & $\begin{array}{l}\text { SCRF® } \\
\text { NH }_{3} \\
\text { Slip }\end{array}$ & $\begin{array}{l}\text { Sys. } \\
\mathbf{N H}_{3} \\
\text { Slip }\end{array}$ & $\begin{array}{l}\text { Sys. } \\
\mathbf{N}_{2} \\
\text { Bal. }\end{array}$ \\
\hline - & - & $\min$ & $\%$ & ${ }^{\circ} \mathrm{C}$ & $10^{-4} / \mathrm{s}$ & $\begin{array}{l}10^{6} / \\
\mathrm{ppm} / \mathrm{s}\end{array}$ & $\%$ & ppm & $\%$ & & $\min$ & $\%$ & ${ }^{\circ} \mathrm{C}$ & $10^{-4} / \mathrm{s}$ & $\begin{array}{l}10^{6} / \\
\mathrm{ppm} / \mathrm{s}\end{array}$ & $\%$ & $\%$ & ppm & ppm & $\%$ \\
\hline A & 1.03 & 601 & 11 & 274 & 0.04 & 0.01 & 91 & 12 & 90 & 1.1 & 551 & 14 & 278 & 0.10 & 0.05 & 100 & 100 & 30 & 28 & 92 \\
\hline C & 0.89 & 125 & 36 & 349 & 0.62 & 0.20 & 88 & 1 & 98 & 1.02 & 141 & 38 & 348 & 0.63 & 0.22 & 99 & 100 & 17 & 18 & 99 \\
\hline E & 1.01 & 57 & 39 & 360 & 1.44 & 0.22 & 94 & 5 & 94 & 1.03 & 67 & 37 & 362 & 1.25 & 0.21 & 99 & 100 & 29 & 32 & 98 \\
\hline B & 1.1 & 258 & 16 & 284 & 0.11 & 0.01 & 99 & 6 & 90 & 1.1 & 258 & 15 & 274 & 0.11 & 0.01 & 99 & 99 & 10 & 4 & 91 \\
\hline D & 0.99 & 149 & 45 & 371 & 0.74 & 0.39 & 95 & 17 & 100 & 1.06 & 166 & 43 & 374 & 0.64 & 0.40 & 99 & 100 & 41 & 36 & 94 \\
\hline
\end{tabular}

*: $\mathrm{NO}_{x}$ and $\mathrm{NH}_{3}$ slip values at the outlet of $\mathrm{SCRF}^{\circledR}$ and $\mathrm{SCR}$ are the average values during the beginning of the $\mathrm{PO}$ stage 
Table F.2. Comparison of $\mathrm{NO}_{x}$ Conversion Efficiencies across $\mathrm{SCRF}^{\circledR}$ in Configurations 1, 2 and 3. [2,3]

\begin{tabular}{|c|c|c|c|c|c|c|c|c|c|c|c|c|c|c|c|}
\hline & \multicolumn{5}{|c|}{ Configuration 1} & \multicolumn{5}{|c|}{ Configuration 2} & \multicolumn{5}{|c|}{ Configuration 3} \\
\hline $\begin{array}{l}\text { Test } \\
\text { Point }\end{array}$ & $\begin{array}{c}\mathrm{NO}_{\mathrm{x}} \\
\mathrm{SCRF}^{\circledR} \\
\text { In }\end{array}$ & $\begin{array}{c}\text { NO }_{x} \\
\text { SCRF }^{\circledR} \\
\text { Out }\end{array}$ & ANR & $\begin{array}{c}\mathrm{NO}_{\mathrm{x}} \\
\text { Conv. } \\
\text { Eff. }\end{array}$ & $\begin{array}{l}\mathrm{NH}_{3} \\
\text { Slip }\end{array}$ & $\begin{array}{c}\mathrm{NO}_{\mathrm{x}} \\
\mathrm{SCRF}^{\circledR} \\
\text { In }\end{array}$ & $\begin{array}{c}\text { NO }_{x} \\
\text { SCRF }^{\circledR} \\
\text { Out }\end{array}$ & ANR & $\begin{array}{c}\mathrm{NO}_{\mathrm{x}} \\
\text { Conv. } \\
\text { Eff. }\end{array}$ & $\begin{array}{l}\mathrm{NH}_{3} \\
\text { Slip }\end{array}$ & $\begin{array}{c}\mathrm{NO}_{\mathrm{x}} \\
\mathrm{SCRF}^{\circledR} \\
\text { In }\end{array}$ & $\begin{array}{c}\mathrm{NO}_{\mathrm{x}} \\
\text { SCRF }^{\circledR} \\
\text { Out }\end{array}$ & ANR & $\begin{array}{c}\mathrm{NO}_{\mathrm{x}} \\
\text { Conv. } \\
\text { Eff }\end{array}$ & $\begin{array}{l}\mathrm{NH}_{3} \\
\text { Slip }\end{array}$ \\
\hline & PPM & PPM & & $\%$ & PPM & PPM & PPM & & $\%$ & PPM & PPM & PPM & & $\%$ & PPM \\
\hline A & 590 & 55 & 1.03 & 91 & 12 & - & - & - & - & - & 485 & 2 & 1.10 & 100 & 30 \\
\hline $\mathbf{C}$ & 689 & 86 & 0.89 & 88 & 1 & - & - & - & - & - & 651 & 4 & 1.02 & 99 & 17 \\
\hline$E$ & 1451 & 80 & 1.01 & 94 & 5 & - & - & - & - & - & 1584 & 9 & 1.03 & 99 & 29 \\
\hline B & 1580 & 10 & 1.10 & 99 & 6 & - & - & - & - & - & 1580 & 6 & 1.10 & 99 & 10 \\
\hline D & 497 & 26 & 0.99 & 95 & 17 & - & - & - & - & - & 426 & 3 & 1.06 & 99 & 41 \\
\hline 1 & - & - & - & - & - & 606 & 49 & 1.0 & 92 & 3 & 625 & 7 & 1.06 & 99 & 1 \\
\hline
\end{tabular}

*: $\mathrm{NO}_{\mathrm{x}}$ and $\mathrm{NH}_{3}$ slip values at the outlet of $\mathrm{SCRF}^{\oplus}$ and $\mathrm{SCR}$ are the average values during the beginning of the $\mathrm{PO}$ stage

Table F.3. Comparison of $\mathrm{NO}$ and $\mathrm{NO}_{2}$ in and Out of DOC in Configurations 1,2 and 3. [2,3]

\begin{tabular}{|c|c|c|c|c|c|c|c|c|c|c|c|c|}
\hline \multirow[b]{2}{*}{$\begin{array}{l}\text { Test } \\
\text { Point }\end{array}$} & \multicolumn{4}{|c|}{ Configuration 1} & \multicolumn{4}{|c|}{ Configuration 2} & \multicolumn{4}{|c|}{ Configuartion 3} \\
\hline & $\begin{array}{l}\text { NO } \\
\text { DOC } \\
\text { in }\end{array}$ & $\begin{array}{c}\mathrm{NO}_{2} \\
\mathrm{DOC} \\
\text { in }\end{array}$ & $\begin{array}{c}\text { NO } \\
\text { DOC } \\
\text { Out }\end{array}$ & $\begin{array}{c}\mathrm{NO}_{2} \\
\mathrm{DOC} \\
\text { Out }\end{array}$ & $\begin{array}{l}\text { NO } \\
\text { DOC } \\
\text { in }\end{array}$ & $\begin{array}{c}\mathrm{NO}_{2} \\
\mathrm{DOC} \\
\text { in }\end{array}$ & $\begin{array}{c}\text { NO } \\
\text { DOC } \\
\text { Out }\end{array}$ & $\begin{array}{c}\mathrm{NO}_{2} \\
\mathrm{DOC} \\
\text { Out }\end{array}$ & $\begin{array}{l}\text { NO } \\
\text { DOC } \\
\text { in }\end{array}$ & $\begin{array}{c}\mathrm{NO}_{2} \\
\mathrm{DOC} \\
\text { in }\end{array}$ & $\begin{array}{c}\text { NO } \\
\text { DOC } \\
\text { Out }\end{array}$ & $\begin{array}{c}\mathrm{NO}_{2} \\
\mathrm{DOC} \\
\text { Out }\end{array}$ \\
\hline & PPM & PPM & PPM & PPM & PPM & PPM & PPM & PPM & PPM & PPM & PPM & PPM \\
\hline A & 546 & 4 & 286 & 304 & - & - & - & - & 453 & 21 & 270 & 215 \\
\hline $\mathrm{C}$ & 700 & 2 & 387 & 301 & - & - & - & - & 627 & 5 & 361 & 290 \\
\hline $\mathbf{E}$ & 1474 & 24 & 798 & 653 & - & - & - & - & 1543 & 14 & 1001 & 584 \\
\hline B & 1559 & 24 & 822 & 758 & - & - & - & - & 1559 & 24 & 822 & 758 \\
\hline D & 447 & 11 & 306 & 191 & - & - & - & - & 414 & 7 & 265 & 161 \\
\hline 1 & - & - & - & - & 581 & 2 & 403 & 203 & 568 & 46 & 443 & 182 \\
\hline
\end{tabular}


Table F.4. Comparison for NO conversion Efficiency across DOC in

Configurations 1, 2 and 3

\begin{tabular}{|c|c|c|c|}
\hline & $\begin{array}{c}\text { Configuration } \\
\mathbf{1}\end{array}$ & $\begin{array}{c}\text { Configuration } \\
\mathbf{2}\end{array}$ & $\begin{array}{c}\text { Configuration } \\
\mathbf{3}\end{array}$ \\
\hline Test Point & $\begin{array}{c}\text { NO Conv. } \\
\text { Across DOC } \\
\text { (\%) }\end{array}$ & $\begin{array}{c}\text { NO Conv. } \\
\text { Across DOC } \\
\text { (\%) }\end{array}$ & $\begin{array}{c}\text { NO Conv. } \\
\text { Across DOC } \\
\text { (\%) }\end{array}$ \\
\hline A & 48 & - & 40 \\
\hline C & 45 & - & 42 \\
\hline E & 46 & - & 35 \\
\hline B & 47 & - & 47 \\
\hline D & 36 & - & 36 \\
\hline 1 & - & 31 & 22 \\
\hline
\end{tabular}

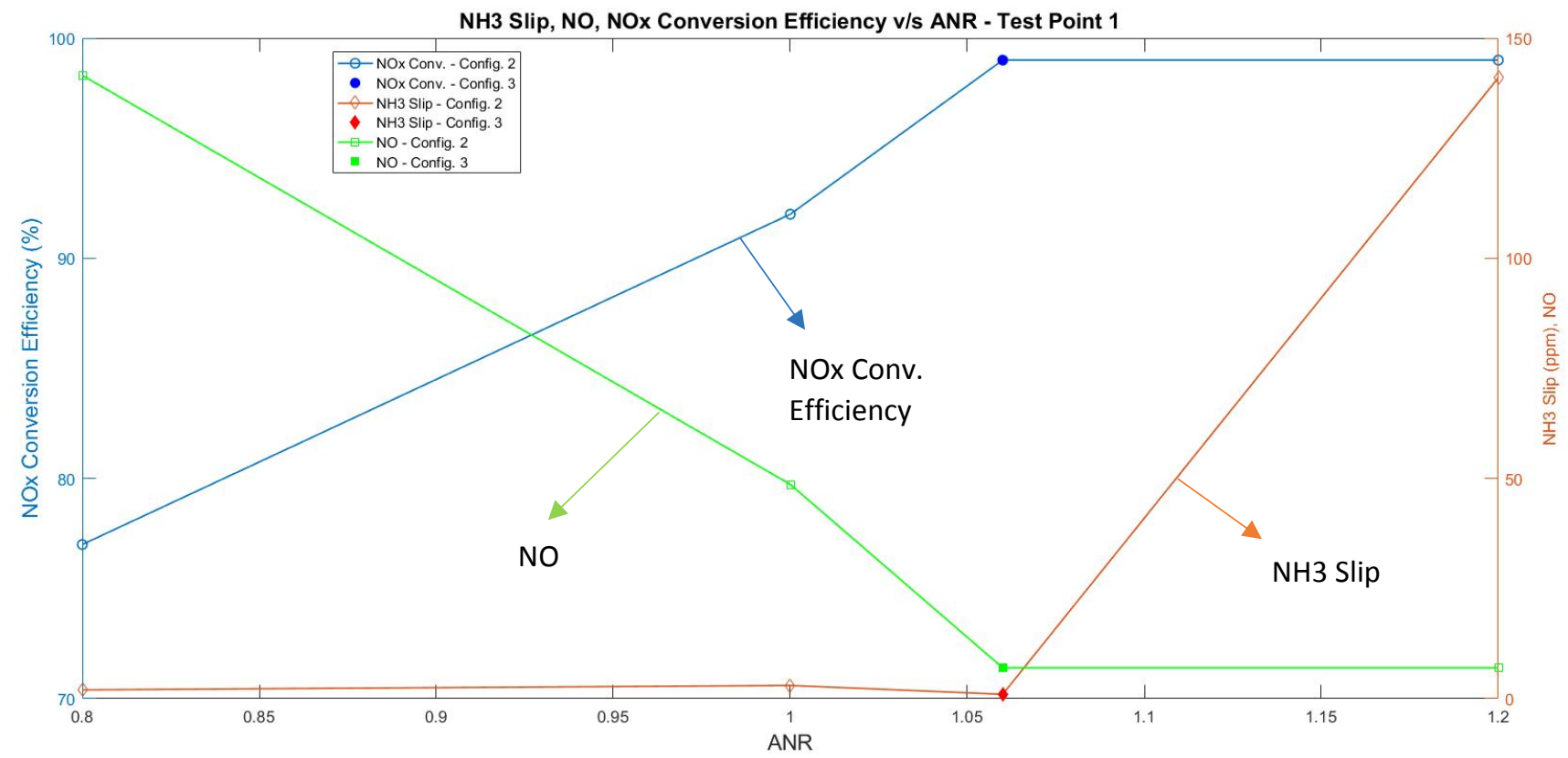

Figure F.5: Comparison for NOx conversion efficiency, $\mathrm{NH}_{3}$ slip and $\mathrm{NO}$ vs ANR for Test Point 1 (ANR 0.8, 1.0, 1.2 in Configurations 2 and ANR 1.06 in Configuration 3) 
Figure F.6 and F.7 present a comparison of ANR and $\mathrm{NO}_{x}$ conversion efficiency for different test conditions in Confgurations 1 vs Configuration 3 . The figure shows that for a slight increase in the ANR, there is a large increase in $\mathrm{NO}_{\mathrm{x}}$ conversion efficiency across the $\mathrm{SCRF}^{\circledR}$. This may be due to error in emission measurement at the outlet of the $\mathrm{SCRF}^{\circledR}$.

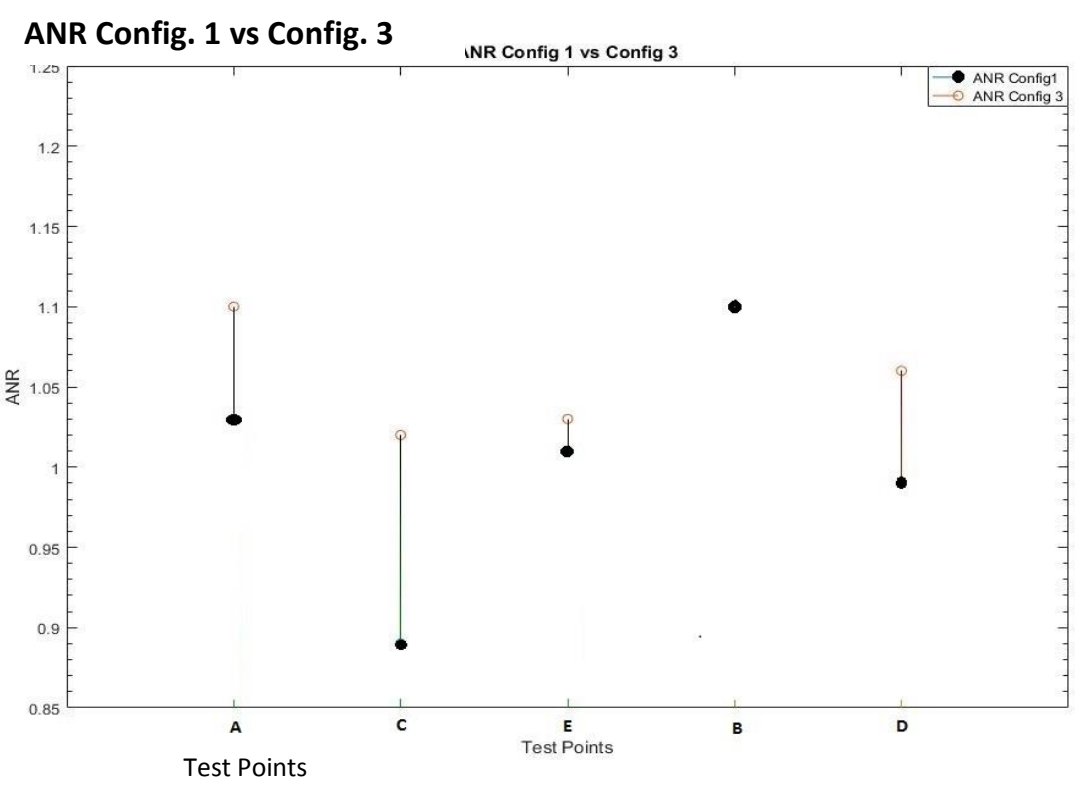

Figure F.6: Comparison for ANR in Configuration 1 and Configuration 3

NO Conversion Efficiency in Config. 1 vs Config. 3 


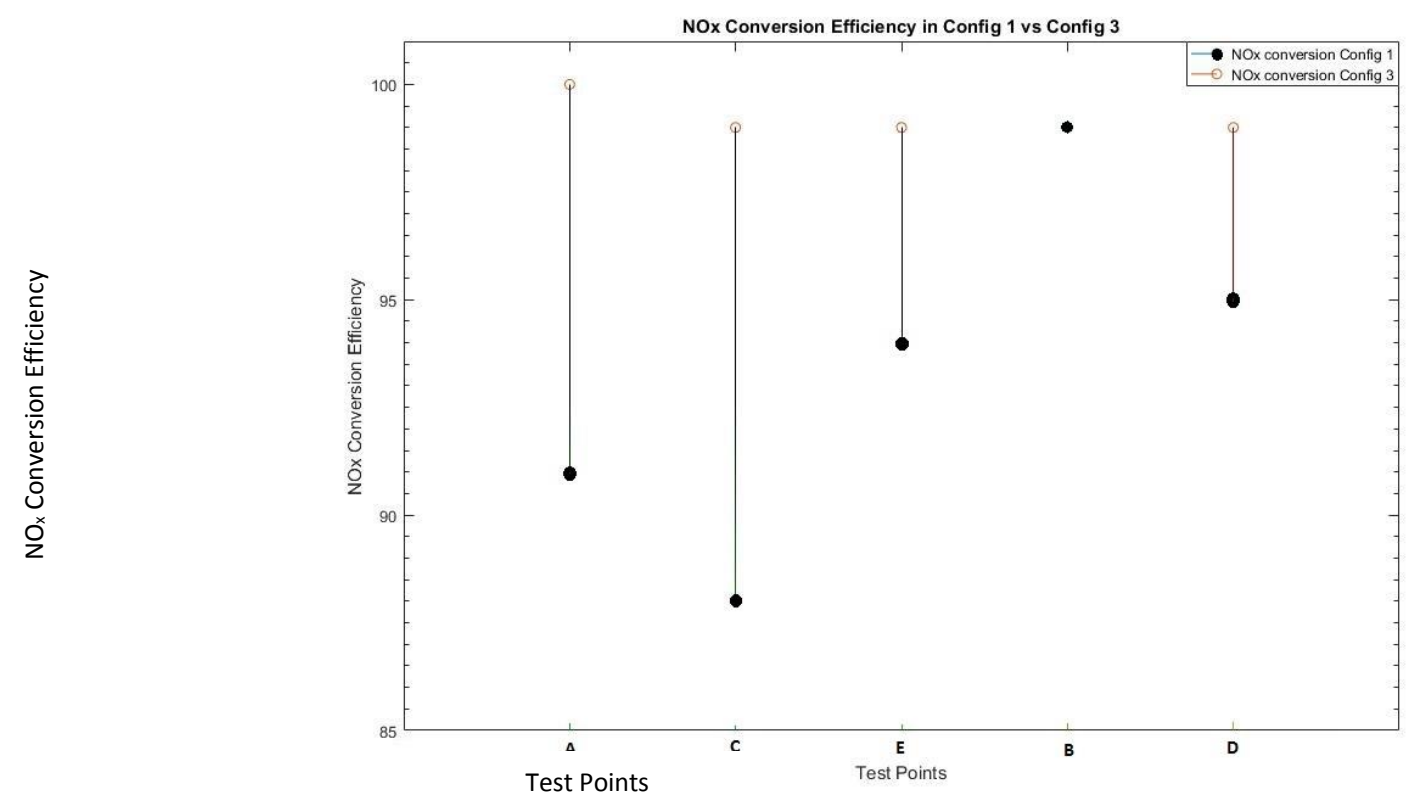

Figure F.7: Comparison for $\mathrm{NO}_{\mathrm{x}}$ Conversion Efficiencies in Configuration 1 and Configuration 3 


\section{Appendix G. Calculation of ANR for Configuration 3}

This appendix provides description for the calculation procedure for the target ANR that was chosen to be dozed in Configuration 3 [3]. It then discusses a correct procedure that should have been adopted to calculate these values. The results for the corrected target ANR are then tabulated in Table G.1.

\section{G.1. Procedure used for Calculation of ANR for Configuration 3 [3]}

Procedure adopted for the calculation of ANR in reference [3] is based on the fact that an additional amount of urea must be dozed in order to convert all the $\mathrm{NO}_{\mathrm{x}}$ coming out of the $\mathrm{SCRF}^{\circledR}$. The amount of this additional urea dozed much be such that the $\mathrm{NH}_{3}$ formed from it decomposition must be just enough to convert all the $\mathrm{NO}_{\mathrm{x}}$ across the $\mathrm{SCRF}^{\circledR}$. Also the $\mathrm{NH}_{3}$ slip out of the $\mathrm{SCRF}^{\circledR}$ should theoretically be 0 . A sample calculation for this is shown below for Test Point A. The data is taken from Configuration 1 [2] for estimating the ANR for Configuration 3.

From Table G.1 for Test Point A:

$\mathrm{NO}_{\mathrm{x}}$ into $\mathrm{SCRF}^{\circledR}=590 \mathrm{ppm}$

Corresponding $\mathrm{NH}_{3}$ into $\mathrm{SCRF}^{\circledR}=\mathrm{ANR}$ dosed $* \mathrm{NO}_{x}$ into the $\mathrm{SCRF}^{\circledR}=1.03 * 590$

$$
=607 \mathrm{ppm}
$$

$\mathrm{NO}_{\mathrm{x}}$ out of the $\mathrm{SCRF}^{\circledR}=55 \mathrm{ppm}$

$\mathrm{NH}_{3}$ out of the $\mathrm{SCRF}^{\circledR}=12 \mathrm{ppm}$

Additional $\mathrm{NH}_{3}$ required at $\mathrm{SCRF}^{\circledR}$ inlet $=\mathrm{NO}_{x}$ out of the $\mathrm{SCRF}^{\circledast} /$ Nitrogen Balance $=55 / .90$ 
Therefore,

New value of $\mathrm{NH}_{3}$ that is required for total $\mathrm{NO}_{x}$ conversion and $0 \mathrm{NH}_{3}$ slip (theoretically) $=607+61=668 \mathrm{ppm}$

Hence,

Target $\mathrm{ANR}=\mathrm{New} \mathrm{NH} / \mathrm{NO}_{\mathrm{x}}$ into $\mathrm{SCRF}^{\circledR}=668 / 590$

Target ANR $=1.13$

\section{G.2. Corrected Procedure to Calculate the ANR's for Configuration 3}

Configuration 3 consists of the DOC, the $\mathrm{SCRF}^{\circledR}$ and a downstream SCR. The calculations made by reference [3] for computations of ANR were based on conversion across the $\mathrm{SCRF}^{\circledR}$ only. This made the $\mathrm{SCR}$ a passive device, meaning any considerable amount of $\mathrm{NO}_{\mathrm{x}}$ was not converted in the SCR. This was because the ANR dosing was computed in such a way that the entire $\mathrm{NO}_{\mathrm{x}}$ conversion occurred across the $\mathrm{SCRF}^{\circledR}$ only. The $\mathrm{NO}_{\mathrm{x}}$ with this dosing out of the $\mathrm{SCRF}^{\circledR}$ (into the SCR) was very low $\left(<10\right.$ ppm). The $\mathrm{NH}_{3}$ entering the $\mathrm{SCR}$ was also low (1-40 ppm). Thus, no significant SCR reactions occurred in the downstream SCR.

To calculate the target ANR for Configuration 3, the effect of a downstream SCR must be considered. This could have been done by assuming a downstream SCR during analysis and then applying the same concept of attaining a theoretical $\mathrm{NO}_{\mathrm{x}}$ conversion efficiency of $100 \%$ and $\mathrm{NH}_{3}$ slip out of the $\mathrm{SCRF}^{\circledR}+\mathrm{SCR}$ system as a whole. This methodology would have yielded more realistic values for ANR dosing. The values computed using this methodology are presented in Table G.1. Below is the sample calculation procedure for Test Point A.

From Table G.1 for Test Point A: 
$\mathrm{NO}_{\mathrm{x}}$ into $\mathrm{SCRF}^{\circledR}=590 \mathrm{ppm}$

Corresponding $\mathrm{NH}_{3}$ into $\mathrm{SCRF}^{\circledR}=\mathrm{ANR}$ dosed ${ }^{*} \mathrm{NO}_{\mathrm{x}}$ into the $\mathrm{SCRF}^{\circledR}=1.03 * 590$

$$
=607 \mathrm{ppm}
$$

$\mathrm{NO}_{\times}$out of the $\mathrm{SCRF}^{\oplus}=55 \mathrm{ppm}$

$\mathrm{NH}_{3}$ out of the $\mathrm{SCRF}^{\oplus}=12 \mathrm{ppm}$

Assuming a downstream SCR for calculation purposes

$\mathrm{NO}_{\mathrm{x}}$ out of the $\mathrm{SCRF}^{\circledR}=\mathrm{NO}_{\mathrm{x}}$ into the $\mathrm{SCR}$

$\mathrm{NH}_{3}$ out of the $\mathrm{SCRF}^{\circledR}=\mathrm{NH}_{3}$ into the $\mathrm{SCR}$

$\mathrm{NO}_{x}$ out of the $\mathrm{SCR}=\mathrm{NO}_{x}$ into $\mathrm{SCR}-\mathrm{NH}_{3}$ into $\mathrm{SCR}=55-12=43 \mathrm{ppm}$

Therefore,

Additional $\mathrm{NH}_{3}$ required at $\mathrm{SCRF}^{\circledR}$ inlet $=\mathrm{NO}_{x}$ out of the $\mathrm{SCR} /$ Nitrogen Balance $=43 / .90$

$$
=48 \mathrm{ppm}
$$

Therefore,

New value of $\mathrm{NH}_{3}$ that is required for total $\mathrm{NO}_{x}$ conversion and $0 \mathrm{NH}_{3}$ slip (theoretically) $=607+48=655 \mathrm{ppm}$ Hence, 
Target $\mathrm{ANR}=\mathrm{New} \mathrm{NH} / \mathrm{NO}_{\mathrm{x}}$ into $\mathrm{SCRF}^{\circledR}=655 / 590$

Target ANR = 1.11

The values for the Target ANR for all the Test Points run in Configuration 3 by both reference [3] and the new procedures as well as the actual ANR dosed during Configuration 3 are presented in Table G.1. It is seen that the actual ANR dosed is same as the corrected Target ANR for three of the test point A, B and C and varies slightly for Test Points $E, D$ and 1 . This is because some fine tuning of the ANR was done while conducting experiments so that $\mathrm{NH}_{3}$ slip was reduced to a minimum and $\mathrm{NO}_{\mathrm{x}}$ conversion efficiency was maximum (99-100\%). Thus, it is evident that considering the effect of a downstream SCR in calculation of the ANR predicts correct Target ANR's.

Table G.1: Corrected Target ANR for Configuration 3

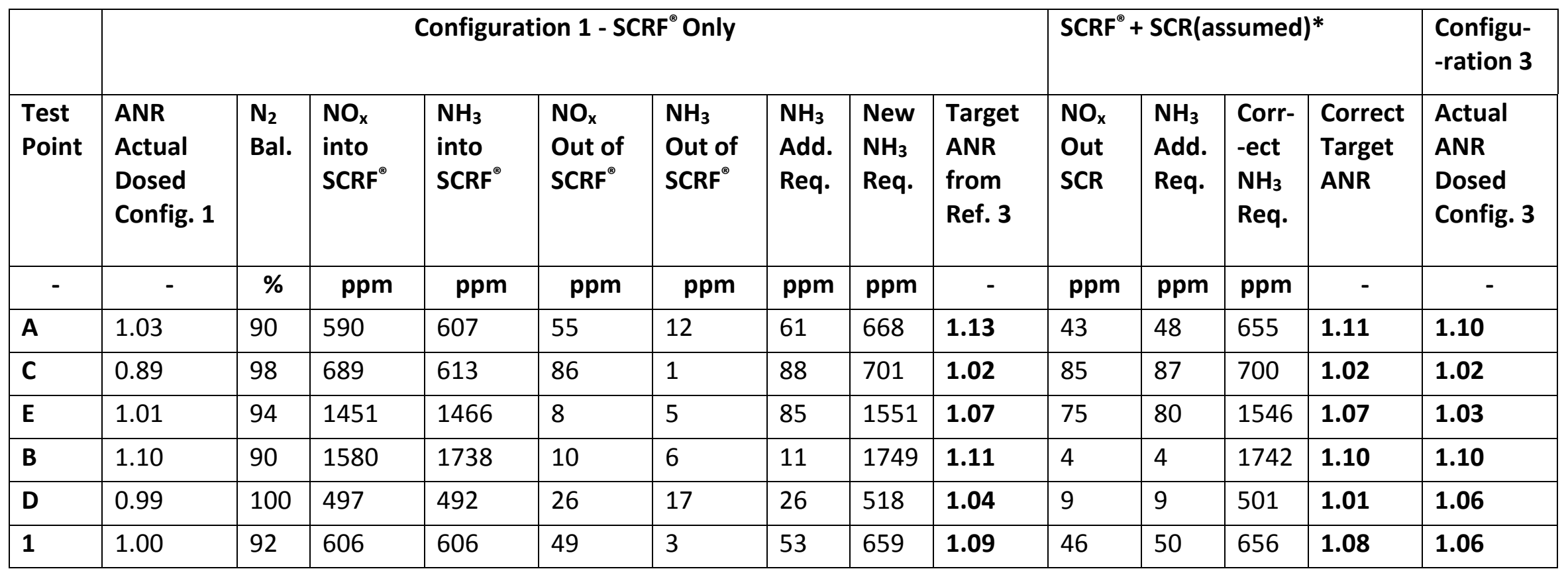

*: $\mathrm{NO}_{\mathrm{x}}$ and $\mathrm{NH}_{3}$ slip values at the outlet of $\mathrm{SCRF}^{\circledR}$ and $\mathrm{SCR}$ are the average values during the beginning of the $\mathrm{PO}$ stage 


\section{Appendix H. Permissions to Use Copyrighted Material}

$6 / 21 / 2017$

Michigan Tech
Michigan Technological University Mail - Requesting permission to use material from your MS thesis

Sagar Sharma <sagsharm@mtu.edu>

\section{Requesting permission to use material from your MS thesis \\ 2 messages}

Sagar Sharma <sagsharm@mtu.edu>

Wed, Dec 7, 2016 at 12:59 PM

To: Erik Gustafson <eagustaf@mtu.edu>

Hello Erik

How are you?

I am writing this email requesting your permission to use the methods developed, data, figures and tables from you MS thesis into my report.

Thanks \& Regards,

Sagar Sharma

Graduate Student, HDD Lab, MEEM

Michigan Technological University

9062759530

Erik Gustafson <eagustaf@mtu.edu>

Wed, Dec 7, 2016 at 5:59 PM

To: Sagar Sharma <sagsharm@mtu.edu>

Sagar,

Please use any data, figures, tables, or methods that you need

Regards

Erik Gustafson

Sent from my iPhone

[Quoted text hidden] 
Requesting Permission to use data from your Masters Thesis.

2 messages

Sagar Sharma <sagsharm@mtu.edu>

Sat, Apr 29, 2017 at 4:24 PM

To: Vaibhav Kadam < vkadam@mtu.edu>

Hello Vaibhav,

How are you?

I am writing this email requesting your permission to use the methods developed, data, figures and tables from you MS thesis into my report.

Thanks \& Regards,

Sagar Sharma

812-343-3932

Vaibhav Kadam <vkadam@mtu.edu>

To: Sagar Sharma <sagsharm@mtu.edu>

Sat, Apr 29, 2017 at 9:11 PM

Hi Sagar,

Please feel free to use any material from my thesis for your MS report. Wish you good luck!

Best Regards

Vaibhav Kadam

[Quoted text hidden] 
6/21/2017 Michigan Technological University Mail - Permission to use figures from a Joumal article for comparison in current study as a part of MS Report

Michigan Tech

Sagar Sharma <sagsharm@mtu.edu>

\section{Permission to use figures from a Journal article for comparison in current study as a part of MS Report \\ 2 messages}

Sagar Sharma <sagsharm@mtu.edu>

Mon, May 22, 2017 at 3:01 PM

To: permissions@sagepub.com

Hello.

My name is Sagar Sharma. I am currently pursuing MS in Mechanical Engineering from Michigan Technological University. My research is focused on studying the Passive Oxidation characteristics of a SCR on DPF with a downstream SCR. Also, my work includes study of the effects of fuel rail injection pressure on soot morphology. My adviser's are Dr. John H. Johnson and Dr. Jeffrey D. Naber.

I intend to use a few figures in my report that were published in International Journal Of Engine Research. The purpose of using these is to compare my results with the literature available. I, therefore, request you to please allow me to use the below mentioned figures in my MS report.

The details of the publication are mentioned below.

1. Ye, P., Sun, C., Lapuerta, M. et al, "Impact of Rail Pressure and Biodiesel Fueling on the Particulate Morphology and Soot Nanostructures from a Common-Rail Turbocharged Direct Injection Diesel Engine", International J of Engine Research, DOI: 10.1177/1468087414564229, 2014.

Figure 4, Page 11

Figure 2, Page 9

The details of my Masters Report are as follows

Title of Report: The Emission and Particulate Matter Oxidation Performance of a SCR Catalyst on a Diesel Particulate Filter with a Downstream SCR

Name of School: Michigan Technological University

Number of Copies to be distributed: 1 to the library (No sure about others)

Format: Electronic (MTU Library)

Expected Publication Date: August, 2017

I am grateful to you for your help and support. Please let me know if there is anything I can do to make the process smooth.

Thanks \& Regards,

Sagar Sharma

Michigan Technological University.

Houghton, MI, USA.

$+1-812-343-3932$

PermissionsUK <PermissionsUK@sagepub.com>

Tue, May 23, 2017 at 12:58 PM

To: Sagar Sharma <sagsharm@mtu.edu>

Dear Sagar Sharma, 
6/21/2017 Michigan Technological University Mail - Permission to use figures from a Joumal article for comparison in current study as a part of MS Report Thank you for your email. I am pleased to report we can grant your request without a fee as part of your masters report.

Please accept this email as permission for your request as detailed below. Permission is granted for the life of the edition on a non-exclusive basis, in the English language, throughout the world in all formats provided full citation is made to the original SAGE publication.

a courtesy, we ask that you contact the author to let them know the content will be republished. Please note this approval excludes any content which requires additional permission from a separate copyright holder. If the SAGE material includes anything not '(C) the Author' or '(C) SAGE', please contact the rights holder for permission to reuse those items.

Best Wishes,

Craig Myles

on behalf of SAGE Ltd. Permissions Team

SAGE Publications Ltd

1 Oliver's Yard, 55 City Road

London, ECIY 1SP

UK

www.sagepub.co.uk

SAGE Publications Ltd, Registered in England No.1017514

Los Angeles | London | New Delhi

Singapore | Washington DC

The natural home for authors, editors \& societies

Thank you for considering the emvironment before printing this email.

From: Sagar Sharma [mailto-sagsharm@mtu.edu]

Sent: Monday, May 22, 2017 12:01 PM

To: permissions (US) <permissions@sagepub.com>

Subject: Permission to use figures from a Journal article for comparison in current study as a part of MS Report

[Quoted text hidden]

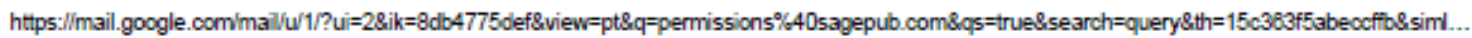


Updated request seeking permission to use figures from SAE papers in MS report 2 messages

Sagar Sharma <sagsharm@mtu.edu>

Tue, May 2, 2017 at 12:00 PM

To: copyright@sae.org

Hello,

My name is Sagar Sharma. I am currently pursuing MS in Mechanical Engineering from Michigan Technological University. My research is focused on studying the Passive Oxidation characteristics of a SCR on DPF with a downstream SCR. Also, my work includes study of the effects of fuel rail injection pressure on soot morphology. My adviser's are Dr. John H. Johnson and Dr. Jeffrey D. Naber.

I intend to use a few figures in my report that were published in SAE papers. The purpose of using these is to compare my results with the literature available. I, therefore, request you to please allow me to use the below mentioned figures in my MS report.

The details of the SAE papers are as follows:

1. López - De Jesús, Y., Chigada, P., Watling, T., Arulraj, K. et al., "NOx and PM Reduction from Diesel Exhaust Using Vanadia SCRF(B)," SAE Int. J. Engines 9(2): doi:10.4271/2016-01-0914, 2016.

Figure 6, Page 1252

Figure 7, Page 1252

2. Balland, J., Parmentier, M., and Schmitt, J., "Control of a Combined SCR on Filter and Under-Floor SCR System for Low Emission Passenger Cars," SAE Int. J. Engines 7(3): doi:10.4271/2014-01-1522, 2014.

Figure 4, Page 3

Figure 5, Page 3

3. Ye, P., Sun, C., Lapuerta, M. et al, "Impact of Rail Pressure and Biodiesel Fueling on the Particulate Morphology and Soot Nanostructures from a Common-Rail Turbocharged Direct Injection Diesel Engine", International J of Engine Research, DOI: 10.1177/1468087414564229, 2014.

Figure 4, Page 11

Figure 2, Page 9

4. Iwata, H., Konstandopoulos, A., Nakamura, K., Ogyu, K. et al., "Experimental Study of Physical and Chemical Properties of Soot under Several EGR Conditions," SAE Technical Paper 2014-01-1593, DOI:10.4271/2014-01-1593, 2014.

Figure 7, Page 4

Title of Report: The Emission and Particulate Matter Oxidation Performance of a SCR Catalyst on a Diesel Particulate Filter with a Downstream SCR

Name of School: Michigan Technological University

Number of Copies to be distributed: 1 to the library (No sure about others)

Format: Electronic (MTU Library)

Expected Publication Date: August, 2017 
6/21/2017 Michigan Technological University Mail - Updated request seeking permission to use figures from SAE papers in MS report

I am grateful to you for your help and support. Please let me know if there is anything I can do to make the process smooth.

Thanks \& regards,

Sagar Sharma

MTU, Houghton, MI

812-343-3932

Mandy May <Mandy.May@sae.org>

Mon, May 22, 2017 at 7:09 PM

To: Sagar Sharma <sagsharm@mtu.edu>

Hello Sagar,

It was good to talk with you today.

Please be advised, reproduction use of the following has been granted for your thesis:

1. López - De Jesús, Y., Chigada, P., Watling, T., Arulraj, K. et al., "NOx and PM Reduction from Diesel Exhaust Using Vanadia SCRF@," SAE Int. J. Engines 9(2): doi:10.4271/2016-01-0914, 2016.

Figure 6, Page 1252

Figure 7, Page 1252

2. Balland, J., Parmentier, M., and Schmitt, J., "Control of a Combined SCR on Filter and Under-Floor SCR System for Low Emission Passenger Cars," SAE Int. J. Engines 7(3): doi:10.4271/2014-01-1522, 2014.

Figure 4, Page 3

Figure 5, Page 3

4. Iwata, H., Konstandopoulos, A., Nakamura, K., Ogyu, K. et al., "Experimental Study of Physical and Chemical Properties of Soot under Several EGR Conditions," SAE Technical Paper 2014-01-1593, DOI:10.4271/2014-01-1593, 2014.

Figure 7, Page 4

-Permission is granted for non-exclusive English language rights, and for the specific use as indicated in your email;

-A new Copyright Permission Request is required for any further use of this material, other than that specified within your original Request;

-The SAE material must be clearly identified and include the following statement "Reprinted with permission Copyright (8) xxxx(insert correct year for each use)l. Further distribution of this material is not permitted without prior permission from

https $/ /$ mail.google.com/mailu/1/?ui $=28 \mathrm{ik}=8 \mathrm{db} 4775 \mathrm{def} \&$ view=pt\&q=sae\&qs=true\&search=query\&th=15c32604be2c639e\&siml=15bc9e450ae8d87c\&si... $2 / 4$ 


\begin{abstract}
6/21/2017 Michigan Technological University Mail - Updated request seeking permission to use figures from SAE papers in MS report
$S A E$;

-We also request that you include a complete reference to the SAE document in the reference section for each figure used;
\end{abstract}

-This permission does not cover any third-party copyrighted work which may appear in the material requested;

-Any language use, other than specified within your email, requires a new copyright request and additional fee;

-Licensor's use of this material, in whole or in part, is entirely its responsibility, and SAE International does not warrant or is not responsible for any use of the material.

Best wishes on your work,

Mandy

Mandy L. May

Manager, Digital Publishing

Content Management

SAE INTERNATIONAL

400 Commonwealth Drive

Warrendale, PA 15096

$\circ+1.724 .772 .8564$

e mandy.may@sae.org

www.sae.org

From: Sagar Sharma [mailto:sagsharm@mtu.edu]

Sent: Tuesday, May 02, 2017 12:01 PM

To: copyright <copyright@sae.org>

Subject: Updated request seeking permission to use figures from SAE papers in MS report

[Quoted text hilden]

Nothing in this message is intended to constitute an electronic signature unless a specific statement to the contrary is included in this message. Confidentiality Note: This message is intended only for the person or entity to which it is

https $/ /$ mail.google.com/mail/u/1/?ui $=28 i k=8 \mathrm{db} 4775 \mathrm{def}$ view=pt\&q=sae\&qs=true\&search=query\&th=15c326c4be2c639e\&siml=15bc9e450ae8d87c\&si... $3 / 4$ 
6/21/2017 Michigan Technological University Mail - Updated request seeking permission to use figures from SAE papers in MS report

addressed. It may contain confidential and/or proprietary material. Any review, transmission, dissemination or other use, or taking of any action in reliance upon this message by persons or entities other than the intended recipient is prohibited. If you received this message in error, please contact the sender and delete it from your computer. 